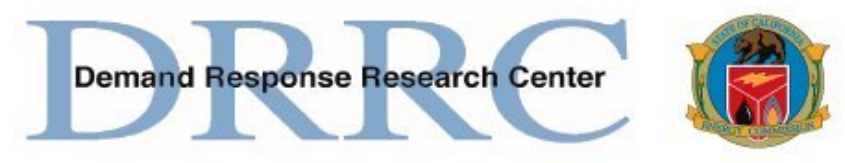

\title{
OPEN AUTOMATED DEMAND RESPONSE FOR SMALL COMMERCIAL BUILDINGS
}

\author{
Sila Kiliccote \\ Mary Ann Piette \\ June Han Dudley \\ Lawrence Berkeley National Laboratory \\ Ed Koch \\ Dan Hennage \\ Akuacom
}




\section{Acknowledgements}

The work described in this report was funded by the Demand Response Research Center which is funded by the California Energy Commission (Energy Commission), Public Interest Energy Research (PIER) Program, under Work for Others Contract No.500-03-026, Am \#1 and by the U.S. Department of Energy under Contract No. DE-AC02-05CH11231. Additional funding was provided by Southern California Edison Company through the Emerging Technologies Program. The authors are grateful for the extensive support from numerous individuals who assisted in this project:

Kristy Chew, Chris Scruton and Martha Brook (California Energy Commission)

California Institute for Energy and the Environment for their assistance with the contract.

Ron Hofmann and Roger Levy for their on going support.

Paul Mathew for his assistance with access to CEUS data and definitions.

Carlos Haid and Teren Abear (Southern California Edison)

Austen D’Lima (San Diego Gas and Electric Company)

Stephen Moss (San Francisco Community Power)

Gus Ezcurra, Tom Naylor and Mike Denny (Advanced Telemetry) 


\section{Table of Contents}

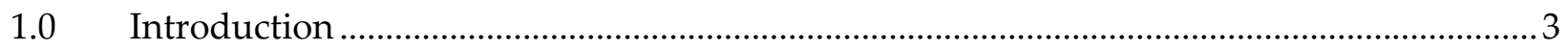

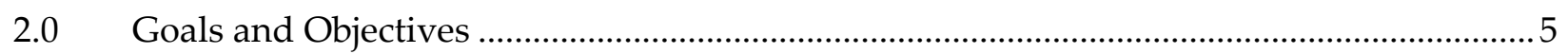

3.0 Open Automated Demand Response Communications Infrastructure.............................. 6

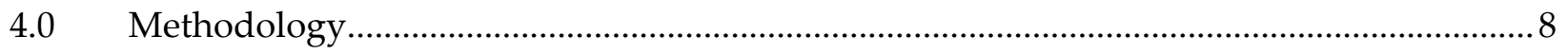

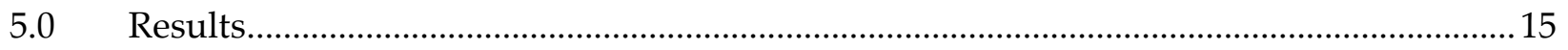

5.1. Small Commercial Building Characterization ............................................................ 15

5.1.1. Heating Ventilation and Air Conditioning (HVAC) Systems ............................... 18

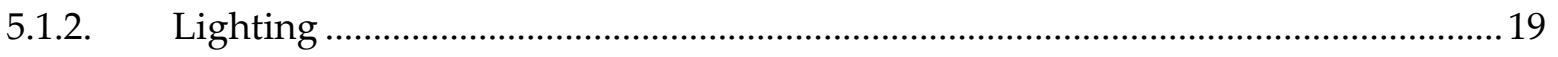

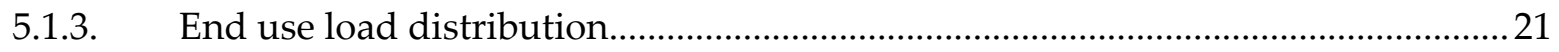

5.2. DR Technology Framework Development for Small Commercial Buildings................21

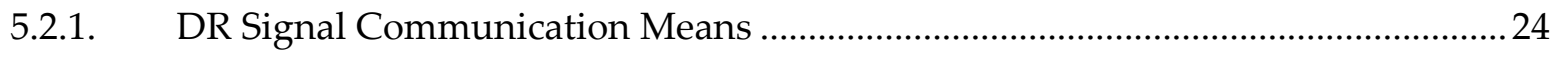

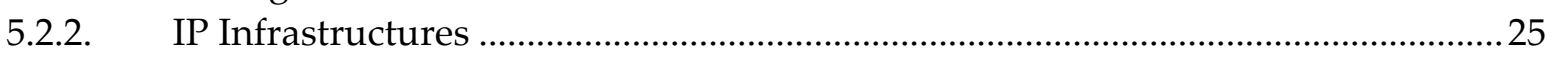

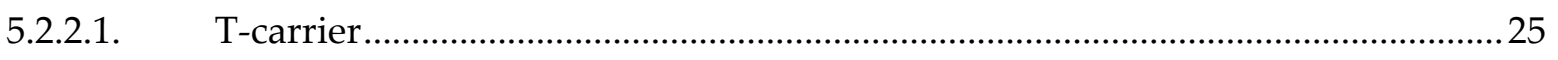

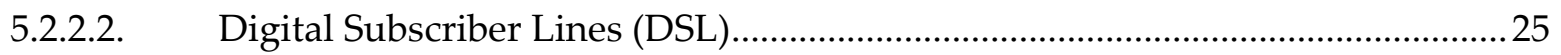

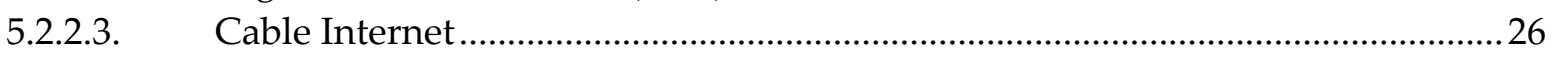

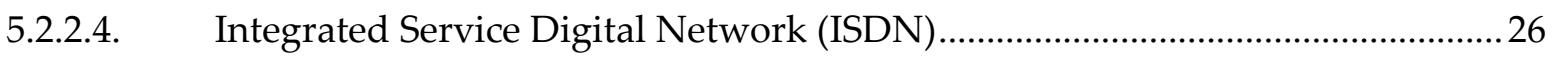

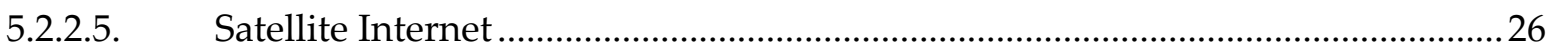

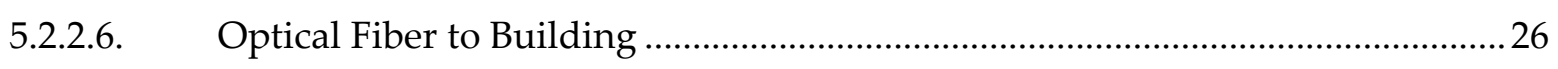

5.2.2.7. Worldwide Inter-operability for Microwave Access (WiMAX).........................2 27

5.2.2.8. Mobile Communications (Cellular) ….............................................................. 27

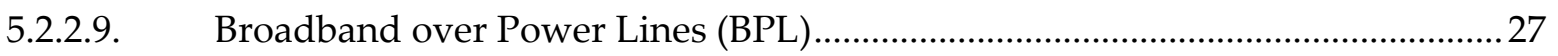

5.2.2.10. Plain Old Telephone Service (POTS) …............................................................. 28

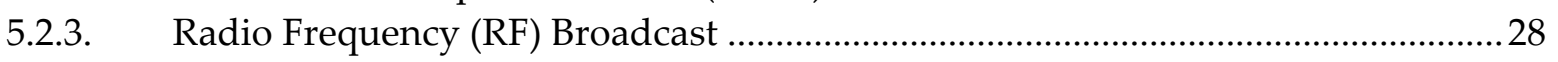

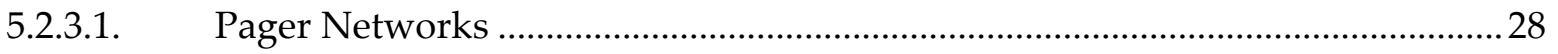

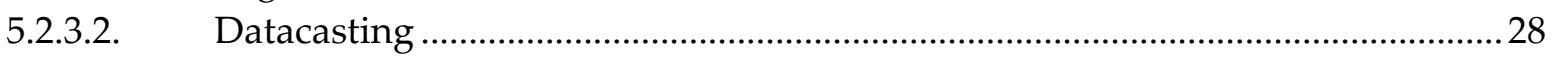

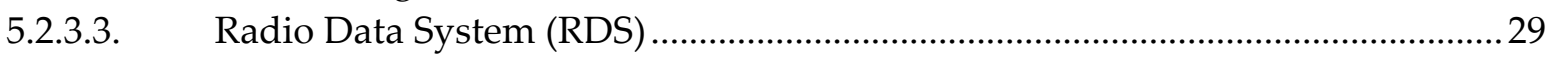

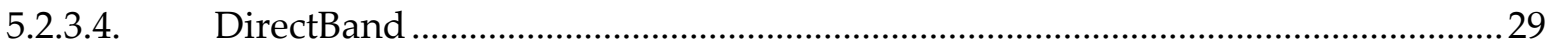

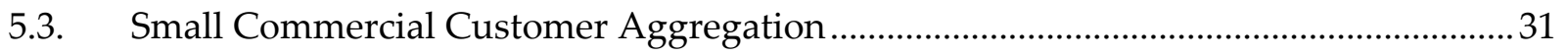

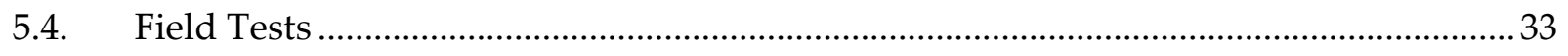

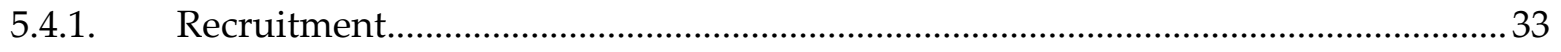

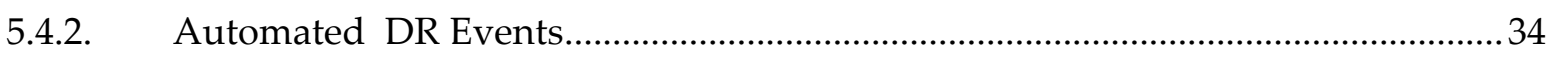

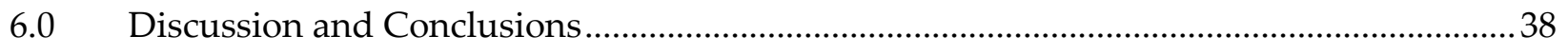

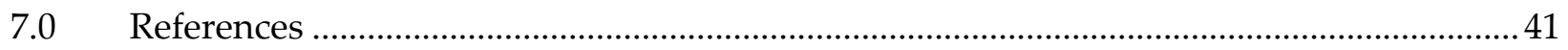

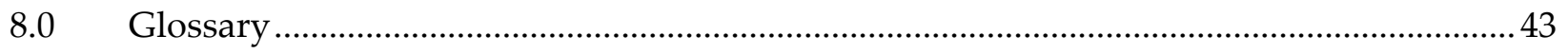




\section{Table of Figures}

Figure 1. Generic Open Automated DR Interface Architecture ..................................................

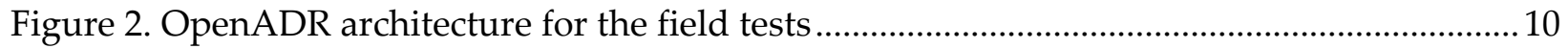

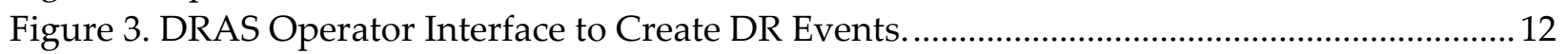

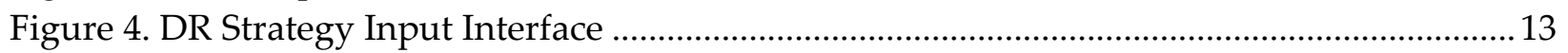

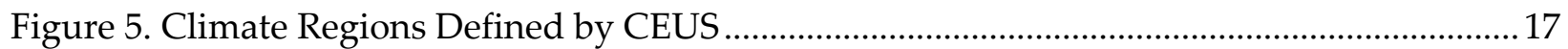

Figure 6. Light Source Distribution in Small Commercial Buildings (Source: EnergyIQ) ............ 20

Figure 7. Ballast Types Used in Small Commercial Buildings (Source: EnergyIQ) ...................... 20

Figure 8. Lighting Controls in Small Commercial Buildings (Source: EnergyIQ) ......................... 21

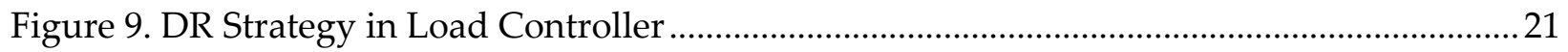

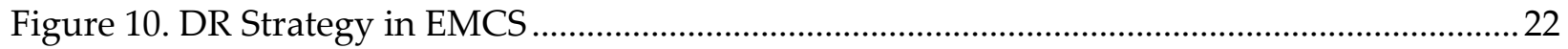

Figure 11. DR Strategy External to the Facility ….................................................................... 22

Figure 13. Load Profile for Hesperia Site on November 7, 2008 .................................................... 36 


\begin{abstract}
This report characterizes small commercial buildings by market segments, systems and enduses; develops a framework for identifying demand response (DR) enabling technologies and communication means; and reports on the design and development of a low-cost OpenADR enabling technology that delivers demand reductions as a percentage of the total predicted building peak electric demand.

The results show that small offices, restaurants and retail buildings are the major contributors making up over one third of the small commercial peak demand. The majority of the small commercial buildings in California are located in southern inland areas and the central valley. Single-zone packaged units with manual and programmable thermostat controls make up the majority of heating ventilation and air conditioning (HVAC) systems for small commercial buildings with less than $200 \mathrm{~kW}$ peak electric demand. Fluorescent tubes with magnetic ballast and manual controls dominate this customer group's lighting systems. There are various ways, each with its pros and cons for a particular application, to communicate with these systems and three methods to enable automated DR in small commercial buildings using the Open Automated Demand Response (or OpenADR) communications infrastructure. Development of DR strategies must consider building characteristics, such as weather sensitivity and load variability, as well as system design (i.e. under-sizing, under-lighting, over-sizing, etc). Finally, field tests show that requesting demand reductions as a percentage of the total building predicted peak electric demand is feasible using the OpenADR infrastructure.
\end{abstract}

Keywords: open automated demand response, OpenADR, OpenADR, small commercial buildings, CEUS 


\section{Executive Summary}

Small commercial buildings, those with less than $200 \mathrm{~kW}$ of peak demand, make up 20-25\% of peak electric demand in California. We have identified small office buildings, restaurants and retail buildings as the major contributors making up over one third of the small commercial

peak demand. A ten percent reduction in only these three types of facilities can yield overall peak demand reductions of up to $0.5 \%-0.7 \%$ in California.

The goal of this project was to characterize small commercial buildings by market segments, systems and end-uses; to develop a framework for identifying DR enabling technologies and communication means; and to consider the feasibility of a low cost OpenADR enabling technology that delivers demand reductions as a percentage of the total predicted building electric peak demand.

The project has four key elements. First, California commercial end use survey (CEUS) was examined to understand the market segments, the regional concentration of small commercial buildings and the diversity of end-uses and controls. Second, a framework was developed for technologies that are compatible with the Open Automated Demand Response (or OpenADR) communication infrastructure for small commercial buildings. Third, we worked with five buildings that participated in manual DR with an aggregator to understand building characterization. Finally, a system that delivers demand reduction as a percentage of the wholebuilding peak electric demand was designed, developed and field tested in two quick-service restaurants in Southern California Edison's service territory.

The goal of the characterization of small commercial buildings was to identify opportunities and low hanging fruit for this customer group. Small office, restaurants and retail buildings are the major contributors making up over one third of the small commercial peak demand. A majority of the small commercial buildings are located in southern inland areas and the central valley. Single-zone packaged units with manual and programmable thermostat controls make up the majority of heating ventilation and air conditioning (HVAC) systems in this group of customers. Fluorescent tubes with magnetic ballasts and manual controls dominate this customer group's lighting systems.

The framework development provides a reference to small commercial building owners to evaluate their investment in various OpenADR enabling technologies. The small commercial building owner can use this framework to identify which method would work for his/her building and look for products that accommodate the selected method. Information on various means of DR signal communication is provided to assist small commercial building owners to select appropriate means of communication for their DR automation.

We worked with an aggregator and compiled data from five larger sites that participated in DR events in 2007, either manually or semi-automatically. The aggregator notifies the customers that a DR event is issued but has no information on the DR strategies or real-time meter data and is provided information on the portfolio's performance weeks after the events are dispatched. The deployment of advance metering infrastructure (AMI) will largely solve the existing information related issues. Meter data, when available, should be used to calculate load 
variability and weather sensitivity of buildings to better assess the DR potential in small commercial buildings.

Finally, the feasibility of using OpenADR to request demand reductions as a percentage of total predicted demand was demonstrated for Southern California Edison with field tests in two quick-service restaurants. The method to predict demand should be carefully chosen as there is no one baseline method that predicts peak demand for all facilities accurately. Building characteristics and building systems issues, such as design and controls, have to be considered when estimating how much and when demand reduction is available at each facility.

As a next step, first, we propose continuing field studies to characterize ownership, management and operational issues; to identify opportunities in small offices, restaurants and retail facilities especially for lighting systems; to consider the feasibility of using AMI infrastructure to deliver OpenADR signals to small commercial buildings; and to understand price-point requirements. Second, tools must be developed for small building owners to better understand their buildings' loads. Finally, a guide developed for small buildings owners to enable automation of DR can create awareness and facilitate deployment of enabling technologies. 


\subsection{Introduction}

California requires about $53 \mathrm{GW}$ of peak electric demand on the hottest summer day (CPUC FAQ). The commercial sector accounts for 35\% percent of this peak demand. Large buildings or those with peak electric demand greater than $200 \mathrm{~kW}$ demand account for about 5 to $7 \mathrm{GW}$, or $10-15 \%$ percent of the summer peak demand, while small commercial buildings account for 10 to $12 \mathrm{GW}$, or 20 to $25 \%$ percent of the peak. This report develops and discusses a framework to deploy automated demand response (DR) for small commercial facilities as well as technologies and strategies to enable automated demand response. Enabling small commercial buildings to participate in automated DR programs and tariffs could substantially decrease summer peak demand.

Demand Response (DR) is a set of actions taken to reduce electric loads when contingencies, such as emergencies or congestion, threaten supply-demand balance, and/or market conditions occur that raise electric supply costs. DR programs and tariffs are designed to improve the reliability of the electric grid and to lower the use of electricity during peak times to reduce the total system costs. This effort builds on ongoing Demand Response Research Center (DRRC) research, development, demonstration and deployment activities related to Open Automated Demand Response (known as OpenADR). OpenADR is a set of standard, continuous, open communication signals and systems provided over the Internet to allow facilities to automate their demand response with no "human in the loop."

OpenADR has been proven in large commercial buildings because of the ability to use the Energy Management Control Systems (EMCS) to automate the DR control strategies. Although a detailed study of applicable technologies and installation of direct digital controls in small commercial buildings was undertaken by Southern California Edison in the past (Lockheed Martin Aspen 2006), this report begins to explore methods to deploy OpenADR in smaller commercial buildings that do not have centralized or sophisticated control systems and concentrates on how various technologies fit within the OpenADR enablement framework. Also, while the lack of an EMCS is a challenge, the lack of Internet connectivity is also an issue in small commercial buildings. Therefore this report compares various communication means to deliver OpenADR signals to small commercial buildings.

Finally, a new, standard Programmable Communicating Thermostat (PCT) designed for DR in residential buildings is also being tested in small commercial buildings (Herter 2008). Careful evaluation of control systems in small commercial facilities is needed to understand which type of cooling and ventilation technologies could work well with PCTs.

The structure of this report is as follows.

Section 2, Project Objectives, provides a discussion of the project objectives.

Section 3, Open Automated Demand Response Communication Infrastructure, describes the infrastructure currently being used for large commercial and industrial facilities to participate in fully automated demand response in California. The feasibility of the same infrastructure to be extended to small and medium commercial facilities is discussed in following sections. 
Section 4, Methodology, outlines the project methodology covering the analysis of CEUS data, the framework for technology, evaluation of communication media, and analysis of SF Community Power data.

Section 5, Results, outlines small commercial facility characterization in California; presents the framework, technologies and communication media that can be used by small commercial facilities;

Section 6, Discussions and Recommendations, summarizes findings and next steps.

Appendices provide reporting on a parallel effort with San Francisco Community Power to understand the issues around small commercial facilities, baseline methods used for analysis, and a DR technology survey. 


\subsection{Goals and Objectives}

The overall goal of this research is to better understand the opportunities for DR in small commercial buildings. The specific objectives of this research are:

1. To evaluate the summer whole-building electric load shapes, consider end-use load patterns, and understand the diversity and characteristics of small commercial buildings to understand the opportunities for DR.

2. To ascertain low-cost and effective ways to automate demand response (DR) for small commercial facilities that may lack effective communications and control infrastructure. The research concentrates on existing small commercial buildings, but also addresses new commercial buildings, which might benefit from the installation of newer technologies or infrastructure.

3. To evaluate the use of programmable communicating thermostats (PCT) in small commercial buildings and understand the market for the PCT beyond residential buildings. Additional questions include: 1 ) if a PCT is in a small commercial building, what modes of DR automation would be available for other end-uses such as commercial lighting, and 2) how might home automation network (HAN) technologies migrate into the small commercial sector. 


\subsection{Open Automated Demand Response Communications Infrastructure}

This section provides an introduction into OpenADR. The Demand Response Research Center developed OpenADR to facilitate deployment of low-cost DR automation. OpenADR is a set of standard and open information exchange model to allow facilities to automate their demand response with no "human in the loop." OpenADR uses utility provided price, reliability, or event signals to automatically initiate customer pre-programmed energy management strategies. Key features of OpenADR include (Piette et al. 2007):

Signaling - OpenADR provides continuous, secure, reliable, two-way communication with end-use customers to allow end-use sites to be identified as listening and acknowledging receipt of DR signals.

Open Industry Standards - OpenADR consists of open, interoperable industry standard information exchange model designed to integrate with both common energy management and control systems and other end-use devices that can receive a dry contact relay or similar signals (such as Internet based eXtensible Markup Language).

Timing of Notification - Day ahead and day of signals are provided by OpenADR technologies and systems to facilitate a diverse set of end-use strategies such as building pre-cooling for "day ahead" notification, or near real-time communications to implement "day of" control strategies. Timing of a DR automation server (DRAS) communications must consider day-ahead events that include weekends and holidays

Most large commercial buildings with energy management and control systems (EMCS) and related lighting and other controls can be pre-programmed to initiate and manage electric demand response.

OpenADR architecture, as displayed in Figure 1, consists of two major elements built on openinterface standards model. First, a Demand Response Automation Server (DRAS) provides signals that notify electricity customers of DR events. Second, a DRAS client is at the customer's site to listen and provide automation signals to existing pre-programmed controls. There are two types of DRAS clients:

1. A Client and Logic with Integrated Relay (CLIR) or a simple client for legacy control systems.

2. A Web Services software or smart client for sophisticated control systems. 


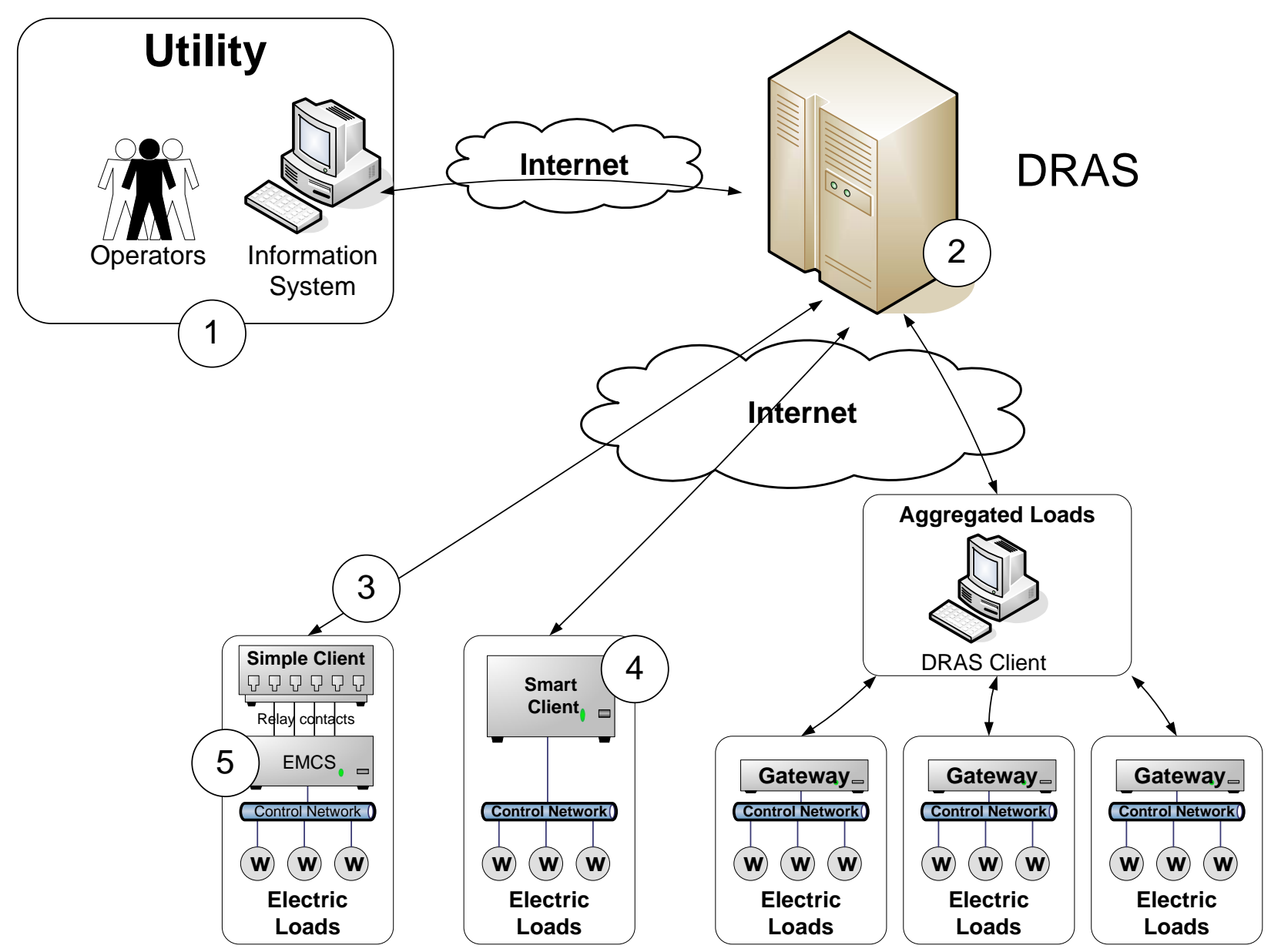

Figure 1. Generic Open Automated DR Interface Architecture

As shown in above figure, the steps involved in the OpenADR process during a DR event are:

1. The Utility or ISO defined DR event and price/mode signals are sent to the DRAS.

2. DR event and price services published on a DRAS.

3. DRAS Clients (CLIR or Web Service) request event data from the DRAS every minute.

4. Customized pre-programmed DR strategies determine action based on event price/mode.

5. Facility Energy Management Control System (EMCS) carries out load reduction based on DR event signals and strategies.

The EMCS allows for central control of heating, ventilation, and air conditioning systems. 


\subsection{Methodology}

There are three major differences between small versus large commercial buildings with respect to the applicability of OpenADR:

1. Small buildings are generally not equipped with centralized energy management and control systems (EMCS). Furthermore, they lack on-site personnel and metering infrastructure to measure their demand and set up strategies for DR.

2. They have a wider variety of ownership models, energy management and related professional services. Very small commercial buildings are being operated like residential buildings where the owner, with limited information such as a utility bill, has to make decisions, and medium sized small commercial buildings are being operated more like their large counterparts.

3. They have more varied and limited availability of the Internet.

In addition, years of research on DR strategies for building systems in large commercial buildings resulted in an understanding of systems and strategies that are applicable to those systems (Motegi et al. 2006). There seems to be a lack of similar understanding of small commercial systems and technologies customers can utilize.

This study investigates the small commercial buildings landscape, its contribution to the peak electric load, end-uses, automation opportunities, means of delivering automation signals, categorizing technologies and finally presents a field study. The next step would be to understand various market segments, especially the top three that contribute to the peak electricity most and identifying best, common and poor practices in order to map technologies on structure and operations of small commercial buildings.

The methodology in this study involved four key elements.

\section{Analysis of the California Commercial End-Use Survey (CEUS) Data}

CEUS is a comprehensive study of commercial building sector end-use energy use in California (Itron 2004). It captures detailed building systems data, building geometry, electricity and gas usage, envelope characteristics, building systems, operating schedules, and other commercial building characteristics. A random sample of about 2800 surveys was completed. Commercial buildings are weighted and aggregated to building segment results. For the commercial building analysis we used Energy-IQ which uses CEUS as its initial database. Peak electric load data are non-coincident and limited so, for this study we selected buildings under 25,000 $\mathrm{ft}^{2}$. In addition, investor-owned utilities provided information on the number of accounts by peak load segments. The following summaries are prepared:

- Peak electric load distribution by market segment - The purpose of the analysis is to understand which market segments contribute more to the peak electric load. Market segments include small and large office, retail, restaurant, school, refrigerated and nonrefrigerated warehouse, grocery, health care, lodging, colleges and a large uncategorized 
miscellaneous group. For each market segment, percent non-coincident peak electric load, total area of building and demand intensity is presented.

- Peak electric load distribution by location - The information on the concentration of small commercial buildings within California identifies the key areas where DR may be of value. Seven major areas within the database include southern inland, central valley, southern coast, central coast, desert, northern coast and mountains.

- Peak electric load distribution by utility - Number of accounts in various peak electric load categories are collected to understand how closely the data from the utilities matches with the CEUS data.

- Lighting system type and controls distribution - Initial starting point for developing DR strategies is understanding the type of systems and controls in small commercial buildings. These data is summarized to understand OpenADR potential for lighting systems in small commercial buildings.

- HVAC system type and distribution - These data is summarized to gain an understanding of OpenADR potential for HVAC systems in small commercial buildings.

2. Framework development for technologies compatible with automated demand response

For small commercial buildings, three basic models for implementing DR are identified:

- Shed strategy is implemented completely outside the facility. This is the model used for direct load control programs by utilities and aggregators.

- Shed strategy is implemented completely within the load controllers themselves, i.e. within the lighting or HVAC controls.

- Use of a centralized controller within the facility (EMCS lite) to program and control the shed strategies for the entire facility.

After identifying the three basic models, we collected information on the various communication media that may be used for delivering DR automation signals. In addition, we interviewed over 20 vendors whose products may be applicable to automation of DR in small commercial buildings. A summary of findings are outlined in the results section. Further details are included in the appendices.

\section{Understanding small commercial building characterization issues}

There are various ways that a small commercial facility can participate in DR tariffs and programs in California. OpenADR is a communication standard for machine-to-machine communication that allows the customer to participate directly with a utility's tariff or program. Some aggregators have contracts with utilities to bring in small commercial buildings to DR programs (Koch 2008). In both cases, where a customer participates in a program directly or through an aggregator, a metering infrastructure is required to measure the amount of demand reduction. While this is still a research issue now, we expect AMI initiative to solve metering issues for this group of customers. The remaining key issues with this group of customers is 1) understanding their load shapes by analyzing their load variability to determine if they are good DR candidates at all; and 2) the whole building demand's weather sensitivity by correlating hourly outside air temperature with hourly 
load. By analyzing SF Community Power's portfolio in 2007, we were able to understand some of these issues.

\section{Automated DR Field Tests}

In order to put the strategies and technologies to test, two quick service restaurants were equipped with a relatively low cost technology that allows for multiple levels of demand shedding. The components of the system used for the pilot are shown in Figure 2. The facilities used for the pilot were two Taco Bells buildings located in San Juan Capistrano and Hesperia, CA. The components within the facilities were provided by Advanced Telemetry and customized for this pilot.

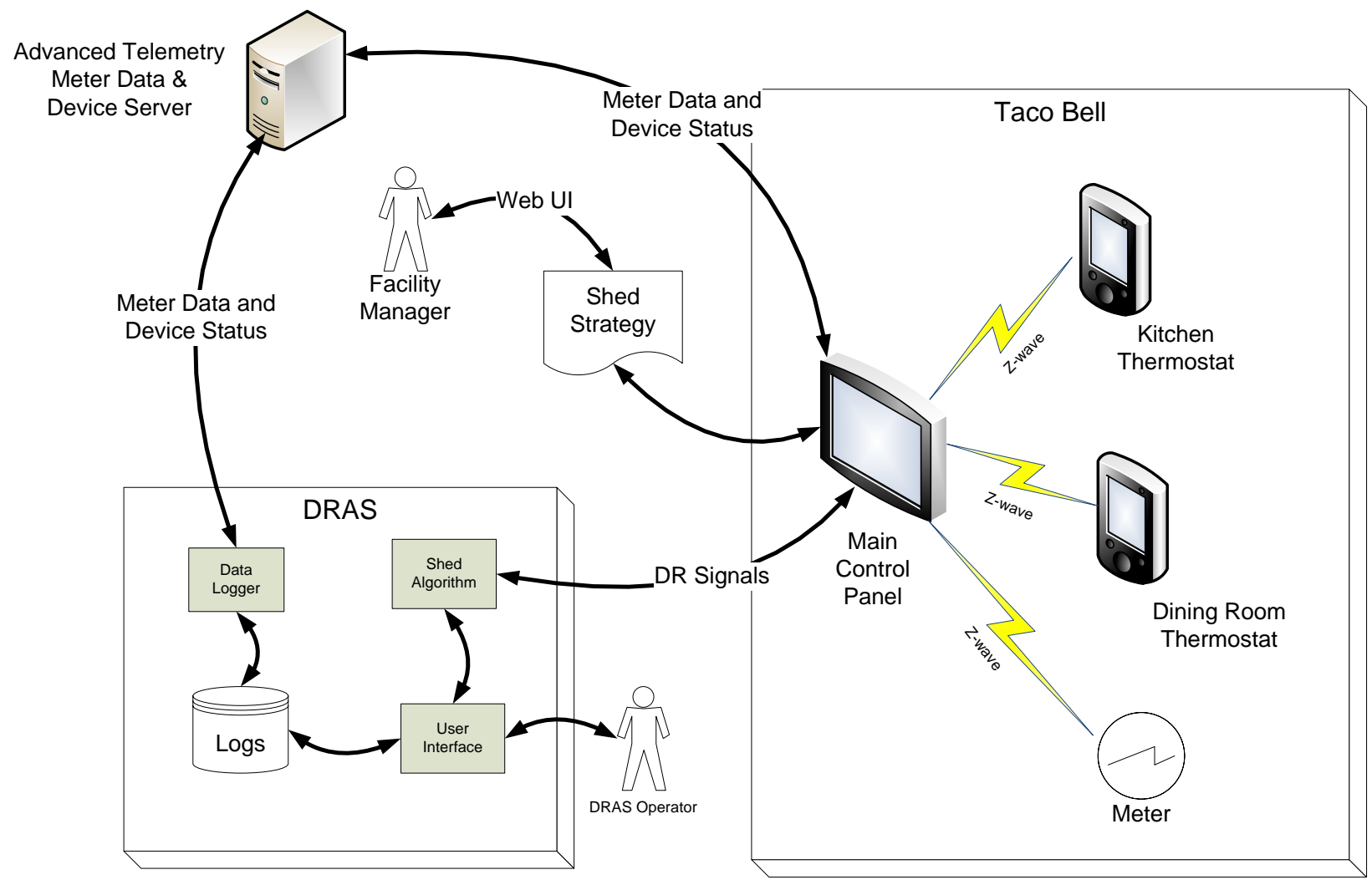

Figure 2. OpenADR architecture for the field tests

The components within the facilities consisted of the following:

- Control panel - This panel implemented the shed strategies for the facility and communicated with the other devices in the facility wirelessly over Z-wave.

- Dining room and kitchen thermostats - Typical installation for these facilities include two wireless thermostats: one located in the dining room area and the other in the kitchen area. These are programmable communicating thermostats (PCTs) that communicate with the control panel via $Z$-wave wireless communications. 
- Meter - This provided whole building demand information in both real time and at 15 minute intervals. The customer owns these data and allows the third party to have access to it for on going maintenance.

As shown in Figure 2, there was also a separate server, owned by Advanced Telemetry, that specifically collected meter and device status information from each facility. Finally, a Demand Response Automation Server (DRAS) was responsible for managing the DR events and providing the DR signaling to the facilities. All the DR signaling used by the DRAS followed the OpenADR standards as documented in version R1 of the OpenADR proposed standard (Piette et al. 2008). All communications between the various servers and the facility was via the Internet and used a broadband connection in the facility.

There are two innovations worth mentioning with the field tests:

1. OpenADR signals were utilized to communicate directly with both facilities small scale EMCS (EMCS Lite) system.

2. A feedback loop was created and several baselines (Appendix D) were pre-calculated so that the utility could request a certain percentage of shed, using a pre-specified baseline, from each facility.

Information on the OpenADR signals can be obtained from http://openard.lbl.gov. The remaining of this section will concentrate on the DRAS operation for achieving a certain percent of demand reduction.

A DRAS was designed and developed to allow the DR events to be managed for each facility. It was designed to allow the operator to specify the amount of load to shed according to a percentage from some baseline. Two baseline methods, three highest within the last ten days (3/10) and 3/10 with morning adjustment were calculated. Calculations are explained in Appendix D. In addition, a third baseline using outside air temperature regression (OAT) was calculated after the events for analysis purposes. This baseline was not used during the events because real-time weather data, which was needed to develop real-time baseline, was not available at each facility.

To initiate a DR Event, the operator entered general DR event parameters such as event date, start time and end time and selected which baseline to use and the percentage from that baseline to shed. Figure 3 show the DRAS operator interface for creating DR events. 


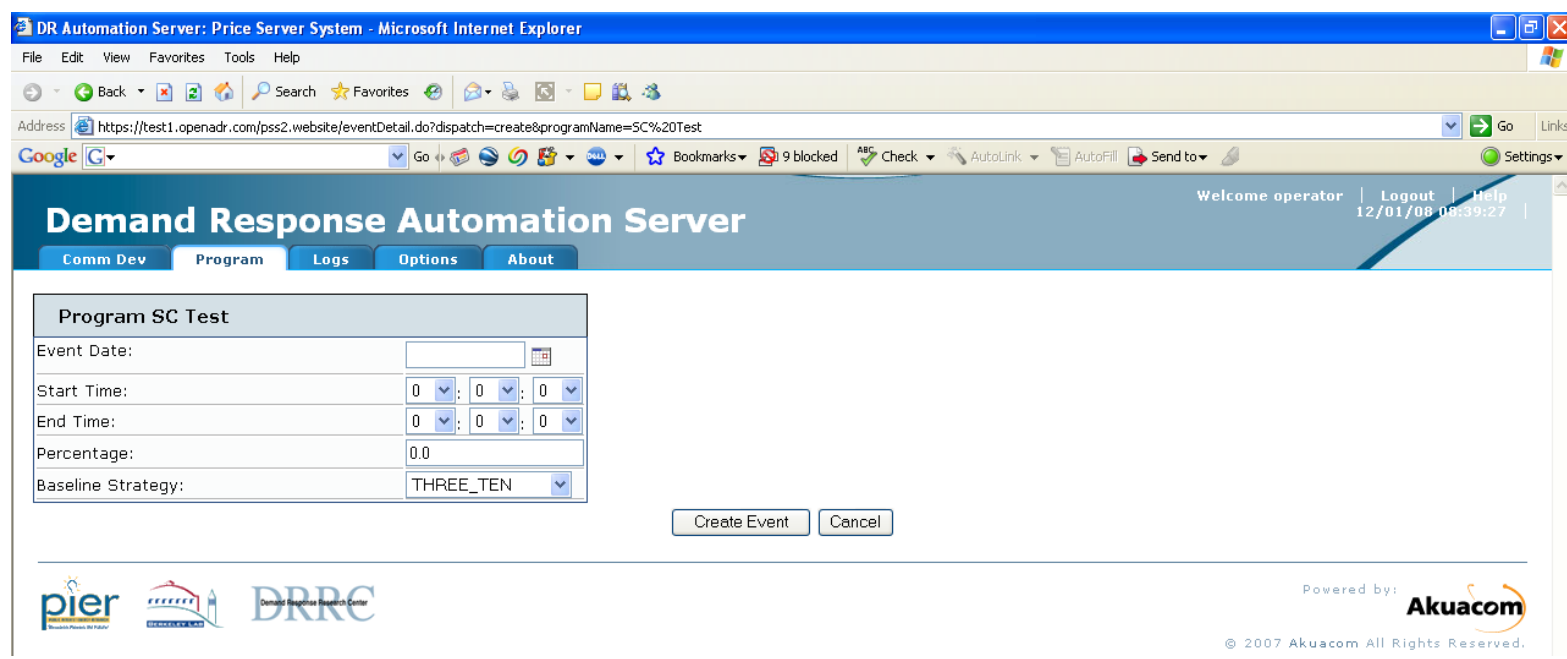

Figure 3. DRAS Operator Interface to Create DR Events.

The DR signals that were designed for this program consisted of 10 levels such that level 0 was considered normal and level 9 was considered the highest shed possible. The number of levels was chosen with a consideration for the level of granularity of controls requirement. Based on these levels, a shed strategy was assembled for each facility that consisted of correlating the device states in the facility with each of the levels. The only rule was that each successively higher level should result in a higher shed in the facility. Figure 4 is a screen capture of this interface. Although lighting sheds were initially part of the DR strategies and were programmed into the interface, final DR strategies only included the HVAC system. 


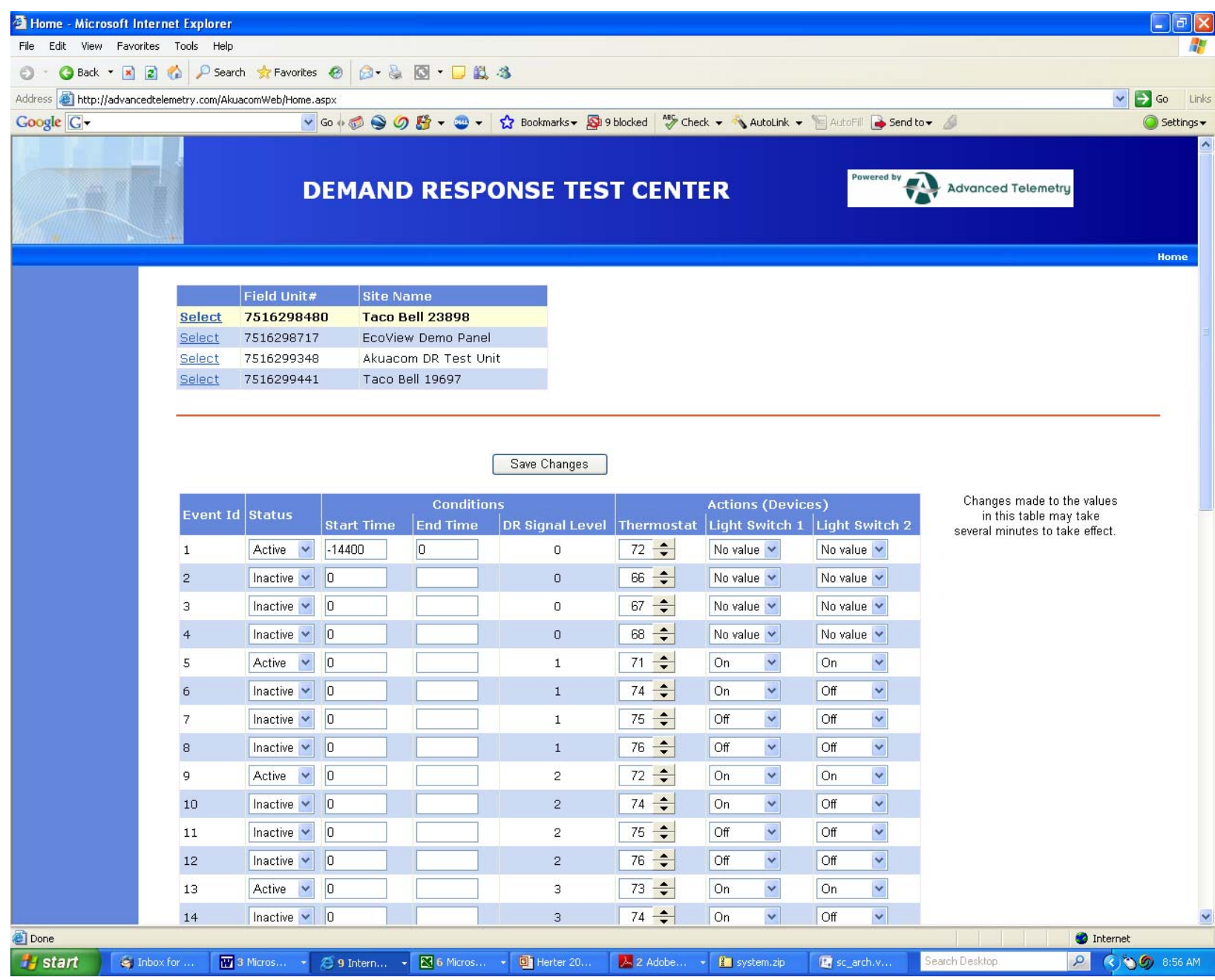

Figure 4. DR Strategy Input Interface

The shed strategy for each facility was programmed using a web based interface that consisted of filling out a table as shown in Figure 4. The table has rows that corresponding to shed levels and columns that correspond to the various device states. Time parameters were added that allowed for different device states for a particular shed level based upon when during the event the level occurs. In addition, there was the ability to input device states that should occur before the event occurs to support strategies such as pre-cooling.

Finally, the DRAS was designed to monitor the facilities response during the event and dynamically change the shed level sent to that facility if it was not shedding according to the percentage that was specified.

The basic process used with the DRAS consisted of the following:

1. Operator initiates an event and specifies the following: time and date for the event, baseline to use, the percentage to shed.

2. The DRAS notifies the facility of the pending event. 
3. The event begins and DRAS sends an initial shed level to the facility.

4. The DRAS calculates the demand since the start of the event and compares it against the baseline.

5. If the facility is not shedding enough (based upon the percentage and baseline specified) then a higher shed level is sent to the facility.

6. If the facility is shedding more than required than a lower shed level is sent to the facility. (Effect of data latency to be examined)

7. Repeat steps $4-6$ for the duration of the DR event.

8. End the event and return the facility to normal operations.

Since the meter data was being updated at 15 minute intervals the algorithm outlined in steps $4-6$ above was being run at a frequency of every 15 minutes.

A total of six events were scheduled in October and November of 2008. The first two were test events scheduled to find and resolve bugs in the communication and algorithm development. Three were successfully completed at each facility. The last one was only completed in the Hesperia facility since there was a problem with the thermostats in San Juan Capistrano facility. The results from these tests are reported in Section 5.4 of this report. 


\subsection{Results}

In this section, results from the four key elements of the study are presented. These are:

Small commercial facility characterization: California Commercial End-Use Survey (CEUS) and data collected from the investor-owned utilities are presented to characterize small commercial buildings, end uses and systems in California.

DR framework development for small commercial buildings: Three basic models and variations on these models are presented to address how small commercial buildings can participate in DR tariffs and programs through OpenADR signals.

Small Commercial customer aggregation: Collaboration with a small commercial facility aggregator to address issues related to the various types of customers is outlined.

Field Tests: Results from field tests are summarized.

\subsection{Small Commercial Building Characterization}

In this section, results from analysis of CEUS data and data shared by the utilities are presented. Analysis of these data is summarized in following categories:

- Peak electric load distribution by market segment - The purpose of the analysis is to understand which market segments contribute more to the peak electric load. Market segments include small and large office, retail, restaurant, school, refrigerated and nonrefrigerated warehouse, grocery, health care, lodging, colleges and a large uncategorized miscellaneous group. For each market segment, percent non-coincident peak electric load, total area of building and demand intensity is presented.

- Peak electric load distribution by location - The information on the concentration of small commercial buildings within California identifies the key areas where DR may be of value. Seven major areas within the database include southern inland, central valley, southern coast, central coast, desert, northern coast and mountains.

- Peak electric load distribution by utility - Number of accounts in various peak electric load categories are collected to understand how closely the data from the utilities matches with the CEUS data.

- Lighting system type and controls distribution - Initial starting point for developing DR strategies is understanding the type of systems and controls in small commercial buildings. These data is summarized to understand OpenADR potential for lighting systems in small commercial buildings.

- HVAC system type and distribution - These data is summarized to gain an understanding of OpenADR potential for HVAC systems in small commercial buildings. 
Table 1. Market Segmentation for Buildings Less Than 200 kW Peak Load (Source: CEUS)

\begin{tabular}{|l|r|r|r|}
\hline Market Segment & $\begin{array}{c}\text { \% Peak Load } \\
\mathbf{n = 9 6 , 8 7 2 ~} \mathbf{~ k W}\end{array}$ & $\begin{array}{c}\text { \% Size } \\
\mathbf{n}=\mathbf{2 7 , 9 6 5 , 2 1 6} \text { sqft }\end{array}$ & Ave.W/sqft \\
\hline \hline Misc & $25 \%$ & $32 \%$ & 2.6 \\
\hline Small Office & $19 \%$ & $12 \%$ & 5.1 \\
\hline Retail & $19 \%$ & $18 \%$ & 3.5 \\
\hline Restaurant & $14 \%$ & $5 \%$ & 8.8 \\
\hline School & $5 \%$ & $6 \%$ & 2.9 \\
\hline Warehouse & $5 \%$ & $14 \%$ & 1.2 \\
\hline Grocery & $4 \%$ & $2 \%$ & 6.6 \\
\hline Health Care & $3 \%$ & $3 \%$ & 3.7 \\
\hline Lodging & $3 \%$ & $4 \%$ & 2.2 \\
\hline Large Office & $3 \%$ & $3 \%$ & 3.5 \\
\hline Refrigerated Warehouse & $1 \%$ & $1 \%$ & 3.3 \\
\hline College & $0 \%$ & $0 \%$ & 3.8 \\
\hline
\end{tabular}

Table 1 shows the non-coincident peak load distribution of buildings less than $200 \mathrm{~kW}$ peak load for various market segments. It displays each segment by their contribution to the percent of total peak load, market segment percent contribution in terms of floor space and demand intensity for each market segment. Retail and small offices dominate the small commercial market in terms of their floor space and peak load followed by restaurants. Restaurants have the highest demand intensity followed by grocery stores and small offices. On the other end of the spectrum, warehouses tend to occupy $14 \%$ of the total floor space with relatively small contribution to the peak load due to their low demand intensity.

Table 2. Geographical Distribution and Peak Load Contribution of Small Commercial Buildings (Source: CEUS)

\begin{tabular}{|l|r|r|r|}
\hline & \% Peak Load & \% Area & W/sqft \\
\hline \hline Southern Inland & $32 \%$ & $31 \%$ & 3.5 \\
\hline Central Valley & $26 \%$ & $25 \%$ & 3.5 \\
\hline Southern Coast & $17 \%$ & $18 \%$ & 3.2 \\
\hline Central Coast & $16 \%$ & $19 \%$ & 2.8 \\
\hline Desert & $4 \%$ & $3 \%$ & 4.3 \\
\hline Northern Coast & $3 \%$ & $3 \%$ & 3.6 \\
\hline Mountains & $1 \%$ & $1 \%$ & 4.6 \\
\hline
\end{tabular}

Table 2 displays the geographical distribution of small commercial buildings by percent of peak load, percent of floor space and by demand intensity. These data are important because it shows the geographical density of small commercial buildings in California. Small commercial buildings in southern inland and central valley contribute to more than half of the total peak load from all small commercial buildings followed by small commercial buildings in southern and central coasts. While the demand intensity of buildings in the desert and mountains tend to be higher, their contribution to the peak load is little because of their small number in these 
areas. Further analysis showed that both in southern inland areas and central valley the highest contributors to peak load are small offices, retail and restaurants. Moreover, more than half peak load contribution of each market segment comes from the two areas.

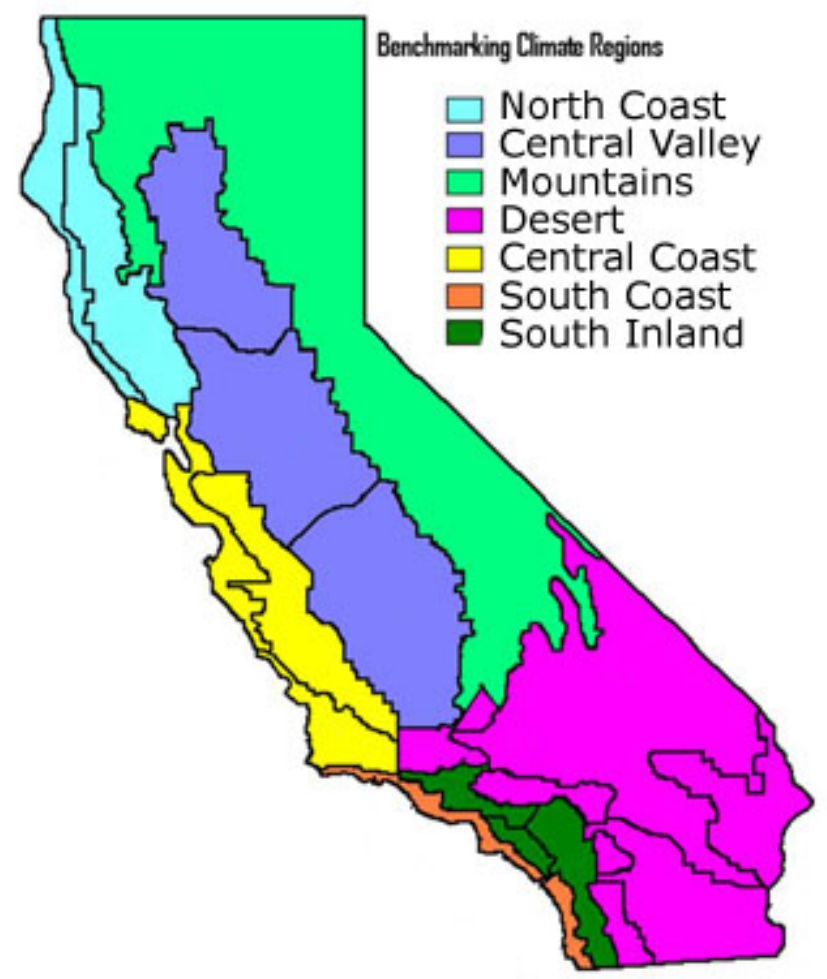

Figure 5. Climate Regions Defined by CEUS

The investor-owned utilities (IOUs) in California were asked to provide number of accounts in each peak load range as displayed in Table 3. The data gathered from CEUS and the IOUs is presented in Table 3. There is a slight difference in the percentage of less than $50 \mathrm{~kW}$ peak accounts but this may be due to IOUs servicing most but not all of California.

Table 3. Comparison of CUES Data with the Actual Percent of Accounts within Various Peak Demand Ranges in Three Investor-Owned Utility Territories in California (Source: Investor-Owned Utilities)

\begin{tabular}{|l|r|r|r|r|r|r|}
\hline & \multicolumn{7}{|c|}{$\mathbf{k W}$ Range } & \\
\cline { 2 - 8 } & $\mathbf{2 0 0}>\mathbf{x}>\mathbf{1 5 0}$ & $\mathbf{1 5 0}>\mathbf{x}>\mathbf{1 0 0}$ & $\mathbf{1 0 0}>\mathbf{x}>\mathbf{5 0}$ & $\mathbf{5 0}>\mathbf{x}>\mathbf{3 5}$ & $\mathbf{5 0}>\mathbf{x}>\mathbf{2 0}$ & less than $\mathbf{2 0} \mathbf{k W}$ \\
\hline \hline CEUS & $1 \%$ & $2 \%$ & $5 \%$ & $5 \%$ & $17 \%$ & $75 \%$ \\
\hline SCE & $1 \%$ & $2 \%$ & $4 \%$ & $3 \%$ & $8 \%$ & $82 \%$ \\
\hline PG\&E & $0 \%$ & $1 \%$ & $2 \%$ & $1 \%$ & $1 \%$ & $96 \%$ \\
\hline SDG\&E & $1 \%$ & $1 \%$ & $3 \%$ & $2 \%$ & $3 \%$ & $90 \%$ \\
\hline
\end{tabular}

The next step in understanding applicability of Auto-DR to small commercial buildings requires characterization of the end-uses and controls that are commonly utilized in small commercial buildings. While CEUS does not have end-use and controls data sorted by peak load, it does 
provide data sorted by building size. For this study, CEUS data for buildings less than 25,000 $\mathrm{ft}^{2}$ were considered.

\subsubsection{Heating Ventilation and Air Conditioning (HVAC) Systems}

On the HVAC side, ninety-nine percent of buildings in California less than $25,000 \mathrm{ft}^{2}$ have single zone systems. Further analysis showed that in this building size group, $65 \%$ of total tonnage is due to packaged single zone units while seventeen percent of total tonnage is due to air-source heat pumps (Table 4).

Table 4. Type of HVAC Systems by Count and Tonnage in Buildings Less Than $25,000 \mathrm{ft}^{2}$

\begin{tabular}{|l|r|r|r|r|}
\hline Type & $\begin{array}{c}\text { Totalby } \\
\text { Count } \\
\mathbf{n = 1 , 1 0 1 , 3 2 0}\end{array}$ & $\begin{array}{c}\text { \% by } \\
\text { Count }\end{array}$ & $\begin{array}{c}\text { Total by Ton } \\
\mathbf{n = 7 9 2 , 0 5 8}\end{array}$ & \% by Ton \\
\hline \hline Single Zone & 3456 & 0 & 4011 & 1 \\
\hline Packaged Single Zone & 586532 & 53 & 511694 & 65 \\
\hline Split-System Single Zone & 55541 & 5 & 54494 & 7 \\
\hline Packaged Terminal Unit & 101014 & 9 & 19068 & 2 \\
\hline Unit Ventilator & 62378 & 6 & 54962 & 7 \\
\hline Two-pipe Fan Coil & 3955 & 0 & 3527 & 0 \\
\hline Four-pipe Fan Coil & 1363 & 0 & 5763 & 1 \\
\hline Baseboard heater & 50106 & 5 & 0 & 0 \\
\hline Air-source Heat Pump & 231966 & 21 & 136542 & 17 \\
\hline Ground-Source Heat Pump & 0 & 0 & 0 & 0 \\
\hline Water Loop Heat Pump & 5009 & 0 & 1997 & 0 \\
\hline
\end{tabular}

Dominance of packaged single zone units in small commercial customer group provides a starting point for DR strategy development. Typical HVAC DR strategies for packaged single zone units include:

- Global temperature adjustment (GTA)

- Compressor shut down

- Unit cycling

- Pre-cooling and/or night ventilation (free-cooling)

In previous research we defined Global Temperature Adjustment (GTA) as a DR strategy to allow commercial building operators to adjust the space temperature setpoints for an entire facility by one command from one location (Motegi et al. 2006). In the case of small commercial buildings with a single packaged unit and a single zone, this means setting up the temperature at the thermostat. However this becomes complicated when there are multiple packaged units because a way to network thermostats to provide the "global" or central temperature adjustment is required. This is also the case for large commercial facilities which are made up of small commercial type buildings.

Compressor shut down can be defined as turning off the compressor in a single compressor system for a short period time or turning off second stage of two stage compressor units. This requires either a small energy management control system (EMCS) or direct communication to 
the packaged unit system. When this strategy is used, ventilation requirements of buildings must not be compromised.

Unit cycling refers to shutting off a small number of units for a limited time if there are others that can continue servicing the facility. Again, ventilation requirements should not be compromised especially in retail buildings where out-gassing from merchandise may cause indoor air quality issues (Hotchi et al. 2006).

Table 5. Controls for Single Zone Packaged Air Units (Source: CEUS)

\begin{tabular}{|l|r|r|r|r|}
\hline Type & $\begin{array}{l}\text { Total by } \\
\text { Count }\end{array}$ & $\begin{array}{l}\text { \% by } \\
\text { Count }\end{array}$ & $\begin{array}{l}\text { Total by } \\
\text { Ton }\end{array}$ & \% by Ton \\
\hline \hline Manual & 609736 & 61.26 & 338609 & 47.52 \\
\hline Always on cons temp & 29527 & 2.97 & 28352 & 3.98 \\
\hline Time clock & 59925 & 6.02 & 62324 & 8.75 \\
\hline EMS & 16628 & 1.67 & 29127 & 4.09 \\
\hline Programmable Tstat & 279473 & 28.08 & 254093 & 35.66 \\
\hline
\end{tabular}

In order to implement the DR strategies outlined above, the next step is to understand the kind of controls that are being used in small commercial buildings. Table 5 displays the type of controls in buildings less than $25,000 \mathrm{ft}^{2}$. Energy management and control systems (EMCS) is by far the most preferred way to implement DR strategies in buildings because they allow for preprogramming strategies and either manually or automatically call the strategies when a DR event is dispatched. Unfortunately, the penetration rate of these systems into small commercial buildings is low because they are expensive. Most of the buildings have manual control.

Manual control is adjusting thermostat setting manually. Programmable thermostats are the second widely used controls with a penetration rate of $28 \%$.

\subsubsection{Lighting}

Electrical lighting in buildings is responsible for $30-33 \%$ of the commercial sector peak load (Rubinstein et al.2006). Lighting may provide opportunities in small commercial buildings as well. CEUS data shows that fluorescent lamps dominate small commercial buildings with $76 \%$ penetration followed by $11 \%$ penetration of incandescent light sources. Ballast types in small commercial buildings are magnetic ballasts, electronic ballasts and high efficiency magnetic ballasts, $41 \%, 31 \%$ and $27 \%$, respectively. There is little penetration of advanced electronic ballasts in small commercial buildings. 
1441 sites, 9146 datapoints

Aggregated by $\mathrm{kW}$

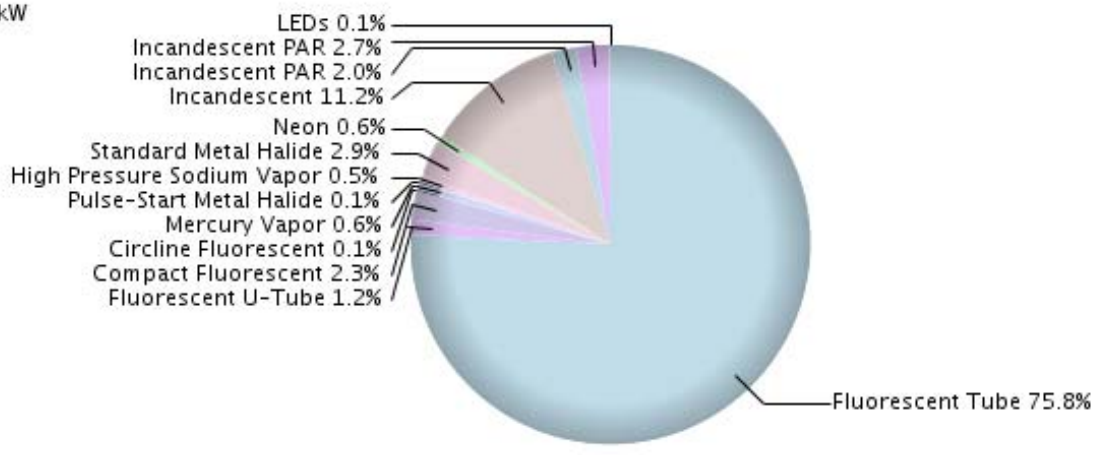

Figure 6. Light Source Distribution in Small Commercial Buildings (Source: EnergylQ)

1426 sites, 5776 datapoints

Aggregated by $\mathrm{kW}$

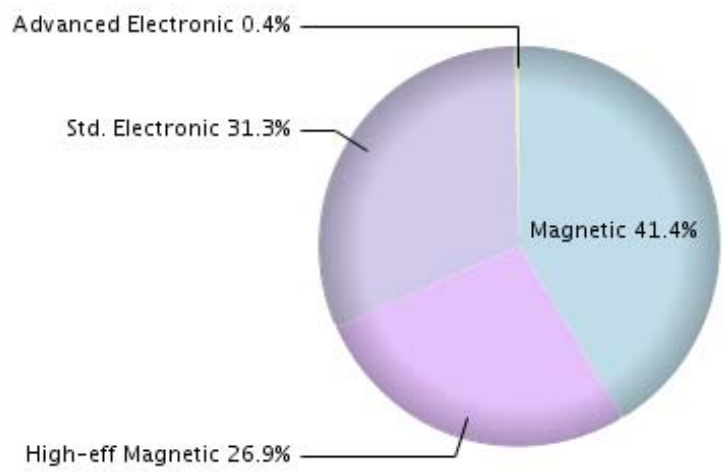

Figure 7. Ballast Types Used in Small Commercial Buildings (Source: EnergylQ)

Centralized control systems allow for easy implementation of DR automation. CEUS data show that $93 \%$ of small commercial buildings have only manual control over lighting systems and that only about $2 \%$ have EMCS. 
1441 sites, 9337 datapoints

Aggregated by $\mathrm{kW}$

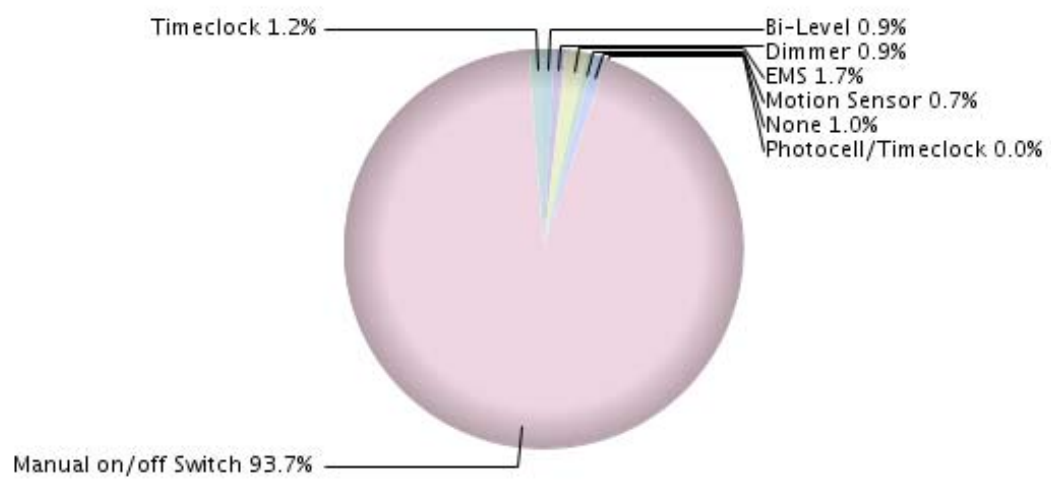

Figure 8. Lighting Controls in Small Commercial Buildings (Source: EnergylQ)

\subsubsection{End use load distribution}

HVAC and lighting systems make up more than half of the peak load in large commercial buildings in California. In small commercial building market segments, other end uses such as refrigeration may also contribute largely to the peak load. It is extremely important to understand how much each end use contributes to the total peak load because for any demand reduction to be visible and measurable, reduction has to be outside of the standard deviation of the whole building peak load. Experience in large commercial buildings of various types indicates that reduction has to be between 5 to $10 \%$ reduction in peak demand to be visible.

\subsection{DR Technology Framework Development for Small Commercial Buildings}

For small commercial buildings, three basic models for implementing DR are identified:

1. Shed strategy is implemented completely within the load controllers themselves, i.e. within the lighting or HVAC controls (see Figure 9).

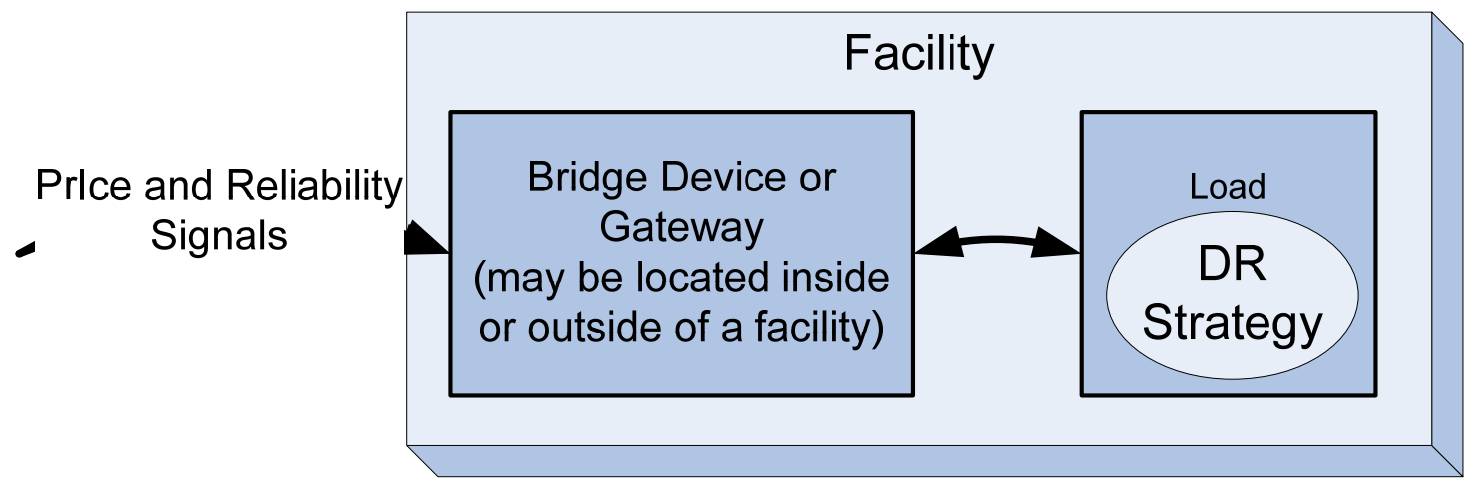

Figure 9. DR Strategy in Load Controller 
2. Use of a centralized controller within the facility (EMCS lite) to program and control the shed strategies for the entire facility (see Figure 10).

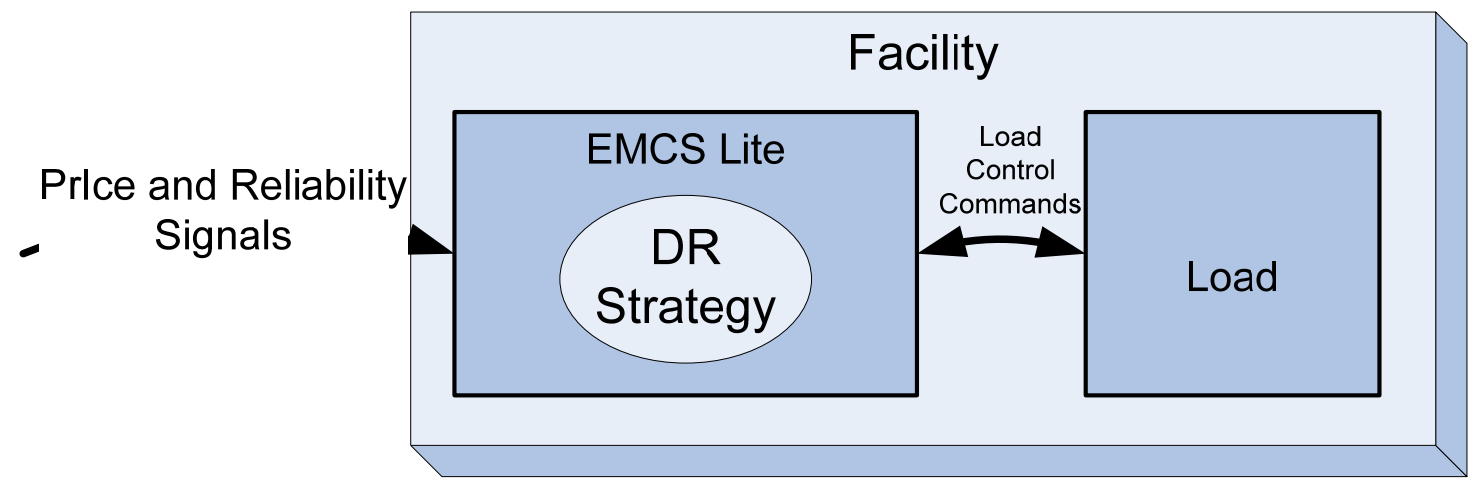

Figure 10. DR Strategy in EMCS

3. Shed strategy is implemented completely outside the facility. This is the model used for direct load control programs by utilities and managing load reductions for customer groups by aggregators (see Figure 11).

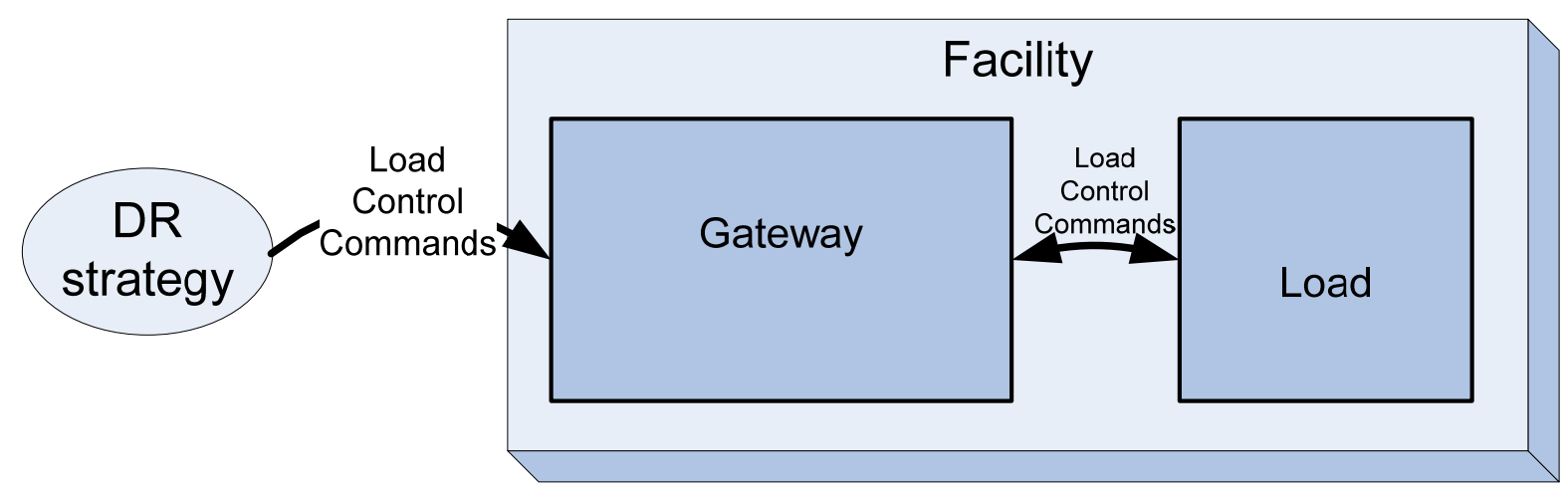

Figure 11. DR Strategy External to the Facility

The difference among the three models is the location where the price signals (DR signals) are converted into DR strategies (controls signals or commands). There are variations in implementation for each of the three models that make up the framework for technology evaluation. This section describes each model, implementation variations and describes the pros and cons of each implementation. At its core, there is a DR automation server that publishes prices and reliability signals. At each facility, there are software or hardware clients that poll the information and bring it into the buildings. There are three types of clients: smart, simple and bridge. A smart client is any hardware or software client that can take the entire information model, parse and use it to call the necessary programs and strategies to activate DR strategies. A simple client is any hardware or software client that listens to a portion of the information model where the information is presented in simpler (or mapped) manner. A bridge client translates OpenADR information into device-specific and/or communication-specific information. The bridge client is conceived to be used to send information via broadcast to thermostats and to allow third-party entities (e.g., aggregators) to map information to proprietary networks. 
Figures 9, 10 and 11 show that the nature of the signals sent to the facility is related to where the DR strategy is implemented. In cases where the DR strategy is in an EMCS lite device or in the load controllers, a DR signal containing business level information (i.e. prices or shed levels) may be sent to the facility. In the case where the DR strategy is implemented outside of the facility, load control commands are sent. For the purposes of this report, the first two methods are considered equivalent since they both involve the same type of DR signal being sent to the facility.

In the first model (Figure 9), standalone communicating load controllers contain the DR strategy, which is implemented at the facility, and are able to receive OpenADR signals. This method may or may not require a bridge client that requires some level of configuration to distribute messages. If a bridge client is not required, then it requires enough intelligence at the standalone load controllers to accept DR event information from the DRAS. An example of a device that fits in with this framework is a programmable communicating thermostat (PCT). In this model, each load controller has to be pre-programmed. While the DR strategy implemented at the standalone load controllers grant increase granularity of controls, it is difficult if not impossible, to implement system wide shed strategies unless they are centralized. In 2006, Lawrence Berkeley National Laboratory (LBNL) collaborated with two Whole Foods Market stores and installed client logic with integrated relay (CLIR) boxes to control lighting in the buildings. One installation issue was the spacing of loads. When the loads to be controlled are further away from each other, the installation may require more than one client device for each facility thus possibly increasing the cost of implementation.

In the second model (Figure 10), EMCS Lite provides centralization of controls. It is defined as a type of EMCS controller that is designed specifically for the type of loads and logic that are used for DR applications in small commercial buildings. Thus, by definition it should be easy to program and not necessarily rely on a computer to display a user interface and pre-program control strategies. It should also be able to receive standard DR event information such as OpenADR signals. The existence of an EMCS Lite at a small commercial building enables the customer to design and implement shed strategies for their own buildings thus being able to make decisions about the site's control strategies including opting out of an event. Many large commercial buildings are equipped with more sophisticated EMCSs where the EMCS is able to host a smart client to poll DR signals. For the small commercial Auto-DR pilot with Southern California Edison (SCE), LBNL and Akuacom partnered with Advanced Telemetry to experiment with their OpenADR ready EMCS Lite device. Another advantage with partnering with Advanced Telemetry was to work with them to recruit from their customer pool for the pilot project.

For the last model (Figure 11), where the DR strategy is completely implemented outside of the facility, the facility does not receive any price or reliability signals, just control and set point signals. Signal conversion from prices to DR strategies takes place somewhere between when utility sends the price signals and the site receives commands. One way to do this is that all site specific DR strategies are implemented in an external server. This requires that the external server have generic device models, a description of inputs and outputs, for each load controller. Depending upon the DR strategy it may require that certain state, or systems status, 
information from the facility to be fed back into the external server. In the case of retail or fast food chains, a cookie cutter approach may simplify DR strategy implementation and lower the cost of installations. While this model allows for minimum installations at each site, the price paid for such a system is that control of a facility is relinquished to an external server and DR strategy decisions are no longer made at each site and that opting out of an event may be problematic. This is a model closely followed by aggregators participating in DR programs in California. However, instead of using open communications with the end use, they send command and control signals out to the facilities that participate in DR programs.

Table 6 categorizes the products of some of the companies LBNL surveyed into three basic Auto-DR models outlined above. A detailed analysis is presented in Appendix A.

\section{Table 6. Sample of Products That Support Different Models}

\begin{tabular}{|c|c|c|c|}
\hline End Use & EMCS/EMCS Lite & DR Strategy at Load & Remote DR Strategy \\
\hline HVAC & $\begin{array}{l}\text { Advanced Telemetry, } \\
\text { Alerton, Automated } \\
\text { Logic, Echelon, Green } \\
\text { Box, Loytec, Teletrol }\end{array}$ & $\begin{array}{l}\text { Novar, Tendril, } \\
\text { Universal Devices, } \\
\text { Carrier, Golden Power, } \\
\text { Lennox, Lightstat, } \\
\text { Proliphix, RCS, White } \\
\text { Rogers } \\
\end{array}$ & $\begin{array}{l}\text { Canon, PowerMand, } \\
\text { Site Controls }\end{array}$ \\
\hline Lighting & Universal, Lumenergi & Adura, Echoflex & Adura \\
\hline
\end{tabular}

\subsubsection{DR Signal Communication Means}

For any small commercial facility to participate in automated DR, it needs to receive price and reliability signals over a communication media. For large commercial and industrial facilities that participated in Auto-DR programs in California, their local area network (LAN) or digital subscriber lines (DSL) has been utilized. However, not every small commercial facility may have a LAN or dedicated DSL lines. Therefore, this section outlines other media that may be used to communicate DR signals to small commercial customers and compares the various choices.

In general the following are the desired characteristics of any communications means for the purposes of automated DR.

- Reliable

- Two way

- Secure

- Reasonable latency. This requirement depends upon the type of DR program that is being implemented. For most types of DR keeping the latency less than a minute is adequate, but there may be requirements of seconds if doing DR for the purposes of grid reliability.

- Support for open and widely adopted protocols such as Internet Protocol 
- Cost effective to design into automation equipment. This means that the equipment should be cheap enough to keep the overall equipment manufacturing cost down and it should be simple enough to keep the development costs within reason.

- Cost effective to operate. This means that there should not be high operational costs associated with using the communications means.

\subsubsection{IP Infrastructures}

Communications infrastructures that support Internet Protocol (IP) communications and can utilize the Internet as the main means for communicating are as follows:

- T-Carrier

- Digital Subscriber Lines (DSL)

- Cable Internet

- Integrated Service Digital Network (ISDN)

- Satellite

- Optical Fiber to Building

- WiMAX

- Mobile Cellular

- Broadband Power Line

- Plain Old Telephone Service (POTS)

\subsubsection{T-carrier}

Many buildings have dedicated T-carrier connections. This includes T1 connection which has a 1.544 Mbit/s line rate. T-carrier connections are typically dedicated cables to the facility with a monthly service charge of a few hundred dollars per month. Because of this cost, they are not appropriate for DR only applications in small commercial buildings. If there is an existing T1 connection into a facility, which is highly unlikely in small commercial buildings, it can be leveraged for the purposes of DR. With the advent of faster and cheaper DSL and Cable broadband connections $\mathrm{T} 1$ is becoming less prevalent.

Devices receiving DR signals over this medium will typically utilize an Ethernet connection to the facility LAN or T1 router.

\subsubsection{Digital Subscriber Lines (DSL)}

This is a class of broadband service that is offered by the telephone companies. DSL is generally cheaper than a T1 connection and has become a more viable broadband connection. Monthly service charges for business are approximately \$50 - \$250 depending upon the nature of the service. Since DSL utilizes existing phone lines into the facility it is relatively inexpensive to initiate service. The monthly service charge may be too high to be dedicated to DR, but if there is an existing DSL service it can be utilized for DR. 
Devices receiving DR signals over this medium will typically utilize an Ethernet connection to the facility LAN or DSL router.

\subsubsection{Cable Internet}

This is a class of service that is offered by the cable television service providers. Cable Internet originated with television service providers and has traditionally been a residential service. Recently it has been growing in popularity among businesses due to its higher throughput and lower cost compared to DSL and T1. Typically Cable Internet has higher installation costs over DSL due to the fact that cables need to be installed. The monthly cost is comparable to DSL and probably would not be appropriate for a dedicated DR communications infrastructure, but if it existed for other purposes, could easily be utilized for DR.

Devices receiving DR signals over this medium will typically utilize an Ethernet connection the facility LAN or Cable Modem/Router.

\subsubsection{Integrated Service Digital Network (ISDN)}

This is a data service provided by telephone companies. Although it still exists, in general this is an obsolete means of communications and has been replaced by DSL services. Devices receiving DR signals over this medium would typically use Ethernet connect to an ISDN router.

\subsubsection{Satellite Internet}

This is a form of broadband connection in which the downstream connectivity is via a satellite transmission and the upstream is typically via terrestrial land line such as a simple phone connection. This is typically used in residential applications where it is either difficult to get DSL or cable service. In some cases it is used where the customers already have existing satellite television service. This type of connection is rarely used in businesses and would not be appropriate for a dedicated DR communications channel due to its relatively high cost.

Devices receiving DR signals over this medium would typically use Ethernet connect to a router.

\subsubsection{Optical Fiber to Building}

Optical fiber communications are an integral part of the backbone of most communications networks in use today. This is due to its high bandwidth and cost effectiveness in terms of the amount of data that can be transferred compared to the cost of the infrastructure. This section specifically addresses the use case where fiber is run to the building itself as opposed to just being part of the backbone.

The market penetration of optical fiber to the building is small and varies widely by country. Most analysts agree that it represents the future of data connection to the building due to its high bandwidth capabilities. There are businesses today that have fiber installed and this number will increase over time. Due to the relatively high cost of installing fiber this would not be an appropriate means of communication dedicated to DR, but if it did exist it could easily be used for DR applications.

Devices receiving DR signals over this medium would typically use Ethernet to connect to a router. 


\subsubsection{Worldwide Inter-operability for Microwave Access (WiMAX)}

WiMAX is a wireless technology that is quickly gaining acceptance for data communications.

Since it is a wireless network, the cost of building out the infrastructure is relatively low. In addition the wireless service providers view this as a means to compete with DSL and Cable broadband providers. The current market penetration of WiMAX is still relatively low, but increasing fast. The monthly service charges for WiMAX are comparable to DSL and Cable and as such means that it probably is not appropriate to be dedicated for DR, but if it already exists in the facility it can easily be shared for DR applications.

Devices receiving DR signals over this medium would typically use Ethernet connect to a router, but if the prices of WiMAX continue to drop and approach the levels of WiFi it may be possible to embed the WiMAX network interface directly in the device.

\subsubsection{Mobile Communications (Cellular)}

Mobile communications covers a wide range of technologies, networks, protocols and service providers. Although the technologies primarily exist to support wireless voice services they have evolved over the years to also support mobile wireless data services as well. Table 7 summarizes a wide range of communication means for DR.

Cellular mobile communications are not appropriate and rarely used to bridge LANs within buildings to the Internet. They are typically used to provide connectivity to specific devices such as cell phones and other handheld devices. Therefore, if a DR device were to use these technologies, the connections would most likely be dedicated to the device. This means that all the deployment and monthly costs will be dedicated entirely to DR. In addition, embedding cellular technology into a device is somewhat more costly and difficult than other communications interfaces. For these reasons cellular wireless is not an appropriate means of communications for DR.

\subsubsection{Broadband over Power Lines (BPL)}

Broadband over Power Lines is a service that utilizes existing power lines to offer communications services.

Electrical power is transmitted over high voltage transmission lines, distributed over medium voltage, and used inside buildings at lower voltages. Power line communications can be applied at each stage. Most PLC technologies limit themselves to one set of wires (for example, premises wiring), but some can cross between two levels (for example, both the distribution network and premises wiring).

BPL services have met with some resistance due to concerns about interference with existing wireless systems and are not widely offered today. Nonetheless, it is a service that offers some promise for providing the communications infrastructure for AMI systems.

Devices receiving DR signals over this medium would typically use Ethernet to connect to a router. 


\subsubsection{Plain Old Telephone Service (POTS)}

POTS refers to the existing land line based telephone network. Although wireless voice services are starting to supplant POTS, it still remains the most widely available communications network in existence. Because of its widespread deployment and relatively inexpensive cost, POTS remains a potential candidate for providing communications for purposes of DR. The main problem with POTS is that it is not an always on connection and therefore, the DR signals can not be polled from the DR signal server. This means that the DR signal must be pushed to the facility, thus requiring a dedicated POTS line. This will increase the costs of using POTS since there will be a monthly service cost associated with any POTS service. These charges can be relatively low, but they may still be too much for a DR program for small commercial buildings.

DR devices that utilize POTS will most likely have an analog modem embedded in the device. This is a relatively low cost and mature technology.

\subsubsection{Radio Frequency (RF) Broadcast}

This section describes a number of RF based infrastructures that are not IP based, but may be used for the purposes of DR signaling.

\subsubsection{Pager Networks}

Paging networks are relatively inexpensive and easy to deploy. Some pager networks are two way while others are only one way.

There has been some use of pager networks for DR programs, especially for those that are doing some type of direct load control as in the case of base interruptible programs. In general pager networks suffer from the following drawbacks:

Most pager networks only support one way communications they are not appropriate if it is necessary to receive some sort of feedback from the facility. The amount of information that may be transmitted via the paging network is somewhat limited. Due to latencies in the network it may not be reasonable to send individual messages to a large number of DR participants. Some sort of broadcasting mechanism will have to be employed. The latency of receiving messages in a pager network can be somewhat high. There may be monthly service charges associated with the network if it is provided by a third party service provider.

DR devices that will receive DR signals via the Pager network will most likely embed the RF interface to the pager network directly into the device. This is relatively inexpensive.

\subsubsection{Datacasting}

Datacasting is a generic term that refers to the broadcasting of data using RF and typically refers to using existing broadcast channels such as TV or FM radio. Datacasting networks that utilize FM radio broadcasts are more commonly used for a wide range of applications that can benefit from low bandwidth one way communications. This section further discusses two such Datacasting networks - RDS and Directband. 


\subsubsection{Radio Data System (RDS)}

RDS is a type of datacast network that utilizes existing FM broadcast channels for communications. It is used for a wide range of applications such as radio programming, traffic, advertising, weather, etc., where low bandwidth, small messages can be broadcast to a wide range of devices. RDS holds promise as a communications means for DR signals because it utilizes existing FM broadcast infrastructure and is low cost to embed into devices. It is one of the proposed communications means in the California Programmable Communicating Thermostat initiative. RDS has the following drawbacks:

RDS only supports one way communications and is not appropriate if it is necessary to receive some sort of feedback from the facility. The amount of information that may be transmitted via RDS is somewhat limited. It is not feasible to target individual facilities with RDS broadcast messages and therefore DR signals must be sent in a broadcast fashion to a large number of facilities.

DR devices that will receive DR signals via the RDS will embed the RDS RF interface directly into the device. This can be done at a low cost.

\subsubsection{DirectBand}

DirectBand is a North American wireless datacast network owned and operated by Microsoft. It uses FM radio broadcasts in over 100 cities to constantly transmit data to a variety of devices, including portable GPS devices, wristwatches and home weather stations.

DirectBand is similar to RDS in terms of its functionality and as such has similar advantages and disadvantages with the exception that it is proprietary to Microsoft.

Below is a summary of each means of communication described in this section. 
Table 7. Summary of Communication Means for DR

\begin{tabular}{|c|c|c|c|c|c|}
\hline Type & $\begin{array}{c}\text { Must be } \\
\text { dedicated to } \\
\text { DR devices } \\
\end{array}$ & Two Way & Installation costs & Monthly costs & $\begin{array}{c}\begin{array}{c}\text { Costs to } \\
\text { implement in } \\
\text { devices }\end{array} \\
\end{array}$ \\
\hline T-carrier & No & Yes & $\begin{array}{l}\text { High } \\
\text { if dedicated }\end{array}$ & $\begin{array}{l}\text { High } \\
\text { if dedicated }\end{array}$ & Low (Ethernet) \\
\hline DSL & No & Yes & $\begin{array}{l}\text { Medium if } \\
\text { dedicated }\end{array}$ & $\begin{array}{l}\text { Medium if } \\
\text { dedicated }\end{array}$ & Low (Ethernet) \\
\hline Cable & No & Yes & $\begin{array}{l}\text { Medium if } \\
\text { dedicated }\end{array}$ & $\begin{array}{l}\text { Medium if } \\
\text { dedicated }\end{array}$ & Low (Ethernet) \\
\hline ISDN & No & Yes & $\begin{array}{l}\text { Medium if } \\
\text { dedicated }\end{array}$ & $\begin{array}{l}\text { Medium if } \\
\text { dedicated }\end{array}$ & Low (Ethernet) \\
\hline Fiber & No & Yes & $\begin{array}{l}\text { High } \\
\text { if dedicated }\end{array}$ & $\begin{array}{l}\text { High } \\
\text { if dedicated }\end{array}$ & Low (Ethernet) \\
\hline \begin{tabular}{|l|} 
Satellite \\
\end{tabular} & No & Maybe & \begin{tabular}{|l|} 
High \\
if dedicated
\end{tabular} & $\begin{array}{l}\text { Medium if } \\
\text { dedicated }\end{array}$ & Low (Ethernet) \\
\hline WiMax & No & Yes & $\begin{array}{l}\text { Medium if } \\
\text { dedicated }\end{array}$ & $\begin{array}{l}\text { Medium if } \\
\text { dedicated }\end{array}$ & Low (Ethernet) \\
\hline Mobile & Yes & Yes & Low & Medium & High \\
\hline POTS & No & Yes & Low & Medium & $\begin{array}{l}\text { Low if not } \\
\text { dedicated }\end{array}$ \\
\hline BPL & No & Yes & $\begin{array}{l}\text { Medium if } \\
\text { dedicated }\end{array}$ & $\begin{array}{l}\text { Medium if } \\
\text { dedicated }\end{array}$ & Low (Ethernet) \\
\hline Paging & Yes & Both & Low & Medium & Medium \\
\hline RDS & Yes & No & None & None & Low \\
\hline \begin{tabular}{|l|} 
Direct \\
Band \\
\end{tabular} & Yes & No & None & None & Low \\
\hline
\end{tabular}




\subsection{Small Commercial Customer Aggregation}

In order to understand some of the small commercial customer demand reduction measurement issues, we partnered with SF Community Power to analyze their portfolios' participation in the capacity bidding program with PG\&E in 2007. The goal of the study was to:

- understand the DR performance of SF Power's Capacity Bidding Program (CBP) participation in 2007,

- investigate issues related to baseline

- examine DR strategies related to each individual building, and

- improve the DR performance of the sites.

Appendix B includes the detailed analysis of the data which does not include DR strategies and performance improvements as SF Community Power did not collect DR strategy data from the participants and LBNL did not have access to the sites. However, a site questionnaire was jointly developed to collect information on the sites, DR strategies and automation opportunities Appendix C

SF Power is an aggregator of 26 facilities with 41 service account IDs (SAID) on PG\&E's Capacity Bidding Program (CBP) in 2007. CBP is a voluntary DR program that offers aggregators and customers capacity payments and demand reduction incentives for reducing energy consumption when requested by PG\&E. The program season for CBP is May 1 through October 31 and the events are called between 11 a.m. to 7 p.m. CBP provides participants dayahead and day-of options and three products which are 1-4 hour, 2-6 hour and 4-8 hour.

SF Power has three portfolios which participate in five CBP DR events in 2007 at different times and durations based on their contracts. In this section, we discuss the evaluation of five large facilities by characterizing their loads by their weather sensitivity and load variability. Also, we calculate three different baselines to quantify their manual participation in to the CBP portfolios.

Rank order correlation (ROC) calculation results, which correlate hourly weather and demand for each facilities, and variability (VAR) calculation results, which quantify load variability of facilities, are presented in Table 8. For ROCs higher than 0.7, the facilities are marked highly weather sensitive. For VARs higher than 0.15, the facilities are marked highly variable (Coughlin 2008). For both calculations, the hourly results are averaged over noon to 8 pm period. 
Table 8. Weather Sensitivity and Load Variability of the Five Facilities

\begin{tabular}{|l|c|c|c|c|}
\hline Site & ROC & $\begin{array}{c}\text { Weather } \\
\text { Sensitivity }\end{array}$ & VAR & $\begin{array}{c}\text { Load } \\
\text { Variability }\end{array}$ \\
\hline \hline Site A & 0.007 & Low & 0.157 & High \\
\hline Site B & 0.219 & Low & 0.080 & Low \\
\hline Site C & 0.495 & Low & 0.131 & Low \\
\hline Site D & 0.513 & Low & 0.151 & High \\
\hline Site E & 0.753 & High & 0.177 & High \\
\hline
\end{tabular}

Three baseline methods used to measure demand reduction are outlined in Appendix D. For weather sensitive facilities with low load variability, outside air temperature regression baseline with morning adjustment (OAT with MA) is recommended. For highly variable loads, none of the baselines predict demand for DR events with high accuracy. Table 9 displays the average, minimum and maximum shed amounts for each of the facilities for all of the CBP days they participated using the three baseline methods. A positive number indicates reduction and a negative number indicates and increase in demand as compared with the baseline. Unfortunately, no DR strategy information is available as it was not being collected from the participating sites.

\section{Table 9. Evaluation of the DR Sheds for the Five Facilities Using Three Baseline Methods}

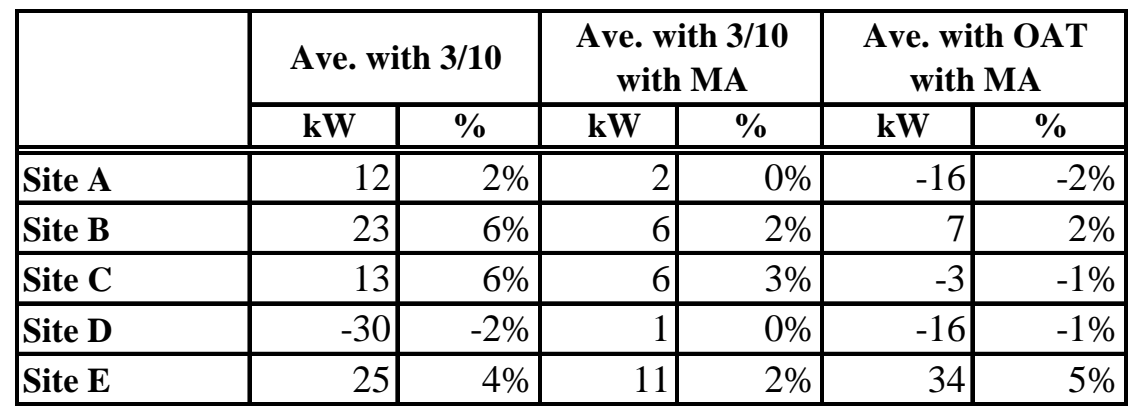

The results of the analysis are summarized below:

- Weather sensitivity and load variability calculations are necessary in predicting loads. While baselines with morning adjustment work better for weather sensitive buildings, load variability in buildings effect how much load reduction is available from facilities. Baseline models do not work well for facilities with highly variable loads.

- Information on DR strategies is important. Information about DR strategies and technologies at these facilities is limited. In order to understand demand reduction opportunities, we need to collect information on the strategies and EMCS operations. Traditionally, Auto-DR participants have been reducing whole building power by 10$15 \%$, which is higher than the average demand reduction from the five facilities. 


\subsection{Field Tests}

\subsubsection{Recruitment}

Site selection criteria were developed by LBNL to assist SCE in their recruitment (Appendix F). Despite SCE's efforts, only two Taco Bell sites, located in San Juan Capistrano and Hesperia, were recruited into the pilot program. Both sites were brought into the pilot by Advanced Telemetry building on their existing relationship with this customer. LBNL visited San Juan Capistrano site and conducted an interview with Advance Telemetry's director of field operations. The results of the interview yielded the following:

- Both buildings are comparable. LBNL requested that the pilots sites fit two main criteria: 1) matching in size and 2) different climates. San Juan Capistrano and Hesperia sites are 2,200 $\mathrm{ft}^{2}$ and 2,150 $\mathrm{ft}^{2}$, respectively. While San Juan Capistrano site is fourteen years old, Hesperia site is only 2 years old.

- The HVAC equipment is undersized. In the San Juan Capistrano site, the set points for dining room and kitchen area are $74^{\circ} \mathrm{F}$ and $76^{\circ} \mathrm{F}$, respectively. On really hot days, the HVAC system can not keep these temperatures. This information was not available from the Hesperia site prior to the tests.

- Lighting will not be included in DR strategies. Initial calculations showed that only about $2.5 \mathrm{~kW}$ of the peak $40 \mathrm{~kW}$ in the San Juan Capistrano store is due to lighting. A lighting shed of $1 \mathrm{~kW}$, which is more than one third of the site, would not be visible in the whole building profile. This information convinced the team not to go through with lighting sheds.

- Trend logs are available to confirm automated events take place. Advanced Telemetry system logs readings from two sensors, located in the kitchen and dining room areas, and space temperature setpoints. In addition, the system has real-time power monitoring capability used to iterate DR strategies to achieve the required shed levels.

Noting the above mentioned issues, in the absence of other candidates for the pilot, Advanced Telemetry installed an updated system that communicates with the DR automation server using the OpenADR standard communication infrastructure. The overall architecture is displayed in Figure 2.

Table 10 displays the results from weather sensitivity and load variability calculations for the two filed test sites. While both sites are not weather sensitive, San Juan Capistrano has variable loads during the DR event periods.

Table 10. Weather Sensitivity and Load Variability of the Field Tested Sites

\begin{tabular}{|l|c|c|c|c|}
\hline \multicolumn{1}{|c|}{ Site } & \multicolumn{2}{|c|}{ Weather Sensitivity } & \multicolumn{2}{c|}{ Load Variability } \\
\hline \hline San Juan Capistrand & Low & 0.34 & High & 0.18 \\
\hline Hesperia & Low & 0.56 & Low & 0.12 \\
\hline
\end{tabular}




\subsubsection{Automated DR Events}

Installation of the OpenADR enabling technologies and initial communications tests were completed in mid October. A total of six events were called and each event lasted for two hours. The first two events were communications and control test events where bugs in the system were identified and resolved. Table 11 summarizes the test events and DR strategies at each site for each event. October $16^{\text {th }}$ and $17^{\text {th }}$ were the communications and controls test events and the rest were actual test events. The first test event, which was planned for two hours, had to be stopped at one hour and fifteen minutes into the event because there were complaints from the sites that the space was too hot. Although the setpoint was adjusted to $78^{\circ} \mathrm{F}$, the indoor temperature had reached $79^{\circ} \mathrm{F}$ at the time of the complaints. Therefore, the upper limit for temperature setpoint was determined to be $77^{\circ} \mathrm{F}$ for the remaining events. The tests were repeated the following day with pre-cooling each site one hour before the event. San Juan Capistrano site's setpoint was adjusted $4^{\circ} \mathrm{F}$ while Hesperia site's setpoint was adjusted $2^{\circ} \mathrm{F}$ during the two hour test period. Results and all the load profiles from all the events are reported in Appendix E.

Table 11. Summary of Test Events and DR Strategies

\begin{tabular}{|c|c|c|c|c|c|}
\hline Site & Test Date & Precooling & Start time & End Time & DR strategy \\
\hline San Juan Capistrano & 10/16/2008 & $1-2 \mathrm{pm}$ & $2 \mathrm{pm}$ & $3: 15 \mathrm{pm}$ & $\begin{array}{l}\text { Pre-cool at 72Deg starting at } 1 \mathrm{pm} \text { and set up temp . 76F from 2- } \\
2: 50,77 \mathrm{~F} \text { from 2:50-3, 78F from 3-3:15, event canceled at 3:15 }\end{array}$ \\
\hline Hesperia & $10 / 16 / 2008$ & No & $2 \mathrm{pm}$ & $3: 15 \mathrm{pm}$ & $\begin{array}{l}\text { 76F from 2-2:50, 77F from 2:50-3, 78F from 3-3:15, event canceld } \\
\text { at 3:15 }\end{array}$ \\
\hline San Juan & 10/17/2008 & $1-2 \mathrm{pm}$ & $2 \mathrm{pm}$ & $4 \mathrm{pm}$ & $\begin{array}{l}\text { Pre-cool starting at } 1 \mathrm{pm} \text { and set up temp at 70Deg. 1-74, 2-75, 3-76, } \\
4-77\end{array}$ \\
\hline Hesperia & 10/17/2008 & $1-2 \mathrm{pm}$ & $2 \mathrm{pm}$ & $4 \mathrm{pm}$ & $\begin{array}{l}\text { precool starting at } 1 \text { pm and set up temp at 70Deg 1-76, 2-76, 3-77, } 4 \\
77\end{array}$ \\
\hline San Juan Capistrano & $10 / 22 / 2008$ & 2-3pm & $3 \mathrm{pm}$ & $5 \mathrm{pm}$ & $\begin{array}{l}\text { Pre-cool at 70F starting at 2pm. 3-5pm 10\% Shed from 3/10 MA } \\
\text { baseline }\end{array}$ \\
\hline Hesperia & $10 / 22 / 2008$ & $2-3 p m$ & $3 \mathrm{pm}$ & $5 \mathrm{pm}$ & $\begin{array}{l}\text { Pre-cool at 70F starting at 2pm. 3-5pm 10\% Shed from 3/10 MA } \\
\text { baseline }\end{array}$ \\
\hline San Juan C & $10 / 24 / 2008$ & 11am-noon & noon & $2 \mathrm{pm}$ & $\begin{array}{l}\text { Pre-cool at 70F starting at } 11 \mathrm{am} \text {. Noon to 2pm, } 10 \% \text { Shed from 3/10 } \\
\text { baseline }\end{array}$ \\
\hline Hesperia & $10 / 24 / 2008$ & 11am-noon & noon & $2 \mathrm{pm}$ & $\begin{array}{l}\text { Pre-cool at } 70 \mathrm{~F} \text { starting at } 11 \mathrm{am} \text {. Noon to } 2 \mathrm{pm}, 10 \% \text { Shed from } 3 / 10 \\
\text { baseline }\end{array}$ \\
\hline San Juan C & $11 / 7 / 2008$ & 8am-noon & noon & $2 \mathrm{pm}$ & $\begin{array}{l}\text { Pre-cool at 70F starting at 8am. Noon to 2pm, } 10 \% \text { Shed from 3/10 } \\
\text { baseline }\end{array}$ \\
\hline Hesperia & $11 / 7 / 2008$ & 8am-noon & noon & $2 \mathrm{pm}$ & $\begin{array}{l}\text { Pre-cool at 70F starting at } 8 \mathrm{am} \text {. Noon to 2pm, } 10 \% \text { Shed from } 3 / 10 \\
\text { baseline }\end{array}$ \\
\hline Hesperia & $11 / 14 / 2008$ & 8am-noon & noon & 2pm & $\begin{array}{l}\text { Pre-cool at 70F starting at } 8 \mathrm{am} \text {. Noon to 2pm, } 19 \% \text { Shed from 3/10 } \\
\text { baseline }\end{array}$ \\
\hline
\end{tabular}

After the initial controls and communication tests, four DR events were dispatched as summarized above. The first test took place on October 22, from $3 \mathrm{pm}$ to $5 \mathrm{pm}$, with an hour long pre-cooling at $70^{\circ} \mathrm{F}$ followed by a request to shed $10 \%$ from the $3 / 10$ with morning adjustment baseline. With only one hour of pre-cooling, of the four zones in two facilities, only one zone reached the setpoint target before the event started (Table 12). Therefore, one-hour pre-cooling is proven to be too short for these sites. For the next event, the event period is moved to noon to $2 \mathrm{pm}$ with one hour pre-cooling starting at $11 \mathrm{am}$ and with a request to shed $10 \%$. Because the pre-cooling period was now within the morning adjustment period, 3/10 baseline was used for percent load reduction calculations. October $24^{\text {th }}$ was the warmest day the 
tests were conducted. While San Juan Capistrano site still could not reach the pre-cooling target temperature, Hesperia kitchen and dining zones reached $72^{\circ} \mathrm{F}$ and $71^{\circ} \mathrm{F}$, respectively. For the next two events, pre-cooling period was extended to bring down the temperatures in all of the zones. DRLAT, a building simulation tool was used to refine the strategy. While, extending precooling period did not have an effect on the kitchen zones, temperature in San Juan Capistrano's dining area was reduced to $72^{\circ} \mathrm{F}$. The system over achieved its goal in Hesperia on November $7^{\text {th }}$ because impact of a strategy is only visible after 15 minutes when the meter collects and sends these data back into the server. On November $14^{\text {th }}$, Hesperia site was the only site tested because of the thermostat problems in San Juan Capistrano. Thermostat manufacturer had to be contacted after the Advanced Telemetry system identified that there was a problem with the thermostat.

\section{Table 12. Summary of Sheds and Indoor Conditions During DR Events}

\begin{tabular}{|l|c|c|r|r|r|c|c|c|c|}
\hline \multicolumn{1}{|c|}{ Site } & Date & Baseline & $\begin{array}{c}\text { Shed } \\
\text { requested }\end{array}$ & $\begin{array}{c}\text { Shed } \\
\text { achieved }\end{array}$ & $\begin{array}{c}\text { Pre-cool Kitchen } \\
\text { Temp (DegF) }\end{array}$ & $\begin{array}{c}\text { Precool Dining } \\
\text { Temp (DegF) }\end{array}$ & $\begin{array}{c}\text { Max Kitchen } \\
\text { Temp (DegF) }\end{array}$ & $\begin{array}{c}\text { Max Dining } \\
\text { Temp (DegF) }\end{array}$ & $\begin{array}{c}\text { Max OAT } \\
\text { (DegF) }\end{array}$ \\
\hline \hline SJC & 22-Oct & $3 / 10 \_M A$ & $10 \%$ & $8 \%$ & 75 & 74 & 80 & 78 & 78 \\
\hline SJC & 24-Oct & $3 / 10$ & $10 \%$ & $7 \%$ & 74 & 74 & 79 & 78 & 100 \\
\hline SJC & 7-Nov & $3 / 10$ & $10 \%$ & $7 \%$ & 76 & 72 & 79 & 78 & 79 \\
\hline Hesperia & 22-Oct & $3 / 10 \_M A$ & $10 \%$ & $13 \%$ & 73 & 70 & 78 & 78 & 78 \\
\hline Hesperia & 24-Oct & $3 / 10$ & $10 \%$ & $11 \%$ & 72 & 71 & 78 & 77 & 82 \\
\hline Hesperia & 7-Nov & $3 / 10$ & $10 \%$ & $17 \%$ & 75 & 70 & 80 & 77 & 66 \\
\hline Hesperia & 14-Nov & $3 / 10$ & $19 \%$ & $18 \%$ & 74 & 71 & 77 & 78 & 70 \\
\hline
\end{tabular}

Outside air temperatures for each facility were collected by a logger installed in a shaded area right outside of the facility. The data collected from the logger at San Juan Capistrano does not match the archived weather data that was available on the Internet for the first two test days, 92 DegF and 85 DegF, respectively. The weather data for the third test date was not available online. 


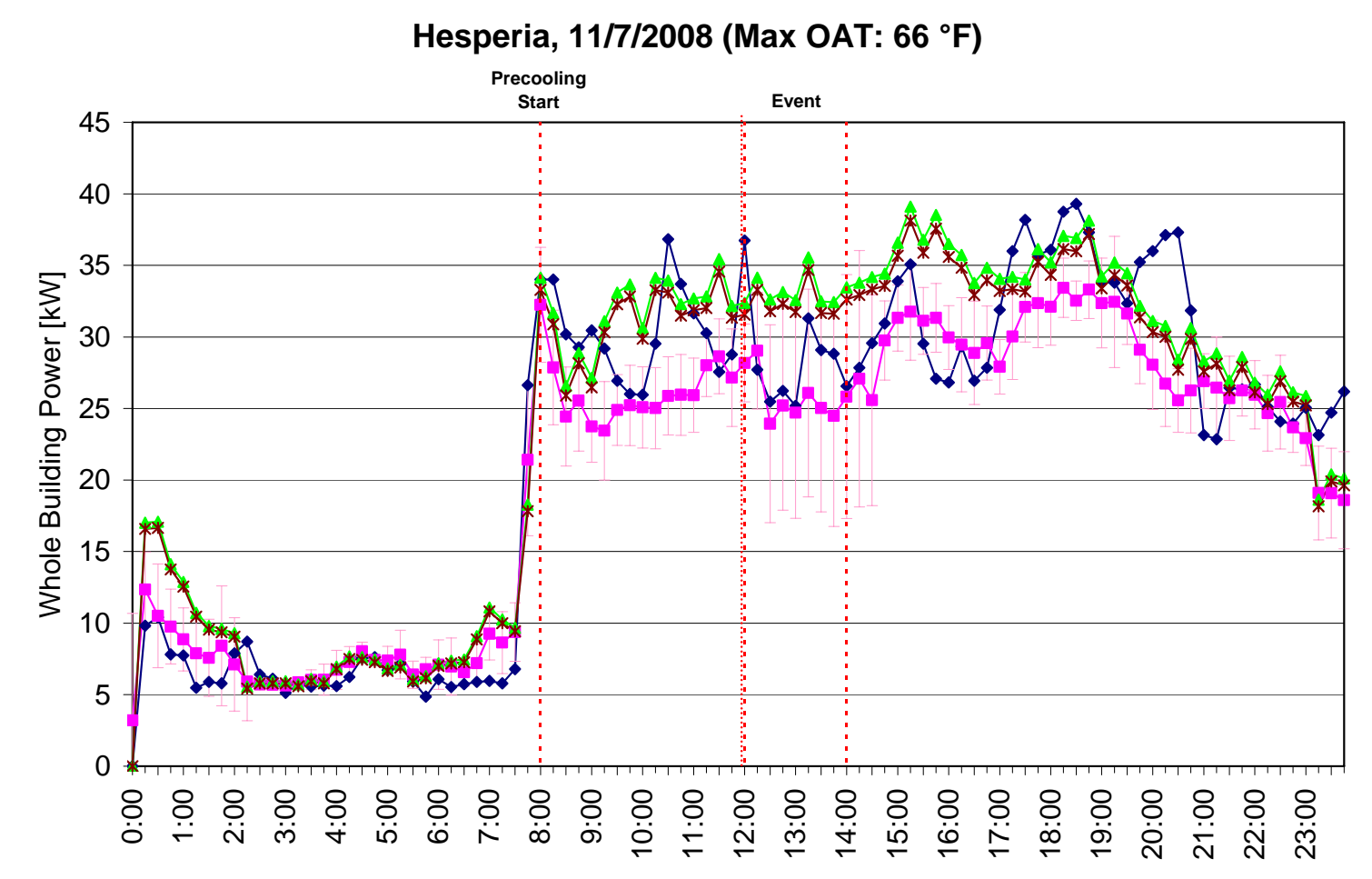

\begin{tabular}{|c|c|c|c|c|c|c|c|c|}
\hline \multirow{3}{*}{ Date } & \multirow{3}{*}{ Baseline } & \multicolumn{7}{|c|}{$\rightarrow$ Actual $\rightarrow$ OAT Baseline $\rightarrow-3 / 10$ beseline $\rightarrow-3 / 10$ MA Baseline } \\
\hline & & \multirow{2}{*}{ Event Time } & \multicolumn{2}{|c|}{$\mathbf{k W}$} & \multicolumn{2}{|c|}{$\mathbf{W} / \mathbf{f} \mathbf{t}^{2}$} & \multicolumn{2}{|c|}{ WBP\% } \\
\hline & & & Max & Ave & Max & Ave & Max & Ave \\
\hline \multirow{3}{*}{ Nov-07 } & $3 / 10$ & \multirow{3}{*}{ 12:00-2:00 } & 7 & 6 & 3.43 & 2.68 & $23 \%$ & $17 \%$ \\
\hline & 3/10 MA & & 7 & 5 & 3.06 & 2.29 & $21 \%$ & $15 \%$ \\
\hline & OAT & & 1 & -2 & 0.62 & -0.94 & $5 \%$ & $-8 \%$ \\
\hline
\end{tabular}

Figure 12. Load Profile for Hesperia Site on November 7, 2008

Figure 12 displays the demand profile of the Hesperia site on November $7^{\text {th }}$. All three baselines are calculated and displayed with the actual whole building demand. There is a large variation between the 3/10 baselines and OAT temperature baseline. If the OAT baseline were chosen to base the demand reduction on that day, the building might not have reached its target. Also, demand profile of the site matches with its schedule where the dining room closes at $10 \mathrm{pm}$ and the kitchen continues to serve customers until $1 \mathrm{am}$. While dining area loads are driven with occupancy and tend to fluctuate, kitchen loads are driven by internal cooking, heating and refrigeration loads.

Additional analysis, using the data collected after the end of the event period, showed that both facilities are not weather sensitive and their loads are not variable. This additional information confirms that $3 / 10$ baseline is an appropriate baseline for these facilities.

The results of the field tests are summarized below:

- Requesting and receiving demand reduction as a percentage of whole building demand from a pre-specified baseline is feasible. The field tests show that requesting a percentage reduction from the whole building peak demand can be achieved. However, it depends 
on understanding 1) which baseline to use; 2) where the reductions come from; and 3) limit of shed including how deep and how long.

- Demand reduction in undersized systems is difficult. Increasing temperature setpoints to reduce demand from compressors and fans does not yield savings if the systems are still running at their maximum capacity to maintain the new setpoints. In the field tests, extending the pre-cooling period seems to help in reducing space temperatures to the target setpoint levels.

- Total cost of the system (two wireless thermostats, two wireless sensors and a control panel) including its development and installation is $\$ 3,345$. With an average of $3-4 \mathrm{~W}$ of reduction for each site, the demonstration cost for $\mathrm{kW}$ is between $\$ 1,115$ and $\$ 835$. Note that these are demonstration unit costs and costs are expected to be lower for commercial products produced in higher quantities.

- Pre-cooling for a longer period of time for these two facilities is more effective. The goal of precooling is to cool the mass in buildings so as to use this thermal capacity when the temperature setpoints are increased. While one-hour pre-cooling only cools the air (and even that not effectively), the extended pre-cooling period cools the exposed masses and yields more sustainable demand reduction. 


\subsection{Discussion and Conclusions}

This report has discussed the research efforts by the Demand Response Research Center (DRRC) to characterize small commercial buildings in California, to develop a framework for automated DR technologies for this customer group and described building related issues. It has also described the collaboration between DRRC, Southern California Edison (SCE), Akuacom and Advance Telemetry for the field studies where DR sheds were requested as a percentage of total buildings' peak demand.

Small commercial buildings make up 20 to 25 percent of peak electric demand in California. Small offices, restaurants and retail buildings are the major contributors making up over one third of the small commercial peak demand. A ten percent reduction in only these three types of buildings can yield up to 0.5 to 0.7 percent of peak demand in California. However, there are several barriers to small commercial buildings' participation into automated DR programs:

1. Small buildings are generally not equipped with centralized energy management and control systems (EMCS). Furthermore, they lack on-site personnel and metering infrastructure to measure their demand and set up strategies for DR.

2. They have a wider variety of ownership models, energy management and related professional services. Very small commercial buildings are being operated like residential buildings where the owner, with limited information such as a utility bill, has to make decisions, and medium sized small commercial buildings are being operated more like their large counterparts.

3. They have more varied and limited use of the Internet.

The goal of the characterization (Section 5.1) of small commercial buildings is to identify opportunities and low hanging fruit for this customer group. Small offices, restaurants and retail buildings are the major contributors making up over one third of the small commercial peak demand. Majority of the small commercial buildings are located in southern inland areas and central valley. Single zone packaged units with manual and programmable thermostat controls make up the majority of heating ventilation and air conditioning (HVAC) systems in this group of customers. Fluorescent tubes with magnetic ballast and manual controls dominate this customer group's lighting systems.

The framework development is presented in section 5.2 as a reference to small commercial building owners to evaluate their investment in various OpenADR enabling technologies. The small commercial building owner can use this framework to identify which method would work for his/her building and look for products that accommodate the selected method. Information on various DR signal communication means is provided to assist small commercial building owners to select appropriate communication means for their DR automation.

We worked with an aggregator and compiled data from five larger sites that participated in DR events in 2007 either manually or semi-automatically. The aggregator notifies the customers that a DR event is issued but has no information on the DR strategies or real-time meter data and is 
provided information on the portfolio's performance weeks after the events are dispatched. The deployment of advance metering infrastructure (AMI) will largely solve the existing information related issues. Meter data, when available, should be used to calculate load variability and weather sensitivity of buildings to better assess the DR potential in small commercial buildings.

Finally, feasibility of using OpenADR to request demand reductions as a percentage of total predicted demand was demonstrated with field tests in two quick service restaurants. The method to predict demand should be carefully chosen as there is no one baseline method that predicts peak demand for all facilities accurately. Building characteristics and building systems issues, such as design and controls, have to be considered when estimating how much and when demand reduction is available at each facility.

Summary of conclusions is as follows:

- There are control technologies and communication means that enable OpenADR. Therefore lack of technology is not the barrier but lack of awareness of options and cost for the small commercial buildings are barriers.

- Opportunities for reducing peak load in small commercial facilities are;

o Small commercial buildings with interval meters - need a way to measure what is being reduced.

o Single owner with multiple small commercial buildings provide one entry point to many buildings. Restaurant and retail chains are good examples.

o Global Temperature Adjustment (GTA) which is a DR strategy widely used in large commercial buildings, is also a good DR strategy for small commercial buildings.

o Lighting is an end use that has potential and buildings with bi-level switching are good candidates.

- Small commercial buildings with more than one zone for lighting and HVAC require centralization of their systems unless the DR strategy is located in the load controllers. In the absence of centralized systems, the number of clients connected to the server will increase drastically possibly introducing scalability issues to the two-way communication (with meter feedback) requirements.

As a next step of this project, we propose the following:

- Developing tools for small building owners to better understand their buildings' loads and to better manage them.

- Continue field studies to characterize ownership, management and operational issues; to identify opportunities in small office, restaurants and retail facilities; to consider the feasibility of using AMI infrastructure to deliver OpenADR signals to small commercial 
buildings; to consider lighting as a potential end use for OpenADR; and to understand price point requirements.

- A guide to small buildings owners to enable automation of DR. 


\subsection{References}

CPUC FAQ

http://www.cpuc.ca.gov/cfaqs/howhighiscaliforniaselectricitydemandandwheredoesthe powercomefrom.htm

Motegi, N., M.A. Piette, D.Watson, S., Kiliccote, P. Xu,. Introduction to Commercial Building Control Strategies and Techniques for Demand Response. LBNL Report 59975. May 2007. Available at drrc.lbl.gov.

Piette, M.A., O. Sezgen, D.S. Watson, N. Motegi, and C. Shockman. 2005a. Development and Evaluation of Fully Automated Demand Response in Large Facilities. Lawrence Berkeley National Laboratory CEC-500-2005-013. LBNL-55085. Berkeley CA, January.

Piette, M.A., D.S. Watson, N. Motegi, N. Bourassa, and C. Shockman. 2005b. Findings from the 2004 Fully Automated Demand Response Tests in Large Facilities. Lawrence Berkeley National Laboratory. CEC-500-03-026. LBNL-58178. Berkeley CA, September. Available at drrc.lbl.gov.

Piette, M. A., D. Watson, N. Motegi, S. Kiliccote, P. Xu (Lawrence Berkeley National Laboratory). Automated Critical Peak Pricing Field Tests: Program Description and Results. Report to the Pacific Gas and Electric Company Emerging Technologies Program and California Institute for Energy and the Environment. LBNL-59351. April 2006.

Itron. California Commercial End-Use Survey. Consultant Report to California Energy Commission. CEC 400-2006-005. March 2006

Koch, E., Piette, M.A., Scenarios for Consuming Standardized Automated Demand Response Signals. Presented at the Grid Interop Forum, Atlanta, GA, November 11-13, 2008.

Lockheed Martin Aspen. Demand Response Enabling Technologies for Small-Medium Businesses - A technical report prepared in conjunction with the 2005 California Statewide Pricing Pilot. April 12, 2006

Piette, M.A., G. Ghatikar, S. Kiliccote, E. Koch, D. Hennage, and P. Palensky. Open Automated Demand Response Communication Standards: Public Review Draft 2008-R1. LBNL number forthcoming. May 2008.

Hotchi, T., AT. Hodgson and W.J. Fisk. Indoor Air Quality Impacts of a Peak Load Shedding Strategy for a Large Retail Building. Lawrence Berkeley National Laboratory. DRRC Report. LBNL-59293. January 2006

Rubinstein, F.M., and S. Kiliccote. Demand Responsive Lighting: A Scoping Study. Lawrence Berkeley National Laboratory. DRRC Report. LBNL-62226. January 2007 
Coughlin, K., M. A. Piette, C. Goldman and S. Kiliccote. Estimating Demand Response Load Impacts: Evaluation of Baseline Load Models for Non-Residential Building in California. Demand Response Research Center, Lawrence Berkeley National Laboratory. LBNL63728. January 2008.

Piette, M.A., D.Watson, N. Motegi, and S., Kiliccote. Automated Critical Peak Pricing Field Tests: 2006 Pilot Program Description and Results. LBNL Report 62218. May 2007.

Piette, M.A., S., Kiliccote and G., Ghatikar. Design and Implementation of an Open, Interoperable Automated Demand Response Infrastructure. Grid Interop Forum. November 2007.

ANSI/ASHRAE Standard 135-2004 - BACnet ${ }^{\circledR}$ - A Data Communication Protocol for Building Automation and Control Networks. Atlanta, Georgia. 2004.

Title 24 - California's Energy Efficiency Standards for Residential and Non-residential Buildings. (CEC-40002005-006-CMF) April 1, 2005. 


\subsection{Glossary}

$\begin{array}{ll}\text { CLIR } & \text { Client and Logic with Integrated Relay } \\ \text { DNS } & \text { Domain Name Server } \\ \text { DR } & \text { Demand Response } \\ \text { DRAS } & \text { Demand Response Automation Server } \\ \text { DRRC } & \text { Demand Response Research Center } \\ \text { EMCS } & \text { Energy Management and Control Systems } \\ \text { EPRI } & \text { Electric Power Research Institute } \\ \text { HVAC } & \text { Heating, Ventilation and Air Conditioning } \\ \text { LBNL } & \text { Lawrence Berkley National Laboratory } \\ \text { NIST } & \text { National Institute of Standards and Technologies } \\ \text { OAT } & \text { Outside Air Temperature } \\ \text { OpenADR } & \text { Open, Non-Proprietary Automated Demand Response } \\ \text { PG\&E } & \text { Pacific Gas and Electric Company } \\ \text { POTS } & \text { Plain Old Telephone Systems } \\ \text { ROC } & \text { Rank Order Correlation } \\ \text { SCE } & \text { Southern California Edison } \\ \text { SDG\&E } & \text { San Diego Gas and Electric Company } \\ \text { SOA } & \text { Service Oriented Architecture } \\ \text { SSL } & \text { Secure Socket Layer } \\ \text { TA/TI } & \text { Technical Audit /Technology Incentives } \\ \text { VPN } & \text { Virtual Private Network } \\ \text { XML } & \text { eXtensible Mark-up Language }\end{array}$




\section{Appendix A: Technology Review 1.0 Load Controls for Small Commercial Applications}

The following gives a breakdown of a variety of existing products that may be appropriate for small commercial DR. Each product is categorized by the following:

- Centralized Gateways/Controllers - these are devices that can be used to act as a centralized EMCS system in the facility or to bridge communications with other devices in the facility.

- HVAC - these are controllers that are used to control HVAC systems and include thermostats.

- $\quad$ Lighting - these are controllers that may be used to control lighting.

- Miscellaneous - these are controller that may be used to control a variety of miscellaneous loads.

For each product the following set of information is given

\begin{tabular}{|c|c|}
\hline Model & The name or model number of the product \\
\hline Vendor & The vendor of the product \\
\hline Load Type & The type of load being controlled, i.e. HVAC, lighting, etc. \\
\hline Type of control & The type of control being applied to the load \\
\hline Feedback/Status & $\begin{array}{l}\text { Whether the product is capable of providing feedback or status of } \\
\text { the load it is controlling }\end{array}$ \\
\hline References & A reference to more information \\
\hline Availability & The availability of the product \\
\hline Cost & The approximate cost of the product \\
\hline Comms Interfaces & The communications interfaces on the product \\
\hline Standards & Any standards that the product supports \\
\hline Integrate with local EMCS & $\begin{array}{l}\text { Whether the product can be integrated or used with a local EMCS } \\
\text { system }\end{array}$ \\
\hline $\begin{array}{l}\text { Communicate to remote } \\
\text { servers }\end{array}$ & $\begin{array}{l}\text { Whether the product can communicate with remote servers to } \\
\text { receive DR related information or commands. In some cases this } \\
\text { amounts to direct load control and in others the DR signal may be } \\
\text { business level logic (i.e. prices or shed levels) and not load control } \\
\text { commands. }\end{array}$ \\
\hline
\end{tabular}




\begin{tabular}{|l|l|}
\hline Implement Shed Logic & Whether the product can implement some form of shed logic itself. \\
\hline User Programmability & $\begin{array}{l}\text { Whether there is a means to support programmability by a user to } \\
\text { respond to DR signals }\end{array}$ \\
\hline Notes & General comments and notes \\
\hline
\end{tabular}




\subsection{Gateways/Controllers}

Within the facility a there may exist a centralized controller or gateway that may be used for the following:

- $\quad$ Receive DR Signals from Utility/ISO

- Implement the shed logic necessary to translate information in the DR Signals to load control commands

- Interface to the load controllers within the facility and send them commands

- Provide a centralized location for the facility managers to program their shed logic

Advanced Telemetry

\begin{tabular}{|l|l|}
\hline Model & EcoView \\
\hline Vendor & Advanced Telemetry \\
\hline Load Type & HVAC and Lighting \\
\hline Type of control & EMCS \\
\hline Feedback/Status & Yes, both usage and device status \\
\hline References & http://www.advancedtelemetry.com/ \\
\hline Availability & In production \\
\hline Cost & $\$ 1000$ - \$1500 for typical system \\
\hline Comms Interfaces & Ethernet, Z-wave, Zigbee \\
\hline Standards & OpenADR \\
\hline $\begin{array}{l}\text { Integrate with local } \\
\text { EMCS }\end{array}$ & Yes \\
\hline $\begin{array}{l}\text { Communicate with } \\
\text { remote servers }\end{array}$ & Yes \\
\hline Implement Shed Logic & Yes \\
\hline User Programmability & Yes, via web site \\
\hline Notes & $\begin{array}{l}\text { The Advanced Telemetry panel allows the system to both } \\
\text { perform energy management and DR functions. System } \\
\text { supports centralized and remote control of HVAC (via } \\
\text { communicating PCT), whole facility metering and lighting } \\
\text { control. Currently involved in pilot projects in CA and } \\
\text { support OpenADR standard. }\end{array}$ \\
\hline
\end{tabular}




\section{Alerton}

This product is probably not appropriate for small commercial

\begin{tabular}{|l|l|}
\hline Model & BCMweb \\
\hline Vendor & Syserco \\
\hline Load Type & HVAC \\
\hline Type of control & EMCS \\
\hline Feedback/Status & No \\
\hline References & http://www.alerton.com/ \\
\hline Availability & Available \\
\hline Cost & Depends on the system \\
\hline Comms Interfaces & Ethernet, BACnet \\
\hline Standards & BACnet (Alerton BACtalk) \\
\hline $\begin{array}{l}\text { Integrate with local } \\
\text { EMCS }\end{array}$ & Yes \\
\hline $\begin{array}{l}\text { Communicate with } \\
\text { remote servers }\end{array}$ & Yes \\
\hline Implement Shed Logic & Yes \\
\hline User Programmability & Yes \\
\hline Notes & $\begin{array}{l}\text { This system is used in schools with distributed loads. The } \\
\text { system does offer wireless communication both for } \\
\text { controllers and Internet communications. }\end{array}$ \\
\hline
\end{tabular}

\section{Automated Logic}

\begin{tabular}{|l|l|}
\hline Model & ME and SE Line \\
\hline Vendor & ALC \\
\hline Load Type & EMCS \\
\hline Type of control & EMCS \\
\hline Feedback/Status & Yes \\
\hline References & http://www.automatedlogic.com/ \\
\hline Availability & In production \\
\hline Cost & \\
\hline Comms Interfaces & Depends on model, Ethernet, EIA-485, ARCNET, MS/TP \\
\hline Standards & BACnet \\
\hline $\begin{array}{l}\text { Integrate with local } \\
\text { EMCS }\end{array}$ & Yes \\
\hline Communicate with & Yes, sometimes via a router or gateway provided by ALC \\
\hline
\end{tabular}




\begin{tabular}{|l|l|}
\hline remote servers & \\
\hline Implement Shed Logic & Yes \\
\hline User Programmability & Yes, including graphical tools for programming logic \\
\hline Notes & ALC has a number of controllers that may be appropriate for \\
& small commercial applications in their SE, ME and ZN lines. \\
& The controllers are programmable and can be used to \\
& interface to a wide range of different types of equipment. \\
& The ALC equipment can be used to put together a complete \\
& solution that includes both HVAC and lighting control. \\
\hline
\end{tabular}

\section{Cannon (COOPER) Power Systems)}

Cannon \& Honeywell together for smart thermostat.

Cannon has virtual EMS system - http://www.cannontech.com/products/drvirtualems.asp

Cannon has software suite for supporting DR -

http://www.cannontech.com/products/softwareapplications.asp

\begin{tabular}{|c|c|}
\hline Model & Load Response Center \\
\hline Vendor & Cannon \\
\hline Load Type & EMCS \\
\hline Type of control & EMCS \\
\hline Feedback/Status & Yes \\
\hline References & $\begin{array}{l}\text { http://www.cannontech.com/products/drvirtualems.asp } \\
\text { http://www.cannontech.com/products/softwareapplications } \\
\text { asp }\end{array}$ \\
\hline Availability & In use by many utilities \\
\hline Cost & \\
\hline Comms Interfaces & Ethernet \\
\hline Standards & \\
\hline $\begin{array}{l}\text { Integrate with local } \\
\text { EMCS }\end{array}$ & Yes \\
\hline $\begin{array}{l}\text { Communicate with } \\
\text { remote servers }\end{array}$ & Yes \\
\hline Implement Shed Logic & Yes, but logic is implemented remotely \\
\hline User Programmability & Yes, but logic is implemented remotely \\
\hline Notes & $\begin{array}{l}\text { A software suite specifically targeted towards DR that is } \\
\text { intended to be used with } 3^{\text {rd }} \text { party vendors such as } \\
\text { Honeywell. Mostly a remote web based application that is }\end{array}$ \\
\hline
\end{tabular}


deployed by the Utilities. Shed logic is implemented on the server side and can be used for both DLC and user programmability.

\section{Echelon}

\begin{tabular}{|l|l|}
\hline Model & iLON smartserver \\
\hline Vendor & Echelon \\
\hline Load Type & EMCS \\
\hline Type of control & Act as EMCS with a wide variety of LonWorks based devices \\
\hline Feedback/Status & yes \\
\hline References & http://www.echelon.com/products/cis/smartserver/default.htm \\
\hline Availability & In production \\
\hline Cost & LonWorks, ethernet \\
\hline Comms Interface & EIA 709.X \\
\hline Standards & Yes \\
\hline $\begin{array}{l}\text { Integrate with local } \\
\text { EMCS }\end{array}$ & Yes \\
\hline $\begin{array}{l}\text { Communicate with } \\
\text { remote servers }\end{array}$ & Yes \\
\hline $\begin{array}{l}\text { Implement Local Shed } \\
\text { Logic }\end{array}$ & Yes \\
\hline User Programmability & $\begin{array}{l}\text { Programmable gateway/controller that can be used for } \\
\text { LonWorks networks. Supports interfacing to a wide range of } \\
\text { LonWorks based devices and load controllers. Can be user } \\
\text { programmed for a variety of functions. Have demonstrated } \\
\text { compatibility with OpenADR. }\end{array}$ \\
\hline \begin{tabular}{l} 
Notes \\
\hline
\end{tabular}
\end{tabular}

\section{Green Box}

Unclear what equipment they interface with in the facilities, but seem to support Zigbee.

\begin{tabular}{|l|l|}
\hline Model & Greenbox \\
\hline Vendor & Greenbox \\
\hline Load Type & EMCS programming front end \\
\hline Type of control & $\begin{array}{l}\text { Programming front end, and web based display of facility } \\
\text { state }\end{array}$ \\
\hline Feedback/Status & Yes \\
\hline References & http://www.getgreenbox.com/ \\
\hline
\end{tabular}




\begin{tabular}{|l|l|}
\hline & http://www.getgreenbox.com/company/for-utilities/ \\
\hline Availability & In trials \\
\hline Cost & IP based SW suite \\
\hline Comms Interfaces & Yes \\
\hline Standards & Yes \\
\hline $\begin{array}{l}\text { Integrate with local } \\
\text { EMCS }\end{array}$ & Yes as a programming front end \\
\hline $\begin{array}{l}\text { Communicate with } \\
\text { remote servers }\end{array}$ & Yes \\
\hline Implement Shed Logic & $\begin{array}{l}\text { Web based software suite that is targeted towards } \\
\text { residential. It is primarily targeted towards providing a GUI } \\
\text { that allows customers to view their energy usage, but may be } \\
\text { used as a programming front end for programming } \\
\text { thermostats for DR applications. }\end{array}$ \\
\hline User Programmability
\end{tabular}


Loytec

\begin{tabular}{|l|l|}
\hline Model & LINX-110 \\
\hline Vendor & Loytec \\
\hline Load Type & EMCS \\
\hline Type of control & EMCS \\
\hline Feedback/Status & Yes \\
\hline References & $\begin{array}{l}\text { http://www.loytec.com/index.php?option=com content\&tas } \\
\text { k=view\&id=43\&Itemid=17 }\end{array}$ \\
\hline Availability & In production \\
\hline Cost & LonWorks, Ethernet, modbus, BACnet \\
\hline Comms Interfaces & EIA 709.X, 852, IEC 61131-3, EN14908, RS232 \\
\hline Standards & Yes \\
\hline $\begin{array}{l}\text { Integrate with local } \\
\text { EMCS }\end{array}$ & Yes \\
\hline $\begin{array}{l}\text { Communicate with } \\
\text { remote servers }\end{array}$ & Yes \\
\hline Implement Shed Logic & Yes \\
\hline User Programmability & $\begin{array}{l}\text { A gateway/EMCS device that provides a high degree of } \\
\text { programmability and interfaces to a wide range of devices } \\
\text { that may be used for DR applications. }\end{array}$ \\
\hline Notes &
\end{tabular}

Novar

\begin{tabular}{|c|c|}
\hline Model & OPUS \\
\hline Vendor & Novar \\
\hline Load Type & EMCS \\
\hline Type of control & EMCS \\
\hline Feedback/Status & Yes \\
\hline References & $\begin{array}{l}\text { http://www.novar.com/ } \\
\text { http://www.novar.com/default.asp?action=category\&ID=56 }\end{array}$ \\
\hline Availability & In production \\
\hline \multicolumn{2}{|l|}{ Cost } \\
\hline Comms Interfaces & Ethenet, RS-232, RS-485 \\
\hline \multicolumn{2}{|l|}{ Standards } \\
\hline $\begin{array}{l}\text { Integrate with local } \\
\text { EMCS }\end{array}$ & Yes \\
\hline Communicate with & Yes \\
\hline
\end{tabular}




\begin{tabular}{|l|l|}
\hline remote servers & \\
\hline Implement Shed Logic & Yes \\
\hline User Programmability & Yes \\
\hline Notes & $\begin{array}{l}\text { The OPUS line is designed for mult-site installations, but } \\
\text { can be used for single sites that need remote connectivity. } \\
\text { It includes a line of controllers and some HVAC control } \\
\text { equipment such as thermostats. The OPUS line is based on } \\
\text { Tridium's Niagra and JACE products. }\end{array}$ \\
\hline
\end{tabular}

\section{PowerMand}

\begin{tabular}{|c|c|}
\hline Model & DreamWatts \\
\hline Vendor & PowerMand \\
\hline Load Type & Web Based Monitoring and control via a gateway \\
\hline Type of control & EMCS \\
\hline Feedback/Status & Yes \\
\hline References & $\begin{array}{l}\text { http://www.powermand.com/corp/index.jsp } \\
\text { http://www.smartgridnews.com/artman/publish/industry/P } \\
\text { owerMand Pioneers New Approach to Demand Respons } \\
\text { e.html }\end{array}$ \\
\hline Availability & In trials \\
\hline Cost & \\
\hline Comms Interfaces & Ethernet, Zigbee \\
\hline Standards & \\
\hline Integrate with local EMCS & Yes \\
\hline $\begin{array}{l}\text { Communicate with } \\
\text { remote servers }\end{array}$ & Yes \\
\hline Implement Shed Logic & Remotely on server \\
\hline User Programmability & unknown \\
\hline Notes & $\begin{array}{l}\text { Build products targeted towards demand response for } \\
\text { residential and small commercial. Has created a web based } \\
\text { product that is used in conjunction with a gateway to } \\
\text { communicate with devices in the facility via Zigbee. The } \\
\text { gateway is a communications facilitator and not a controller. } \\
\text { Control and interfacing to the devices are via web based } \\
\text { interfaces. Mostly sell to Utilities and aggregators. }\end{array}$ \\
\hline
\end{tabular}

Teletrol

Model




\begin{tabular}{|l|l|}
\hline & oller.shtml \\
\hline Vendor & Teletrol \\
\hline Load Type & EMCS \\
\hline Type of control & EMCS \\
\hline Feedback/Status & Yes \\
\hline References & http://www.teletrol.com/ \\
\hline Availability & In production \\
\hline Cost & Ethernet, BACnet, MS/TP, RS-485 \\
\hline Comms Interfaces & BACnet \\
\hline Standards & Yes \\
\hline $\begin{array}{l}\text { Integrate with local } \\
\text { EMCS }\end{array}$ & Yes \\
\hline $\begin{array}{l}\text { Communicate with } \\
\text { remote servers }\end{array}$ & Yes \\
\hline Implement Shed Logic & Yes, via graphical interface \\
\hline User Programmability & $\begin{array}{l}\text { Specifically used for commercial building management } \\
\text { functions and interfaces to a wide range of devices for } \\
\text { control purposes. Has a large number of models to suite } \\
\text { exact needs. }\end{array}$ \\
\hline Notes &
\end{tabular}

\section{Tendril}

\begin{tabular}{|c|c|}
\hline Model & TREE line of products \\
\hline Vendor & Tendril \\
\hline Load Type & EMCS, suite of products for residential \\
\hline Type of control & EMCS \\
\hline Feedback/Status & Yes \\
\hline References & $\begin{array}{l}\text { http://www.tendrilinc.com/ } \\
\text { http://www.tendrilinc.com/consumers/products/ }\end{array}$ \\
\hline Availability & In production \\
\hline \multicolumn{2}{|l|}{ Cost } \\
\hline Comms Interfaces & Ethernet, Zigbee \\
\hline \multicolumn{2}{|l|}{ Standards } \\
\hline $\begin{array}{l}\text { Integrate with local } \\
\text { EMCS }\end{array}$ & Yes \\
\hline $\begin{array}{l}\text { Communicate with } \\
\text { remote servers }\end{array}$ & Yes \\
\hline Implement Shed Logic & Yes \\
\hline
\end{tabular}




\begin{tabular}{|l|l|}
\hline User Programmability & Yes, via web based portal \\
\hline Notes & $\begin{array}{l}\text { Tendril makes a suite of low cost products that are targeted } \\
\text { towards residential energy management including } \\
\text { gateways, controllers, thermostats, and displays. Currently } \\
\text { developing compatibility with OpenADR standard. }\end{array}$ \\
\hline
\end{tabular}

\section{Tridium}

\begin{tabular}{|c|c|}
\hline Model & $\begin{array}{l}\text { JACE (variety of models, JACE- } 200 \text { probably most } \\
\text { appropriate for small commercial) }\end{array}$ \\
\hline Vendor & Tridium \\
\hline Load Type & EMCS \\
\hline Type of control & EMCS \\
\hline Feedback/Status & Yes \\
\hline References & $\begin{array}{l}\text { http://www.tridium.com/ } \\
\text { http://www.tridium.com/cs/products / services/jace }\end{array}$ \\
\hline Availability & In production and OEM'd to a number of manufactures \\
\hline Cost & $\$ 300$ - \$1500 depending upon options \\
\hline Comms Interfaces & Etnernet, RS-232, RS-485, LonWorks, BACnet, MODBus \\
\hline Standards & LonWorks, BACnet, MODBus, OBix \\
\hline $\begin{array}{l}\text { Integrate with local } \\
\text { EMCS }\end{array}$ & Yes \\
\hline $\begin{array}{l}\text { Communicate with } \\
\text { remote servers }\end{array}$ & Yes \\
\hline Implement Shed Logic & Yes \\
\hline User Programmability & Yes \\
\hline Notes & $\begin{array}{l}\text { The JACE platform interfaces to a wide range of devices } \\
\text { through its numerous interface options and Niagra } \\
\text { framework. It is specifically designed for Internet enabled } \\
\text { applications and provides a high degree of } \\
\text { programmability. }\end{array}$ \\
\hline
\end{tabular}

\section{Universal Devices}

\begin{tabular}{|l|l|}
\hline Model & ISY-99i Series \\
\hline Vendor & Universal Devices \\
\hline Load Type & EMCS \\
\hline Type of control & EMCS \\
\hline Feedback/Status & Unknown \\
\hline References & http://www.universal-devices.com/ \\
\hline
\end{tabular}




\begin{tabular}{|l|l|}
\hline & \\
\hline Availability & In production \\
\hline Cost & $\$ 299$ - \$369 \\
\hline Comms Interfaces & $\begin{array}{l}\text { INSTEON, X10, UPB (under development), ZWave (under } \\
\text { development) }\end{array}$ \\
\hline Standards & Yes \\
\hline $\begin{array}{l}\text { Integrate with local } \\
\text { EMCS }\end{array}$ & Yes \\
\hline $\begin{array}{l}\text { Communicate with } \\
\text { remote servers }\end{array}$ & Yes \\
\hline Implement Shed Logic & Yes \\
\hline User Programmability & $\begin{array}{l}\text { A residential control device that is intended to allow users } \\
\text { to interface to and control a wide range of devices. Has a } \\
\text { programming interface that may be adapted for DR } \\
\text { applications. }\end{array}$ \\
\hline Notes &
\end{tabular}




\subsection{HVAC}

There are many aspects and components of a HVAC system that can be controlled. Because of wide variations between different manufacturers and between different facilities in terms of what type of equipment is installed it is difficult to specify a consistent and prototypical approach to controlling individual subsystems and components of an HVAC system that is appropriate for DR. One possible exception to this the direct cycling of HVAC compressors which is sometimes done for the purposes of DR.

For the purposes of this report the control mechanism for the HVAC is considered to be some sort of mechanism that is specifically designed to control the HVAC system as a whole. These can be classified into the following two categories.

Programmable Communicating Thermostats (PCT) - These are thermostats which have the ability to communicate and receive commands and DR signals. The control of the HVAC equipment is done via the thermostat controls which typically means modifying temperature set points and modes of operation.

HVAC control units. These are controllers that are specifically designed for the control of all operations of an HVAC unit as it pertains to the facility. It provides finer grain control over various subsystems of the HVAC than does a thermostat, but controls those subsystems within the context of the overall operation of the HVAC.

\section{Automated Logic}

\begin{tabular}{|c|c|}
\hline Model & Various models in $\mathrm{ZN}$ zone control line \\
\hline Vendor & ALC \\
\hline Load Type & HVAC \\
\hline Type of control & Zone controllers \\
\hline Feedback/Status & Yes \\
\hline References & $\begin{array}{l}\underline{\text { http://www.automatedlogic.com/ }} \\
\text { http://www.automatedlogic.com/alcInternet.nsf/webvie } \\
\text { w/products ZN220?OpenDocument }\end{array}$ \\
\hline Availability & In production \\
\hline \multicolumn{2}{|l|}{ Cost } \\
\hline Comms Interfaces & ARCNET, MS/TP \\
\hline Standards & BACnet \\
\hline $\begin{array}{l}\text { Integrate with local } \\
\text { EMCS }\end{array}$ & Yes \\
\hline $\begin{array}{l}\text { Communicate with } \\
\text { remote servers }\end{array}$ & Yes via gateways or EMCS systems \\
\hline Implement Shed Logic & Yes \\
\hline
\end{tabular}




\begin{tabular}{|l|l|}
\hline User Programmability & Yes \\
\hline Notes & $\begin{array}{l}\text { ALC manufactures a wide range of zone controllers that } \\
\text { are highly programmable and can be used for a wide } \\
\text { range of HVAC applications. They can be interfaced to } \\
\text { a wide range of devices and HVAC subsystems. }\end{array}$ \\
\hline
\end{tabular}

\section{Carrier}

\begin{tabular}{|l|l|}
\hline Model & ComfortChoice Demand Management Solution \\
\hline Vendor & Carrier \\
\hline Load Type & HVAC \\
\hline Type of control & PCT - Temperature setback or compressor duty cycle \\
\hline Feedback/Status & DR state, temperature settings, HVAC operational states \\
\hline References & $\begin{array}{l}\text { http://www.comfortchoice.carrier.com/generic/0,2804,CL } \\
\text { I1 DIV17 ETI777,00.html } \\
\text { http://www.comfortchoice.carrier.com/Files/Comfort Ch } \\
\text { oice/Global/US-en/FirstEnergy Selects Carrier- } \\
\text { final article.doc }\end{array}$ \\
\hline Availability & $\begin{array}{l}\text { Currently used in DR pilots since 2001. Many 10K's units } \\
\text { installed }\end{array}$ \\
\hline Cost & Two way pager \\
\hline Comms Interface & ReFlex-50 wireless protocol \\
\hline Standards & unclear \\
\hline $\begin{array}{l}\text { Integrate with local } \\
\text { EMCS }\end{array}$ & Yes, direct load control \\
\hline $\begin{array}{l}\text { Communicate with } \\
\text { remote servers }\end{array}$ & \begin{tabular}{l} 
limited \\
\hline Implement Shed Logic
\end{tabular} \\
\hline User Programmability & $\begin{array}{l}\text { YES via website } \\
\text { communications to allow direct changing of the set point } \\
\text { and reporting of HVAC status and settings. }\end{array}$ \\
\hline Notes & \\
\hline
\end{tabular}

\section{Golden Power}

\begin{tabular}{|l|l|}
\hline Model & Thermostat \\
\hline Vendor & Golden Power \\
\hline Load Type & HVAC \\
\hline Type of control & PCT \\
\hline Feedback/Status & Yes \\
\hline References & \\
\hline
\end{tabular}




\begin{tabular}{|l|l|}
\hline Availability & In production \\
\hline Cost & \$89 in 100K quantities \\
\hline Comms Interfaces & Zigbee, RDS, ZWave \\
\hline Standards & Yes \\
\hline $\begin{array}{l}\text { Integrate with local } \\
\text { EMCS }\end{array}$ & Yes via RDS \\
\hline $\begin{array}{l}\text { Communicate with } \\
\text { remote servers }\end{array}$ & Yes, limited to HVACs \\
\hline Implement Shed Logic & limited \\
\hline User Programmability & $\begin{array}{l}\text { A protocol independent PCT that is designed to both } \\
\text { receive broadcast information via RDS and to integrate } \\
\text { with EMCS systems via a variety of wireless } \\
\text { connections. }\end{array}$ \\
\hline Notes
\end{tabular}

\section{Honeywell}

Honeywell has many products in various price ranges. Authors recommend checking with the company.

\section{Lennox}

\begin{tabular}{|l|l|}
\hline Model & L Connection Network series of products \\
\hline Vendor & Lennox \\
\hline Load Type & HVAC \\
\hline Type of control & $\begin{array}{l}\text { Various including thermostat, rooftop unit, } \\
\text { centralized controller }\end{array}$ \\
\hline Feedback/Status & Yes \\
\hline References & $\begin{array}{l}\text { http://www.lennox.com/ } \\
\text { http://www.lennoxcommercial.com/products/list con } \\
\text { trols.asp }\end{array}$ \\
\hline Availability & In production \\
\hline Cost & Ethernet, L Connection network \\
\hline Comms Interfaces & Moving toward BACnet \\
\hline Standards & Yes \\
\hline $\begin{array}{l}\text { Integrate with local } \\
\text { EMCS }\end{array}$ & Yes \\
\hline $\begin{array}{l}\text { Communicate with } \\
\text { remote servers }\end{array}$ & Yes \\
\hline Implement Shed Logic & Yes \\
\hline User Programmability & \\
\hline
\end{tabular}




\begin{tabular}{|l|l|}
\hline Notes & The L Connection Network manages HVAC, zoning \\
& and building operations from a single point of \\
& control. It is compatible with all Lennox HVAC \\
equipment, as well as electro-mechanically controlled \\
third-party equipment. Can be used for managing \\
and controlling lighting systems as well.
\end{tabular}

\section{LIGHTSTAT}

\begin{tabular}{|c|c|}
\hline Model & RTPstat \\
\hline Vendor & LIGHTSTAT \\
\hline Load Type & HVAC with optional auxiliary load controls \\
\hline Type of control & PCT - Temperature setback or complete duty cycle \\
\hline Feedback/Status & none \\
\hline References & http://www.lightstat.com/products/utility.asp \\
\hline Availability & Currently in use \\
\hline \multicolumn{2}{|l|}{ Cost } \\
\hline Comms Interface & $930 \mathrm{MHz}$ pager \\
\hline \multicolumn{2}{|l|}{ Standards } \\
\hline $\begin{array}{l}\text { Integrate with local } \\
\text { EMCS }\end{array}$ & No \\
\hline $\begin{array}{l}\text { Communicate with } \\
\text { remote servers }\end{array}$ & Yes \\
\hline Implement Shed Logic & limited \\
\hline User Programmability & Yes via Internet \\
\hline Notes & $\begin{array}{l}\text { Lightstat's RTPstat Internet-programmable } \\
\text { thermostat incorporates a flexible set of built-in load } \\
\text { control commands that allow the utility to reduce } \\
\text { heating and air conditioning power consumption } \\
\text { during peak times. Cycle heating or cooling, offset } \\
\text { the temperature setpoint, or turn off the A/C entirely. } \\
\text { For control of other large residential loads such as } \\
\text { pool pumps and water heaters, Lightstat offers the } \\
\text { Virtual Gateway programmable load control module. } \\
\text { Up to two modules per customer can be cycled or } \\
\text { interrupted to provide additional load reduction. }\end{array}$ \\
\hline
\end{tabular}

Novar

\begin{tabular}{|l|l|}
\hline Model & LOGIC ONE \\
\hline Vendor & Novar \\
\hline
\end{tabular}




\begin{tabular}{|l|l|}
\hline Load Type & HVAC, miscellaneous electrical loads \\
\hline Type of control & Varied, PCT, unit controllers, load controllers \\
\hline Feedback/Status & Yes \\
\hline References & $\begin{array}{l}\text { http://www.novar.com// } \\
\text { http://www.novar.com/default.asp?action=category\&ID }=16\end{array}$ \\
\hline Availability & In production \\
\hline Cost & RS-485, Ethernet, POTS modem, MODBUS, USB, \\
\hline Comms Interfaces & Yes \\
\hline Standards & $\begin{array}{l}\text { Yes, via Envoi interface panel } \\
\text { EMCS }\end{array}$ \\
\hline $\begin{array}{l}\text { Communicate with local } \\
\text { remote servers }\end{array}$ & Yes \\
\hline Implement Shed Logic & Yes \\
\hline User Programmability & $\begin{array}{l}\text { The LOGIC ONE is a complete line of networked } \\
\text { controllers that include EMCS, HVAC, lighting and } \\
\text { miscellaneous loads. The HVAC control includes both } \\
\text { thermostats and unit controllers. }\end{array}$ \\
\hline Notes & $\begin{array}{l}\text { The HVAC equipment may be controlled and accessed via } \\
\text { a variety of devices including the Envoi, Lingo, and Savvy } \\
\text { controllers/gateways. The Lingo is probably most } \\
\text { appropriate for small commercial applications. }\end{array}$ \\
\hline
\end{tabular}

\section{Proliphix}

\begin{tabular}{|l|l|}
\hline Model & NT PRO and Thermal Management Series \\
\hline Vendor & Proliphix \\
\hline Load Type & HVAC \\
\hline Type of control & PCT \\
\hline Feedback/Status & Yes \\
\hline References & $\underline{\text { http://www.proliphix.com/ }}$ \\
& $\underline{\text { http://www.proliphix.com/NT-Pro.aspx }}$ \\
\hline Availability & In production \\
\hline Cost & \$399 $-\$ 499$ \\
\hline Comms Interfaces & Ethernet \\
\hline Standards & \\
\hline
\end{tabular}




\begin{tabular}{|l|l|}
\hline $\begin{array}{l}\text { Integrate with local } \\
\text { EMCS }\end{array}$ & possibly \\
\hline $\begin{array}{l}\text { Communicate with } \\
\text { remote servers }\end{array}$ & Yes \\
\hline Implement Shed Logic & Limited \\
\hline User Programmability & Limited, may be adapted to provide more \\
\hline Notes & $\begin{array}{l}\text { Develops and manufactures inexpensive Internet- } \\
\text { enabled thermostats for use in the residential and } \\
\text { light commercial industries. Most Proliphix } \\
\text { thermostats are used for energy management by } \\
\text { multi-tenant property or corporate facilities } \\
\text { managers, hospitality administrators, retail franchise } \\
\text { owners, as well as electric utility energy curtailment } \\
\text { initiatives. The thermostats employ an embedded } \\
\text { web server which serves up a graphical interface } \\
\text { (GUI). }\end{array}$ \\
\hline
\end{tabular}

Residential Control Systems (RCS)

\begin{tabular}{|l|l|}
\hline Model & Numerous thermostats \\
\hline Vendor & RCS \\
\hline Load Type & HVAC \\
\hline Type of control & PCT \\
\hline Feedback/Status & http://www.resconsys.com/ \\
\hline References & In production \\
\hline Availability & X10, RS-485, UPB, ZWave, LonWorks, RDS \\
\hline Cost & Yes \\
\hline Comms Interfaces & $\begin{array}{l}\text { Thermostats - Yes via RDS } \\
\text { Control Panel - Yes }\end{array}$ \\
\hline $\begin{array}{l}\text { Integrate with local } \\
\text { EMCS }\end{array}$ & Yes, limited in the PCT \\
\hline $\begin{array}{l}\text { Communicate with } \\
\text { remote servers }\end{array}$ & Yes, limited in the PCT \\
\hline Implement Shed Logic & $\begin{array}{l}\text { RCS makes a line of communicating thermostats that } \\
\text { can communicate via a variety of different protocols. }\end{array}$ \\
\hline User Programmability &
\end{tabular}




\begin{tabular}{|l|l|}
\hline & $\begin{array}{l}\text { Mostly targeted towards residential and light } \\
\text { commercial systems. Can also interface with a } \\
\text { number of different EMCS systems. } \\
\text { RCS also makes a control panel that has a touch } \\
\text { screen and can be used as an EMCS and adapted for } \\
\text { DR applications (see Advanced Telemetry). }\end{array}$ \\
$\begin{array}{l}\text { Their PCT is also being used for pilot DR programs in } \\
\text { CA. }\end{array}$ \\
\hline
\end{tabular}

White Rogers

\begin{tabular}{|c|c|}
\hline \multicolumn{2}{|l|}{ Model } \\
\hline \multicolumn{2}{|l|}{ Vendor } \\
\hline Load Type & HVAC \\
\hline Type of control & PCT \\
\hline Feedback/Status & No \\
\hline \multicolumn{2}{|l|}{ References } \\
\hline Availability & Available \\
\hline \multicolumn{2}{|l|}{ Cost } \\
\hline Comms Interfaces & RDS \\
\hline \multicolumn{2}{|l|}{ Standards } \\
\hline $\begin{array}{l}\text { Integrate with local } \\
\text { EMCS }\end{array}$ & No \\
\hline $\begin{array}{l}\text { Communicate with } \\
\text { remote servers }\end{array}$ & Yes \\
\hline Implement Shed Logic & Yes \\
\hline User Programmability & Yes \\
\hline Notes & $\begin{array}{l}\text { This is a stand alone programmable communicating } \\
\text { thermostat where the client is at a radio station and } \\
\text { devices listen to the DR signals over radio lines using } \\
\text { RDS }\end{array}$ \\
\hline
\end{tabular}




\subsection{Lighting}

\begin{tabular}{|c|c|c|}
\hline Lighting Type & Type of Control & $\begin{array}{c}\text { OpenADR ready system } \\
\text { availability* }\end{array}$ \\
\hline $\begin{array}{l}\text { Incandescent - over } 15 \% \text { of small } \\
\text { commercial buildings }\end{array}$ & $\begin{array}{l}\text { On-off } \\
\text { Dimming }\end{array}$ & $\begin{array}{l}\text { Available** } \\
\text { Available** }\end{array}$ \\
\hline \multirow{4}{*}{$\begin{array}{l}\text { Fluorescent - over } 80 \% \text { of small } \\
\text { commercial buildings }\end{array}$} & On-off & Available ${ }^{* *}$ \\
\hline & $\begin{array}{l}\text { On-off with bi- } \\
\text { level switching }\end{array}$ & $\begin{array}{l}\text { Available since Title } 24 \text { requires such } \\
\text { wiring. }\end{array}$ \\
\hline & $\begin{array}{l}\text { Step-level } \\
\text { dimming }\end{array}$ & $\begin{array}{l}\text { Although some of the other systems } \\
\text { can be used to enable step-level } \\
\text { dimming, the authors do not have } \\
\text { any field experience with such } \\
\text { systems. }\end{array}$ \\
\hline & Dimming & Available ${ }^{* *}$ \\
\hline
\end{tabular}

*The lighting controls for small commercial buildings are similar to residential lighting controls. ** Although the systems are available, lighting controls that enable OpenADR is limited. 


\subsection{Miscellaneous}

These categories of controllers are used to control a miscellaneous collection of loads that do not fall into the Lighting or HVAC category.

Cannon Technologies

\begin{tabular}{|c|c|}
\hline Model & LCR-5000 \\
\hline Vendor & Cannon Technologies \\
\hline Load Type & Miscellaneous \\
\hline Type of control & Multiple independent relays \\
\hline Feedback/Status & $?$ \\
\hline References & http://www.cannontech.com/products/drdirectcontrol.asp \\
\hline Availability & Numerous pilots and DR programs \\
\hline \multicolumn{2}{|r|}{ 管 } \\
\hline Comms Interface & $900 \mathrm{MHz}$ FLEX Paging (dual provider for extra reliability) \\
\hline \multicolumn{2}{|r|}{ (r } \\
\hline $\begin{array}{l}\text { Integrate with Local } \\
\text { EMCS }\end{array}$ & unclear \\
\hline $\begin{array}{l}\text { Communicate with } \\
\text { remote servers }\end{array}$ & Yes \\
\hline Implement Shed Logic & Limited \\
\hline User Programmability & Yes via web page \\
\hline Notes & $\begin{array}{l}\text { Part of a suite of products from Cannon for supporting DR } \\
\text { programs, mostly in the area of DLC. }\end{array}$ \\
\hline
\end{tabular}

Others in this category include aggregator technologies currently being used in California. For more information, contact aggregators. 


\section{Appendix B: SF Community Power Data Analysis}

The purpose of this study is to:

- understand the DR performance of SF Power's Capacity Bidding Program (CBP) participation in 2007 ,

- investigate issues related to baseline

- examine DR strategies related to each individual building, and

- improve the DR performance of the sites.

[This report is outlines the phase 1 of this work where the performance of SF Power's three portfolios are evaluated and five individual sites are analyzed in detail. Phase 2 will go into understanding the strategies at these sites and phase 3 will consider automation solutions]

\subsection{Introduction}

As a solution of temporary electric supply shortage, demand response (DR) has been identified as a key demand side management area to reduce rotating electrical outages and improve electric grid reliability. As a major provider of electricity and natural gas in California, PG\&E offers a number of DR programs. Among them, the Capacity Bidding Program (CBP) is a voluntary DR program that offers aggregators and customers capacity payments and demand reduction incentives for reducing energy consumption when requested by PG\&E. The program season for CBP is May 1 through October 31 and the events are called between 11 a.m. to 7 p.m. CBP provides participants day-ahead and day-of options and three products which are 1-4 hour, 2-6 hour and 4-8 hour.

SF Power is an aggregator of 26 facilities with 41 service account IDs (SAID) on CBP. SF Power has three portfolios which participate in five CBP DR events in 2007 at different times and durations based on their contracts. The dates and hours of participation for each portfolio are shown in Table 1.

This report outlines the available data for each portfolio, presents the analysis of five sites that have extensive data and the performance of each portfolio. Final section includes a discussion of next steps. 
Table 13. Summary of 2007 capacity bidding program participation for SF Power

\begin{tabular}{|l|r|r|r|r|r|l|l|l|c|c|}
\hline Portfolio & Event Date & MW & HE12 & HE13 & HE14 & HE15 & HE16 & HE17 & HE18 & HE19 \\
\hline SFCP_PGE3_DA_1-4_BUL & $8 / 31 / 2007$ & 0.084 & & & 1 & 1 & 1 & 1 & & \\
\hline SFCP_PGE3_DA_4-8_BUL & $8 / 31 / 2007$ & 0.209 & & & 1 & 1 & 1 & 1 & 1 & \\
\hline SFCP_PGE3_DA_4-8_DAL_(CNE) & $8 / 31 / 2007$ & 0.075 & & & 1 & 1 & 1 & 1 & 1 & \\
\hline SFCP_PGE3_DA_1-4_BUL & $8 / 30 / 2007$ & 0.084 & & & 1 & 1 & 1 & 1 & & \\
\hline SFCP_PGE3_DA_4-8_BUL & $8 / 30 / 2007$ & 0.209 & & & 1 & 1 & 1 & 1 & 1 & \\
\hline SFCP_PGE3_DA_4-8_DAL_(CNE) & $8 / 30 / 2007$ & 0.075 & & & 1 & 1 & 1 & 1 & 1 & \\
\hline SFCP_PGE3_DA_1-4_BUL & $8 / 29 / 2007$ & 0.084 & & & & 1 & 1 & 1 & 1 & \\
\hline SFCP_PGE3_DA_4-8_BUL & $8 / 29 / 2007$ & 0.209 & & & 1 & 1 & 1 & 1 & 1 & \\
\hline SFCP_PGE3_DA_4-8_DAL_(CNE) & $8 / 29 / 2007$ & 0.075 & & & 1 & 1 & 1 & 1 & 1 & \\
\hline SFCP_PGE3_DA_1-4_BUL & $7 / 5 / 2007$ & 0.03 & & & & & 1 & 1 & 1 & 1 \\
\hline SFCP_PGE3_DA_4-8_BUL & $7 / 5 / 2007$ & 0.113 & & & & & 1 & 1 & 1 & 1 \\
\hline SFCP_PGE3_DA_4-8_DAL_(CNE) & $7 / 5 / 2007$ & 0.115 & & & & & 1 & 1 & 1 & 1 \\
\hline SFCP_PGE3_DA_1-4_BUL & $7 / 3 / 2007$ & 0.03 & & & & 1 & 1 & 1 & 1 & \\
\hline SFCP_PGE3_DA_4-8_BUL & $7 / 3 / 2007$ & 0.113 & & & & 1 & 1 & 1 & 1 & \\
\hline SFCP_PGE3_DA_4-8_DAL_(CNE) & $7 / 3 / 2007$ & 0.115 & & & & 1 & 1 & 1 & 1 & \\
\hline
\end{tabular}




\subsection{Methodology}

In 2007, SF Power participated in PG\&E's Capacity Bidding Program with three portfolios. Three portfolios are:

$>$ SFCP_PGE3_DA_1-4_BUL (Portfolio 1) participated in Capacity Bidding Event Days for four hours between noon and 7pm with one account in July and five accounts in August and September.

$>$ SFCP_PGE3_DA_4-8_BUL (Portfolio 2) participated in Capacity Bidding Event Days for minimum of four hours between noon and 7pm with eleven accounts in July and 28 accounts in August and September.

$>$ SFCP_PGE3_DA_4-8_DAL_(CNE) (Portfolio 3) participated in Capacity Bidding Event Days for minimum of four hours between noon and $7 \mathrm{pm}$ with two accounts in July, August and September.

The analysis is divided into three phases:

Phase 1: Data gathering, portfolio analysis and weather sensitivity and load variability analysis for facilities which have historical data available.

Phase 2: Site and DR strategy information gathering from each site.

Phase 3: Assessment of feasibility of automating demand response strategies.

This report summarizes the phase 1 effort and will be expanded to include information from phases 2 and 3 when they become available.

\subsection{Baselines}

Three baseline models are calculated in for the portfolio analysis and the analysis of the five large sites. CBP baseline is also called $3 / 10$ baseline which is the hourly average based on the three highest energy usage days with the highest total kilowatt hour usages during the program hours of the immediate past ten days excluding weekends, holidays and other DR days. It is used by utilities in California to calculate demand reduction. 3/10 Baseline with morning adjustment (3/10_MA) model is adjusting the 3/10 baseline by a morning adjustment multiplier $\left(r_{a}\right)$ to each hour. The factor $r_{a}$ is defined as the ratio of the actual to the predicted load in the two hours prior to the event period shown in Equation 1. However, the data at the hour end at 12 (HE12) and HE13 were used in this project because of the difficulty of obtaining the data at the prior two hours before the event period start, and no portfolio bid earlier than 14:00 during the five events in 2007. Adjusted OAT-regression (OAT_MA) baseline model uses weather regression model with morning adjustment. The weather regression model is estimating the hourly load by the outside air temperature (OAT) linear regression based on the past ten uncurtailed business days. In this model, the load Lp, can be calculated by equation 2. The morning adjustment methodology is the same as the 3/10_MA model. 


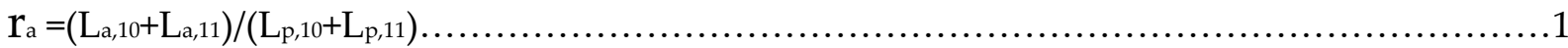

where, $r_{a}$ is the morning adjustment factor

$\mathrm{La}_{10}, \mathrm{La}, 11$ are the actual load at the hour end at 10:00am (HE10), 11:00am (HE11), respectively

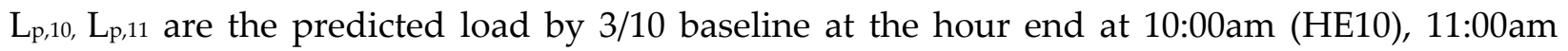
(HE11), respectively

$\mathrm{Lp}_{\mathrm{p}, \mathrm{h}}=\mathrm{ah}_{\mathrm{h}}+\mathrm{bh}_{\mathrm{h}}{ }^{*} \mathrm{Th}$

Where, $\mathrm{L}_{\mathrm{p}, \mathrm{h}}$ is the predicted load at the hour $h$

$\mathrm{ah}, \mathrm{b}_{\mathrm{h}}$ are the linear constants at the hour $h$ which can be calculated by the ten pair of past actual load and OAT data

$\mathrm{T}_{\mathrm{h}}$ is the OAT at the hour $h$ 


\subsection{Data Analysis}

\subsection{Three Portfolios in Capacity Bidding Program}

The data for the portfolio analysis are gathered from APX which facilitated the capacity bidding program for all the IOUs in California. The meter numbers and obtained data range in three portfolios of SF Power from June to September 2007 are shown in Table 2. For each portfolio, two baselines are calculated: 3/10 baseline and 3/10_MA baseline. The site P27692 participated in a different portfolio in 2007.

Table 14 Meter numbers in 3 portfolios of SF Power from July to September 2007

\begin{tabular}{|c|c|c|c|c|}
\hline \multirow{6}{*}{ SFCP_PGE3_DA_1-4_BUL } & July & August & September & Data Range \\
\hline & $7884 \mathrm{R} 5$ & 7884R5 & $7884 \mathrm{R} 5$ & 6/18/2007-9/28/2007 \\
\hline & & $35 \mathrm{P} 421$ & $35 \mathrm{P} 421$ & |7/17/2007-9/28/2007 \\
\hline & & $83 P 385$ & 83Р385 & 7/17/2007-9/28/2007 \\
\hline & & P27692 & P27692 & |7/17/2007-8/31/2007 \\
\hline & & P95868 & P95868 & 7/17/2007-9/28/2007 \\
\hline \multirow{29}{*}{ SFCP_PGE3_DA_4-8_BUL } & $46 \mathrm{T755}$ & $46 T 755$ & $46 \mathrm{T755}$ & 6/18/2007-9/28/2007 \\
\hline & $56 \mathrm{M} 088$ & $56 \mathrm{M} 088$ & 56M088 & 6/18/2007-9/28/2007 \\
\hline & $56 \mathrm{~T} 502$ & $56 \mathrm{~T} 502$ & $56 T 502$ & 6/18/2007-9/28/2007 \\
\hline & 5P3101 & $5 P 3101$ & $5 \mathrm{P} 3101$ & 6/18/2007-8/31/2007 \\
\hline & $5 P 3377$ & 5P3377 & $5 P 3377$ & 6/18/2007-9/28/2007 \\
\hline & $5 P 5512$ & $5 P 5512$ & 5P5512 & 6/18/2007-8/31/2007 \\
\hline & $7932 \mathrm{R} 5$ & $7932 \mathrm{R} 5$ & 7932R5 & 6/18/2007-9/28/2007 \\
\hline & $83 P 505$ & 83P505 & 83P505 & 6/18/2007-9/28/2007 \\
\hline & P27692 & & & 6/18/2007-7/31/2007 \\
\hline & P30706 & P30706 & P30706 & 6/18/2007-8/31/2007 \\
\hline & P95906 & P95906 & P95906 & 6/18/2007-8/31/2007 \\
\hline & & $14 \mathrm{M} 866$ & $14 \mathrm{M} 866$ & |7/17/2007-9/13/2007 \\
\hline & & $18 \mathrm{P} 063$ & $18 \mathrm{P} 063$ & |7/17/2007-9/28/2007 \\
\hline & & $2 \mathrm{P} 2890$ & $2 \mathrm{P} 2890$ & 8/1/2007-9/28/2007 \\
\hline & & $57 P 589$ & $57 \mathrm{P} 589$ & 7/17/2007-9/28/2007 \\
\hline & & $5 P 3376$ & $5 P 3376$ & 7/17/2007-9/28/2007 \\
\hline & & 7P2210 & 7P2210 & |7/17/2007-9/28/2007 \\
\hline & & 7P2211 & 7P2211 & 7/17/2007-9/28/2007 \\
\hline & & 83Р399 & 83Р399 & |7/17/2007-9/28/2007 \\
\hline & & $9 M 4668$ & $9 M 4668$ & 7/17/2007-9/28/2007 \\
\hline & & P29330 & P29330 & 7/17/2007-9/28/2007 \\
\hline & & P29565 & P29565 & |7/17/2007-9/28/2007 \\
\hline & & P30784 & P30784 & |7/17/2007-9/28/2007 \\
\hline & & P31016 & P31016 & |7/17/2007-9/13/2007 \\
\hline & & P94941 & P94941 & |7/17/2007-9/6/2007 \\
\hline & & P95367 & P95367 & 7/17/2007-9/28/2007 \\
\hline & & P95925 & P95925 & 7/17/2007-8/31/2007 \\
\hline & & P95926 & P95926 & /7/17/2007-9/11/2007 \\
\hline & & P95965 & P95965 & $7 / 17 / 2007-9 / 28 / 2007$ \\
\hline \multirow{2}{*}{ SFCP_PGE3_DA_4-8_DAL_(CNE) } & $2623 R 5$ & 2623R5 & 2623R5 & 6/18/2007-9/28/2007 \\
\hline & $2 \mathrm{P} 282$ & $2 \mathrm{P} 2825$ & $2 \mathrm{P} 2825$ & $6 / 18 / 2007-9 / 28 / 2007$ \\
\hline
\end{tabular}

\subsection{Demand Reduction Evaluation}

\subsubsection{Portfolio 1 (SFCP_PGE3_DA_1-4_BUL)}

Portfolio 1 had only one participant in July. Therefore, the baseline for Portfolio 1 in July is the same as 7884R5's individual baseline. The number of participants in this portfolio increased to five in August. In August, 7884R5 still predominated the baseline because it is the absolute large 
load in this portfolio. Table 3 shows the demand contribution of site 7884R5 to Portfolio 1 on CBP event days. Table 4 shows the coincident baseline day No. of the portfolio and individual site in August. In addition, the portfolio's three highest average electricity consumption days are the same as 7884R5's. None of the other sites' all three highest average consumption days match the portfolio's selected three highest days. Table 5 through 7 show the demand savings based on 3/10 baseline and 3/10_MA baseline during CBP events in 2007. 3/10_MA seems to consistently lower the demand reduction calculations suggesting that morning loads for the portfolio are lower that the baseline on the day of the CBP events. Table 5 shows the portfolio 1 aggregated whole building power for each event day in July and August. Columns in the table show the period with hour ending (HE) marks for each hour. Table 6 is the whole building power for meter number 7884R5. Tables 5 and 6 are very close suggesting once again the largest load dominates demand reduction in this portfolio. Although other participants significantly reduce their loads (Table 7), their reductions are a small portion of the entire portfolio.

Table 15 the WBP contribution of Facility 7884R5 to the Portfolio 1 on CBP event days

\begin{tabular}{|r|r|r|r|r|r|r|r|r|}
\hline & HE12 & HE14 & HE15 & HE16 & HE17 & HE18 & HE13 & \multicolumn{1}{l|}{ HE19 } \\
\hline $7 / 3 / 2007$ & $100 \%$ & $100 \%$ & $100 \%$ & $100 \%$ & $100 \%$ & $100 \%$ & $100 \%$ & $100 \%$ \\
\hline $7 / 5 / 2007$ & $100 \%$ & $100 \%$ & $100 \%$ & $100 \%$ & $100 \%$ & $100 \%$ & $100 \%$ & $100 \%$ \\
\hline $8 / 29 / 2007$ & $97 \%$ & $96 \%$ & $97 \%$ & $97 \%$ & $97 \%$ & $95 \%$ & $95 \%$ & $88 \%$ \\
\hline $8 / 30 / 2007$ & $95 \%$ & $96 \%$ & $96 \%$ & $97 \%$ & $96 \%$ & $95 \%$ & $94 \%$ & $89 \%$ \\
\hline $8 / 31 / 2007$ & $97 \%$ & $96 \%$ & $96 \%$ & $96 \%$ & $96 \%$ & $95 \%$ & $93 \%$ & $88 \%$ \\
\hline
\end{tabular}

Table 16 Coincident baseline day No. of Portfolio 1 and single site in August

\begin{tabular}{|l|r|r|}
\hline Site & Max_Load $(\mathrm{kW})$ & Coincident Baseline day No. \\
\hline 7884R5 & 677.1 & 3 \\
\hline P27692 & 10.11 & 2 \\
\hline P95868 & 33.01 & 2 \\
\hline 35P421 & 3.23 & 2 \\
\hline 83P385 & 3.73 & 0 \\
\hline
\end{tabular}


Table 17 Demand savings WBP\% of Portfolio 1

\begin{tabular}{|c|c|c|c|c|c|c|c|c|c|c|}
\hline & & HE12 & HE13 & HE14 & HE15 & HE16 & HE17 & HE18 & HE19 & Average \\
\hline \multirow{5}{*}{ 3/10 Baseline } & $7 / 3$ & & & & $12.0 \%$ & $11.8 \%$ & $14.0 \%$ & $21.2 \%$ & & $14.7 \%$ \\
\hline & $7 / 5$ & & & & & $0.8 \%$ & $1.1 \%$ & $9.9 \%$ & $1.1 \%$ & $3.2 \%$ \\
\hline & $8 / 29$ & & & & $1.9 \%$ & $0.2 \%$ & $-2.1 \%$ & $-9.9 \%$ & & $-2.5 \%$ \\
\hline & $8 / 30$ & & & $2.1 \%$ & $0.2 \%$ & $-0.8 \%$ & $-3.1 \%$ & & & $-0.4 \%$ \\
\hline & $8 / 31$ & & & $13.6 \%$ & $11.8 \%$ & $11.2 \%$ & $8.4 \%$ & & & $11.3 \%$ \\
\hline \multirow{5}{*}{ 3/10_MA Baseline } & $7 / 3$ & & & & $2.4 \%$ & $2.2 \%$ & $4.6 \%$ & $12.6 \%$ & & $5.5 \%$ \\
\hline & $7 / 5$ & & & & & $-3.6 \%$ & $-3.3 \%$ & $6.0 \%$ & $-3.2 \%$ & $-1.0 \%$ \\
\hline & $8 / 29$ & & & & $2.5 \%$ & $0.8 \%$ & $-1.5 \%$ & $-9.2 \%$ & & $-1.9 \%$ \\
\hline & $8 / 30$ & & & $3.6 \%$ & $1.7 \%$ & $0.6 \%$ & $-1.6 \%$ & & & $1.1 \%$ \\
\hline & $8 / 31$ & & & $0.6 \%$ & $-1.4 \%$ & $-2.2 \%$ & $-5.3 \%$ & & & $-2.1 \%$ \\
\hline
\end{tabular}

Table 18 Demand Savings WBP\% of Facility 7884R5

\begin{tabular}{|c|c|c|c|c|c|c|c|c|c|c|}
\hline & & HE12 & HE13 & HE14 & HE15 & HE16 & HE17 & HE18 & HE19 & Average \\
\hline \multirow{5}{*}{ 3/10 Baseline } & $7 / 3$ & & & & $12.0 \%$ & $11.8 \%$ & $14.0 \%$ & $21.2 \%$ & & $14.7 \%$ \\
\hline & $7 / 5$ & & & & & $0.8 \%$ & $1.1 \%$ & $9.9 \%$ & $1.1 \%$ & $3.2 \%$ \\
\hline & $8 / 29$ & & & & $-0.7 \%$ & $-2.0 \%$ & $-2.8 \%$ & $-11.4 \%$ & & $-4.2 \%$ \\
\hline & $8 / 30$ & & & $0.4 \%$ & $-1.9 \%$ & $-2.7 \%$ & $-3.3 \%$ & & & $-1.9 \%$ \\
\hline & $8 / 31$ & & & $12.2 \%$ & $10.5 \%$ & $9.9 \%$ & $8.0 \%$ & & & $10.2 \%$ \\
\hline \multirow{5}{*}{ 3/10_MA Baseline } & $7 / 3$ & & & & $2.4 \%$ & $2.2 \%$ & $4.6 \%$ & $12.6 \%$ & & $5.5 \%$ \\
\hline & $7 / 5$ & & & & & $-3.6 \%$ & $-3.3 \%$ & $6.0 \%$ & $-3.2 \%$ & $-1.0 \%$ \\
\hline & $8 / 29$ & & & & $2.3 \%$ & $1.1 \%$ & $0.3 \%$ & $-8.0 \%$ & & $-1.1 \%$ \\
\hline & $8 / 30$ & & & $2.8 \%$ & $0.6 \%$ & $-0.2 \%$ & $-0.8 \%$ & & & $0.6 \%$ \\
\hline & $8 / 31$ & & & $0.9 \%$ & $-1.0 \%$ & $-1.7 \%$ & $-3.9 \%$ & & & $-1.4 \%$ \\
\hline
\end{tabular}

Table 19 Demand Savings WBP\% of other Facilities

\begin{tabular}{|r|r|r|r|r|r|r|r|r|r|r|}
\hline & & HE12 & HE13 & HE14 & HE15 & HE16 & HE17 & HE18 & HE19 & Average \\
\hline \multirow{3}{*}{$3 / 10$ Baseline } & $8 / 29$ & & & & $48 \%$ & $38 \%$ & $11 \%$ & $10 \%$ & & $27 \%$ \\
\cline { 2 - 10 } & $8 / 30$ & & & $32 \%$ & $37 \%$ & $32 \%$ & $0 \%$ & & & $25 \%$ \\
\cline { 2 - 10 } & $8 / 31$ & & & $37 \%$ & $35 \%$ & $33 \%$ & $16 \%$ & & & $30 \%$ \\
\hline \multirow{3}{*}{$3 / 10 \_$MA Baseline } & $8 / 29$ & & & & $10 \%$ & $-6 \%$ & $-53 \%$ & $-54 \%$ & & $-26 \%$ \\
\cline { 2 - 10 } & $8 / 30$ & & & $20 \%$ & $25 \%$ & $20 \%$ & $-18 \%$ & & & $11 \%$ \\
\cline { 2 - 9 } & $8 / 31$ & & & $-6 \%$ & $-9 \%$ & $-13 \%$ & $-42 \%$ & & & $-18 \%$ \\
\hline
\end{tabular}

\subsubsection{Portfolio 2 (SFCP_PGE3_DA_4-8_BUL)}

Eleven accounts were in Portfolio 2 in July. In August and September, the total number of accounts in portfolio 2 was 28. There is a wide variety of collectable data ranges. Five large facilities over $200 \mathrm{~kW}$ participated in Portfolio 2. The coincident baseline day No. of Portfolio 2 and single site in table 8 shows that in July, two of the five large facilities have two coincident baseline days while three of them have only one or none coincident baseline day to the whole portfolio. In August, one of the five large facilities has the same baseline days as the whole portfolio, three of them have two coincident baseline days, and only one has one coincident baseline day to the portfolio (table 9). The effect of them cause that no site could dominate the portfolio demand. In July, 6/21, 6/25 and 7/2 were chosen as 3/10 baseline days for portfolio 2 . None of the sites had the same dates for three highest days selection. In August four out of 28 had matching three dates with the portfolio highest days. This issue and how it affects portfolio performance will be further analyzed. 
Table 10 shows the demand reduction of portfolio 2. Based on 3/10 baseline, Portfolio 2 had average demand reduction from $0.1 \%$ to $7.9 \%$ on event days. However, based on 3/10_MA baseline, negative demand reduction were observed on $7 / 5$ and $8 / 30$.

Table 20 Coincident baseline day No. of Portfolio 2 and single site in July

\begin{tabular}{|r|r|r|}
\hline Site & Max_Load (kW) & Coincident Baseline day No. \\
\hline P27692 & 9.12 & 1 \\
\hline 56T502 & 694.80 & 2 \\
\hline P30706 & 375.12 & 2 \\
\hline 5P3101 & 27.20 & 2 \\
\hline 5P3377 & 113.00 & 2 \\
\hline 5P5512 & 19.32 & 1 \\
\hline P95906 & 61.71 & 2 \\
\hline 7932R5 & 398.20 & 1 \\
\hline 83P505 & 6.13 & 1 \\
\hline 46T755 & 444.30 & 1 \\
\hline 56M088 & 361.08 & 0 \\
\hline
\end{tabular}

Table 21 Coincident baseline day No. of Portfolio 2 and single site in August

\begin{tabular}{|l|r|r|}
\hline Site & Max_Load $(\mathrm{kW})$ & Coincident Baseline day No. \\
\hline P30706 & 392.28 & 3 \\
\hline 7932R5 & 425.4 & 2 \\
\hline P94941 & 91.1 & 2 \\
\hline 2P2890 & 82.1 & 2 \\
\hline 57P589 & 34.96 & 3 \\
\hline 56M088 & 364.04 & 2 \\
\hline 46T755 & 467.7 & 2 \\
\hline P95906 & 61.94 & 2 \\
\hline P95965 & 53.97 & 3 \\
\hline P31016 & 76.02 & 2 \\
\hline P29565 & 26.24 & 2 \\
\hline P30784 & 57.05 & 2 \\
\hline P95367 & 36.43 & 3 \\
\hline 18P063 & 57.17 & 2 \\
\hline P29330 & 45.34 & 1 \\
\hline 5P3376 & 28.67 & 1 \\
\hline 5P5512 & 20.31 & 1 \\
\hline 56T502 & 727.8 & 1 \\
\hline 5P3101 & 28.17 & 1 \\
\hline 83P505 & 6.14 & 1 \\
\hline $83 P 399$ & 4.8 & 2 \\
\hline P95926 & 135.65 & 1 \\
\hline 7P2211 & 67.81 & 1 \\
\hline P95925 & 9.25 & 0 \\
\hline 14M866 & 7.78 & 0 \\
\hline 7P2210 & 8.49 & 1 \\
\hline 5P3377 & 110.66 & 0 \\
\hline 9M4668 & 6.4 & 0 \\
\hline
\end{tabular}


Table 22 Demand savings WBP\% of Portfolio 2

\begin{tabular}{|r|r|r|r|r|r|r|r|r|r|r|}
\hline & Event Day & HE12 & HE13 & HE14 & HE15 & HE16 & HE17 & HE18 & HE19 & Average \\
\hline \multirow{3}{*}{$3 / 10$ Baseline } & $7 / 3$ & & & & $5.7 \%$ & $8.0 \%$ & $8.8 \%$ & $6.4 \%$ & & $7.2 \%$ \\
\cline { 2 - 10 } & $7 / 5$ & & & & & $1.7 \%$ & $3.0 \%$ & $3.2 \%$ & $3.8 \%$ & $3.0 \%$ \\
\cline { 2 - 10 } & $8 / 29$ & & & $-1.3 \%$ & $0.8 \%$ & $-0.1 \%$ & $0.4 \%$ & $0.8 \%$ & & $0.1 \%$ \\
\cline { 2 - 10 } & $8 / 30$ & & & $1.9 \%$ & $1.4 \%$ & $0.1 \%$ & $0.6 \%$ & $-1.7 \%$ & & $0.5 \%$ \\
\hline & $8 / 31$ & & & $5.3 \%$ & $6.5 \%$ & $6.9 \%$ & $6.2 \%$ & $4.4 \%$ & & $5.9 \%$ \\
\cline { 2 - 9 } & $7 / 3$ & & & & $1.1 \%$ & $3.5 \%$ & $4.4 \%$ & $1.9 \%$ & & $2.7 \%$ \\
\cline { 2 - 9 } & $7 / 5$ & & & & & $-3.7 \%$ & $-2.3 \%$ & $-2.1 \%$ & $-1.5 \%$ & $-2.4 \%$ \\
\cline { 2 - 9 } & $8 / 29$ & & & $2.0 \%$ & $4.0 \%$ & $3.2 \%$ & $3.6 \%$ & $4.0 \%$ & & $3.4 \%$ \\
\cline { 2 - 9 } & $8 / 31$ & & & $1.0 \%$ & $0.5 \%$ & $-0.8 \%$ & $-0.3 \%$ & $-2.6 \%$ & & $-0.5 \%$ \\
\cline { 2 - 9 } & & & $2.2 \%$ & $3.4 \%$ & $3.9 \%$ & $3.1 \%$ & $1.3 \%$ & & $2.8 \%$ \\
\hline
\end{tabular}

\subsubsection{Portfolio 3 (SFCP_PGE3_DA_4-8_DAL_(CNE))}

Portfolio 3 includes two large facilities July through September. Hourly load data during program hours for both facilities are available. The hourly load of 2P2825 is twice larger than 2623R5. Analysis shows that while before 8/21 there is significant reduction after $5 \mathrm{pm}$, after $8 / 21$, the load shape is flatter and reduction is reduced. The demand profile analysis of $2 \mathrm{P} 2825$ showed that the loads are relatively constant between 11:00am-20:00pm on the same day but highly variable from day to day June through September.

3/10 baselines for each individual facility and the entire portfolio were calculated. Two of the three baseline days of Portfolio 3 for event days $7 / 3$ and $7 / 5$ coincide with two of the three highest energy usage days of 2P2825, and one of them fell into the three highest energy usage days of 2623R5. For the event days in August, all the three baseline days for Portfolio 3 are coincident with the three highest energy usage days of $2 \mathrm{P} 2825$, and two of them fell into the three highest energy usage days of 2623R5(TABLE 10). Due to the bigger load, 2 P2825 has bigger effect on Portfolio 3 than 2623R5 does.

The 3/10 baselines in July are shown in figure 3. 2623R5 and 2P2825 show the 3/10 baselines if the facilities are not aggregated. The aggregated $3 / 10$ baseline is a simple aggregation of the two individual $3 / 10$ baselines above. The portfolio baseline is the $3 / 10$ baseline of the whole portfolio which is slightly lower than aggregated $3 / 10$ baseline. The same trending is found in August in Figure 4 . The differences between aggregated 3/10 baseline and portfolio baseline in August are smaller than those in July. That's because more coincident baseline days are included in August.

The demand reduction of the whole portfolio, site 2623R5 and 2P2825 are shown in table 11 to 13. Here, the data of HE12 and HE13 were used for morning adjustment.

Table 23 Coincident baseline day No. of Portfolio 3 and single site in July and August

\begin{tabular}{|c|c|r|r|}
\hline Month & Site & Max_Load (kW) & Coincident Baseline day No. \\
\hline \multirow{2}{*}{ July } & 2P2825 & 1274 & 2 \\
\cline { 2 - 4 } & $2623 R 5$ & 630 & 1 \\
\hline \multirow{2}{*}{ August } & 2P2825 & 1172 & 3 \\
\cline { 2 - 4 } & $2623 R 5$ & 642 & 2 \\
\hline
\end{tabular}


Table 24. Percent demand savings WBP of Portfolio 3

\begin{tabular}{|c|c|c|c|c|c|c|c|c|c|c|}
\hline & & HE12 & HE13 & HE14 & HE15 & HE16 & HE17 & HE18 & HE19 & Average \\
\hline \multirow{5}{*}{ 3/10 Baseline } & $7 / 3$ & & & & $-2 \%$ & $1 \%$ & $2 \%$ & $1 \%$ & & $0.4 \%$ \\
\hline & $7 / 5$ & & & & & $2 \%$ & $-5 \%$ & $4 \%$ & $4 \%$ & $1.2 \%$ \\
\hline & $8 / 29$ & & & $-7 \%$ & $-5 \%$ & $-10 \%$ & $-7 \%$ & $-9 \%$ & & $-7.7 \%$ \\
\hline & $8 / 30$ & & & $-6 \%$ & $-5 \%$ & $-7 \%$ & $-4 \%$ & $-6 \%$ & & $-5.7 \%$ \\
\hline & $8 / 31$ & & & $2 \%$ & $4 \%$ & $3 \%$ & $7 \%$ & $6 \%$ & & $4.6 \%$ \\
\hline \multirow{5}{*}{ 3/10_MA Baseline } & $7 / 3$ & & & & $-9 \%$ & $-6 \%$ & $-5 \%$ & $-5 \%$ & & $-6.2 \%$ \\
\hline & $7 / 5$ & & & & & $0 \%$ & $1 \%$ & $1 \%$ & $1 \%$ & $0.7 \%$ \\
\hline & $8 / 29$ & & & $-1 \%$ & $1 \%$ & $-4 \%$ & $-1 \%$ & $-2 \%$ & & $-1.4 \%$ \\
\hline & $8 / 30$ & & & $-2 \%$ & $-1 \%$ & $-3 \%$ & $0 \%$ & $-2 \%$ & & $-1.5 \%$ \\
\hline & $8 / 31$ & & & $0 \%$ & $3 \%$ & $1 \%$ & $5 \%$ & $5 \%$ & & $2.8 \%$ \\
\hline
\end{tabular}

Table 25. Percent demand savings WBP of Site 2623R5

\begin{tabular}{|c|c|c|c|c|c|c|c|c|c|c|}
\hline & & HE12 & HE13 & HE14 & HE15 & HE16 & HE17 & HE18 & HE19 & Average \\
\hline \multirow{5}{*}{ 3/10 Baseline } & $7 / 3$ & & & & $-10 \%$ & $-9 \%$ & $3 \%$ & $5 \%$ & & $-2.6 \%$ \\
\hline & $7 / 5$ & & & & & $-6 \%$ & $3 \%$ & $5 \%$ & $4 \%$ & $1.5 \%$ \\
\hline & $8 / 29$ & & & $-1 \%$ & $1 \%$ & $-2 \%$ & $-3 \%$ & $-3 \%$ & & $-1.5 \%$ \\
\hline & $8 / 30$ & & & $0 \%$ & $0 \%$ & $-1 \%$ & $1 \%$ & $0 \%$ & & $-0.1 \%$ \\
\hline & $8 / 31$ & & & $6 \%$ & $7 \%$ & $8 \%$ & $11 \%$ & $12 \%$ & & $8.8 \%$ \\
\hline \multirow{5}{*}{ 3/10_MA Baseline } & $7 / 3$ & & & & $-5 \%$ & $-4 \%$ & $8 \%$ & $10 \%$ & & $2.3 \%$ \\
\hline & $7 / 5$ & & & & & $-7 \%$ & $6 \%$ & $8 \%$ & $7 \%$ & $3.6 \%$ \\
\hline & $8 / 29$ & & & $2 \%$ & $4 \%$ & $1 \%$ & $0 \%$ & $0 \%$ & & $1.3 \%$ \\
\hline & $8 / 30$ & & & $2 \%$ & $1 \%$ & $1 \%$ & $3 \%$ & $1 \%$ & & $1.6 \%$ \\
\hline & $8 / 31$ & & & $-1 \%$ & $0 \%$ & $2 \%$ & $4 \%$ & $6 \%$ & & $2.1 \%$ \\
\hline
\end{tabular}

Table 26. Percent demand savings WBP of Site $2 \mathrm{P} 2825$

\begin{tabular}{|c|c|c|c|c|c|c|c|c|c|c|}
\hline & & HE12 & HE13 & HE14 & HE15 & HE16 & HE17 & HE18 & HE19 & Average \\
\hline \multirow{5}{*}{ 3/10 Baseline } & $7 / 3$ & & & & $1 \%$ & $5 \%$ & $1 \%$ & $0 \%$ & & $1.8 \%$ \\
\hline & $7 / 5$ & & & & & $5 \%$ & $-8 \%$ & $4 \%$ & $4 \%$ & $1.1 \%$ \\
\hline & $8 / 29$ & & & $-11 \%$ & $-9 \%$ & $-14 \%$ & $-9 \%$ & $-12 \%$ & & $-11.0 \%$ \\
\hline & $8 / 30$ & & & $-10 \%$ & $-8 \%$ & $-11 \%$ & $-6 \%$ & $-9 \%$ & & $-8.7 \%$ \\
\hline & $8 / 31$ & & & $0 \%$ & $3 \%$ & $0 \%$ & $5 \%$ & $3 \%$ & & $2.3 \%$ \\
\hline \multirow{5}{*}{ 3/10_MA Baseline } & $7 / 3$ & & & & $-12 \%$ & $-7 \%$ & $-12 \%$ & $-13 \%$ & & $-10.9 \%$ \\
\hline & $7 / 5$ & & & & & $3 \%$ & $-1 \%$ & $-3 \%$ & $-1 \%$ & $-0.6 \%$ \\
\hline & $8 / 29$ & & & $-3 \%$ & $-1 \%$ & $-6 \%$ & $-1 \%$ & $-3 \%$ & & $-2.7 \%$ \\
\hline & $8 / 30$ & & & $-4 \%$ & $-2 \%$ & $-5 \%$ & $-1 \%$ & $-3 \%$ & & $-3.1 \%$ \\
\hline & $8 / 31$ & & & $1 \%$ & $4 \%$ & $1 \%$ & $6 \%$ & $4 \%$ & & $3.2 \%$ \\
\hline
\end{tabular}

\subsection{Analysis of five large sites with historical data}

In addition to the portfolio analysis, five accounts, which have historical data available through PG\&E's InterAct system, have been analyzed for their weather sensitivity and load variability. In order to understand the weather sensitivity of these sites, nearest weather station is selected and the hourly weather data is downloaded (section 2.1).

Once the data are obtained, weather sensitivity of five sites was calculated using Rank Order Correlation (ROC) as well as Pearson Moment Correlation Coefficient (PMCC). After a brief description of the baselines which were used to evaluate the demand reduction, section 3.3 concentrates on the demand reduction using different baselines for each portfolio. Section 3.4 concentrates on the variation of load reduction for the five sites with extensive data. Section 4 outlines a final discussion and next steps. 


\subsubsection{Weather data}

The weather data is obtained from the nearest weather station for each facility. The weather data is formatted to show hourly outside air temperature (OAT). Table 14 shows the weather station for each of the five sites.

Table 27 Proximity of Weather Stations

\begin{tabular}{|c|l|c|r|}
\hline Customer & \multicolumn{1}{|c|}{ Weather Station } & WS ID & Distance to WS \\
\hline Site A & Oakland Foothills & Cl149 & 0.8 mile \\
\hline Site B & CW6328 San Francisco & SFOC1 & 2.3 mile \\
\hline Site C & San Fran Sewage Treatment Plant & CQ147 & 2 mile \\
\hline Site D & W6CQZ-10 Alameda & AS562 & 1.5 mile \\
\hline Site E & CW6328 San Francisco & SFOC1 & 2.3 mile \\
\hline
\end{tabular}

\subsubsection{Weather Sensitivity Analysis (5 facilities)}

In this project, the Rank Order Correlation Coefficient (ROC) $r_{s}$ and Pearson Moment Correlation Coefficient (MCC) $\mathrm{r}$ are used for identifying the weather sensitivity of each facility. ROC is used to measure the ordinal data correlation. And the MCC is used to measure the direct correlation of demand data and OAT.

Figure 3 and 4 show the results of ROC and MCC respectively. Swig is identified to be the only weather sensitive facility because its ROC is above 0.7 during the normal operation period. The $\mathrm{r}_{\mathrm{s}}$ and $\mathrm{r}$ for Sites A, B, C and D are lower than 0.7 which means they are not weather sensitive.

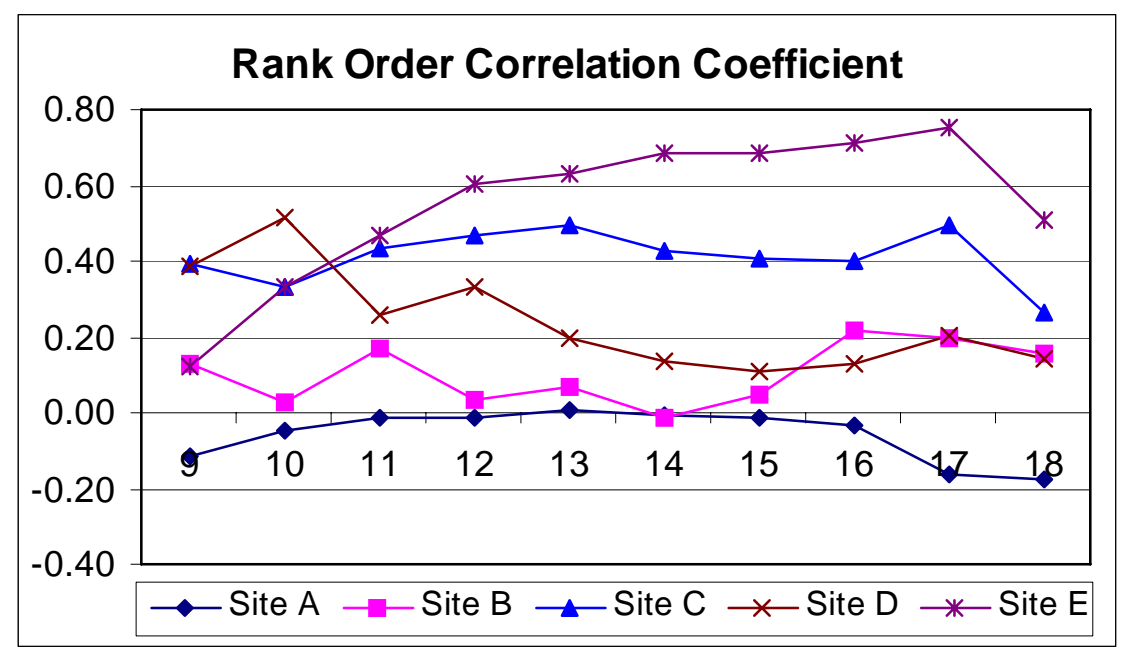

Figure 13 Hourly Rank Order Correlation Coefficient of facilities 


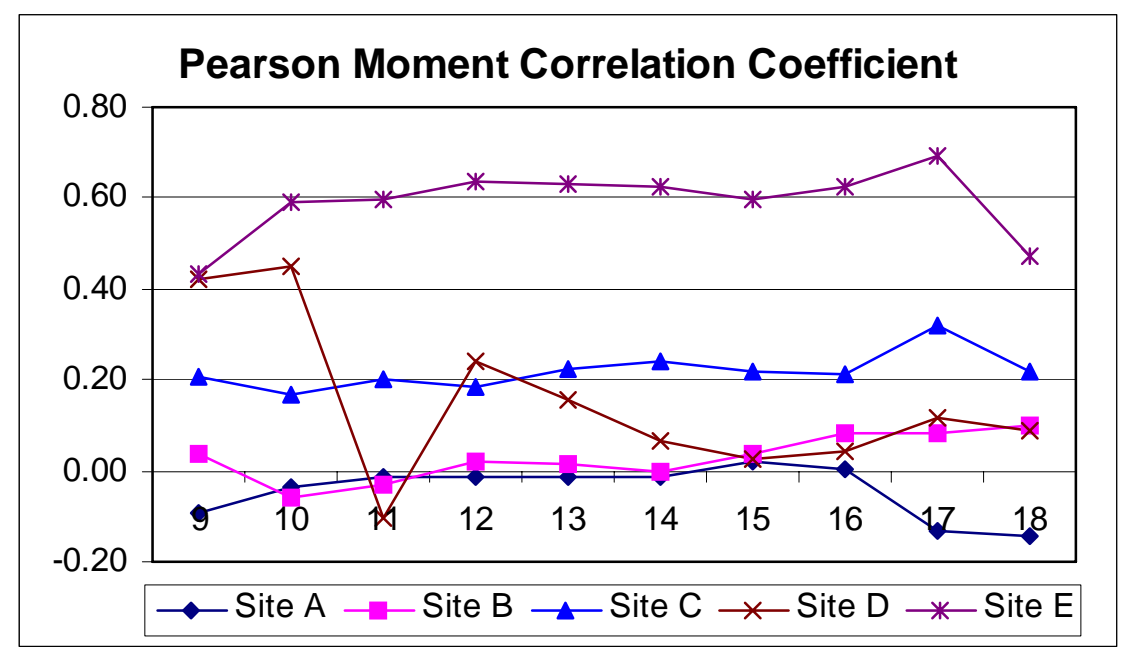

Figure 14 Hourly Moment Correlation Coefficient of facilities

\subsubsection{Variation in demand reduction}

Variation in demand reduction is studied for five sites using 3/10,3/10_MA and OAT_MA baselines. Figure 5 to 7 show the average, minimum and maximum demand reduction for each site with each baseline. Based on the $3 / 10$ baseline, four out of five facilities had positive average demand reductions. Based on 3/10_MA baseline, all of the five facilities had positive average demand reductions; however, the average demand reductions are smaller. Based on OAT_MA baseline, three of the five facilities show negative demand reductions. Baseline development greatly affects demand reduction measurement. Therefore, selecting an appropriate baseline is very important. Site $\mathrm{C}$ is the least variable site. Site D is the most variable site.

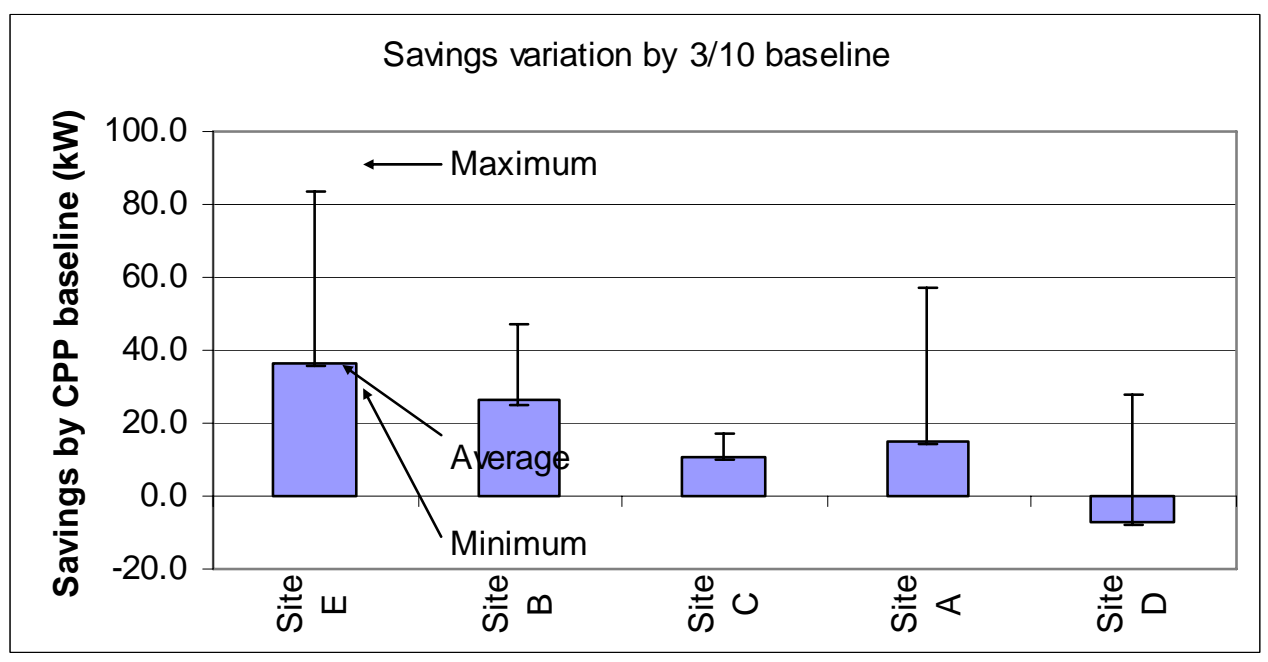

Figure 15 Average, Minimum and Maximum Demand Reduction Based on 3/10 Baseline 


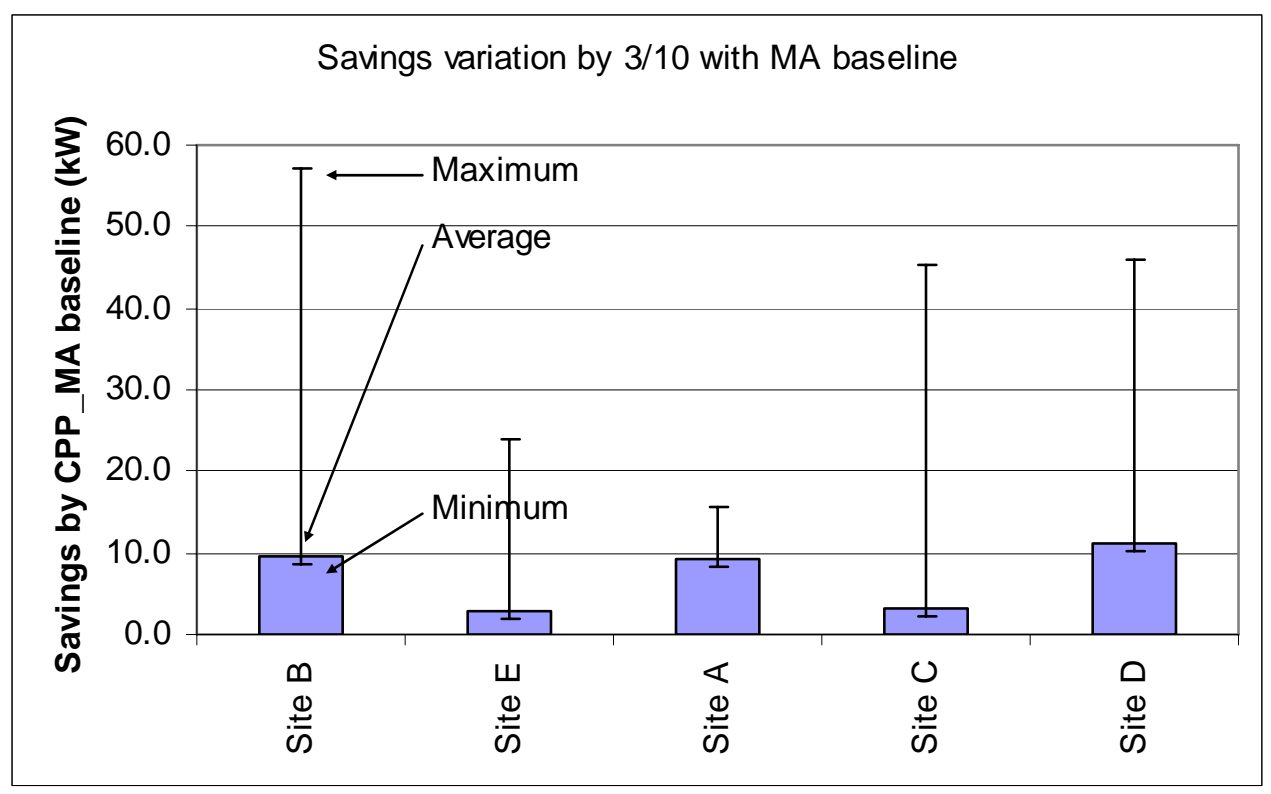

Figure 16 Average, Minimum and Maximum Demand Reduction Based on 3/10_MA Baseline

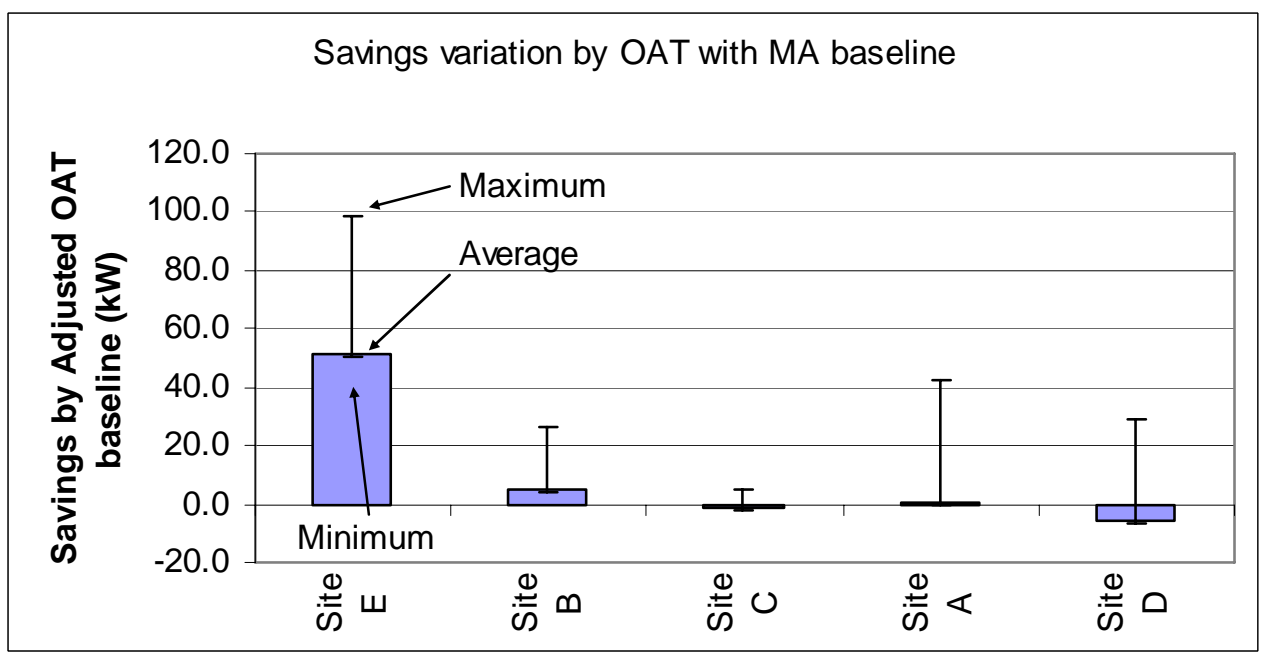

Figure 17 Average, Minimum and Maximum Demand Reduction Based on OAT_MA Baseline 


\subsection{Discussion}

In this report, we analyzed the portfolio performance, and how the individual facility affects the portfolio. Because of insufficient outside air temperature data, 3/10 baseline, 3/10_MA baseline were calculated for each portfolio. Then, weather sensitivity and demand reduction variation analysis were conducted on five large facilities. Only one site was identified to be a weather sensitive facility. Other four facilities' loads had very small correlation with the OAT.

The study was conducted without any information about the buildings, DR control strategies or automation opportunities. A next step to this study to make it more complete would be to collect this information and match it with the performance to better characterize individual buildings' performance. 


\section{Appendix C: Small Commercial Site Survey}

\section{Contact Information}

\begin{tabular}{|l|l|}
\hline Name & \\
\hline Company & \\
\hline E-mail & \\
\hline Phone & \\
\hline Fax & \\
\hline $\begin{array}{l}\text { Contact's } \\
\text { address }\end{array}$ & \\
\hline
\end{tabular}

\section{Site Information}

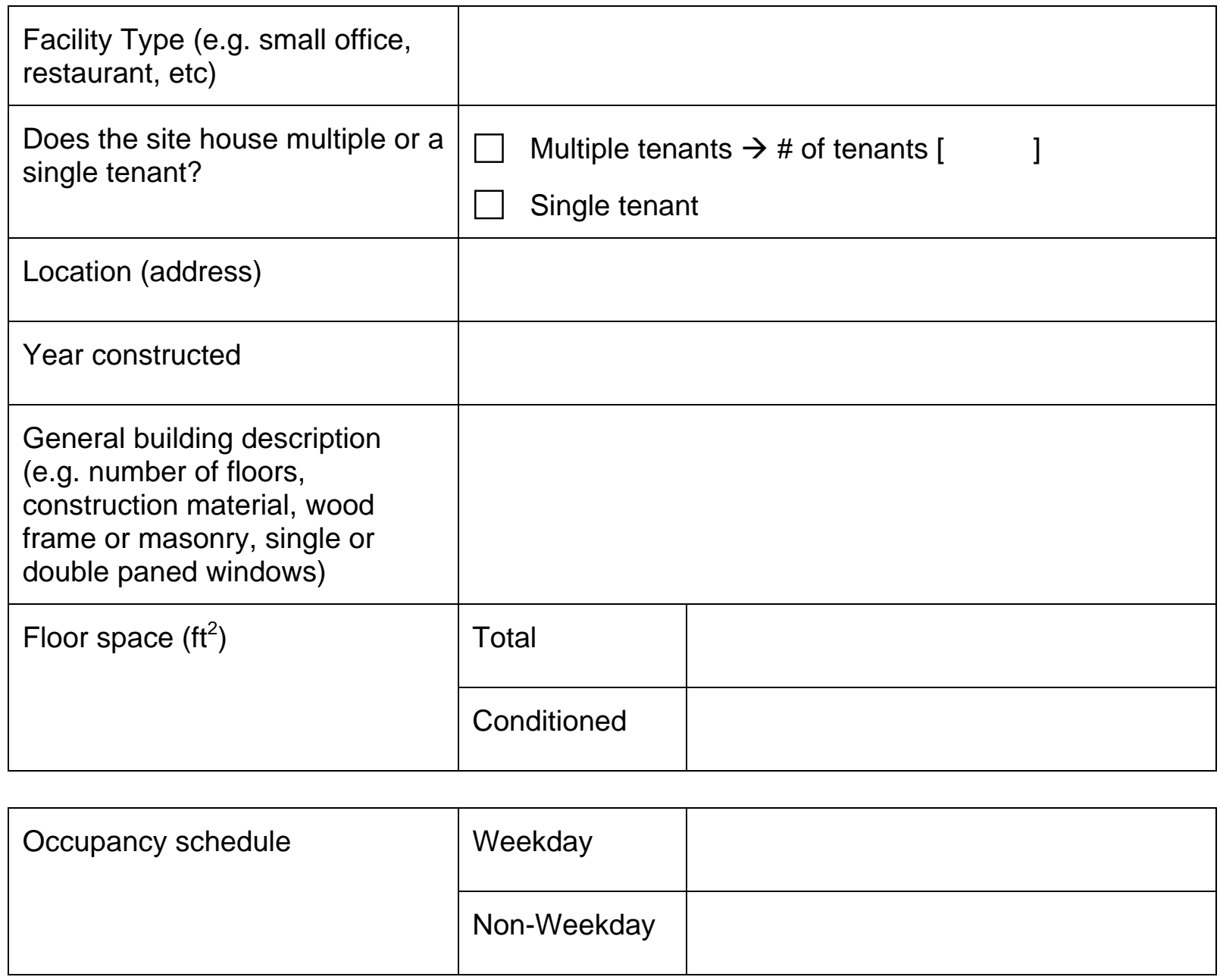




\begin{tabular}{|l|l|}
\hline Facility management type & $\begin{array}{l}\square \text { Self } \\
\square \text { Landlord }\end{array}$ \\
\hline
\end{tabular}

\section{Energy}

\begin{tabular}{|l|l|l|}
\hline Peak load [kW] & \multicolumn{2}{|l|}{} \\
\hline Connected load [kW] & \\
\hline $\begin{array}{l}\text { Approximate breakdown of } \\
\text { summer peak period [in \%] }\end{array}$ & Lighting & \\
\cline { 2 - 3 } & HVAC & \\
\cline { 2 - 3 } & Appliances, misc. & \\
\hline & Process line & \\
\hline
\end{tabular}

\section{HVAC system}

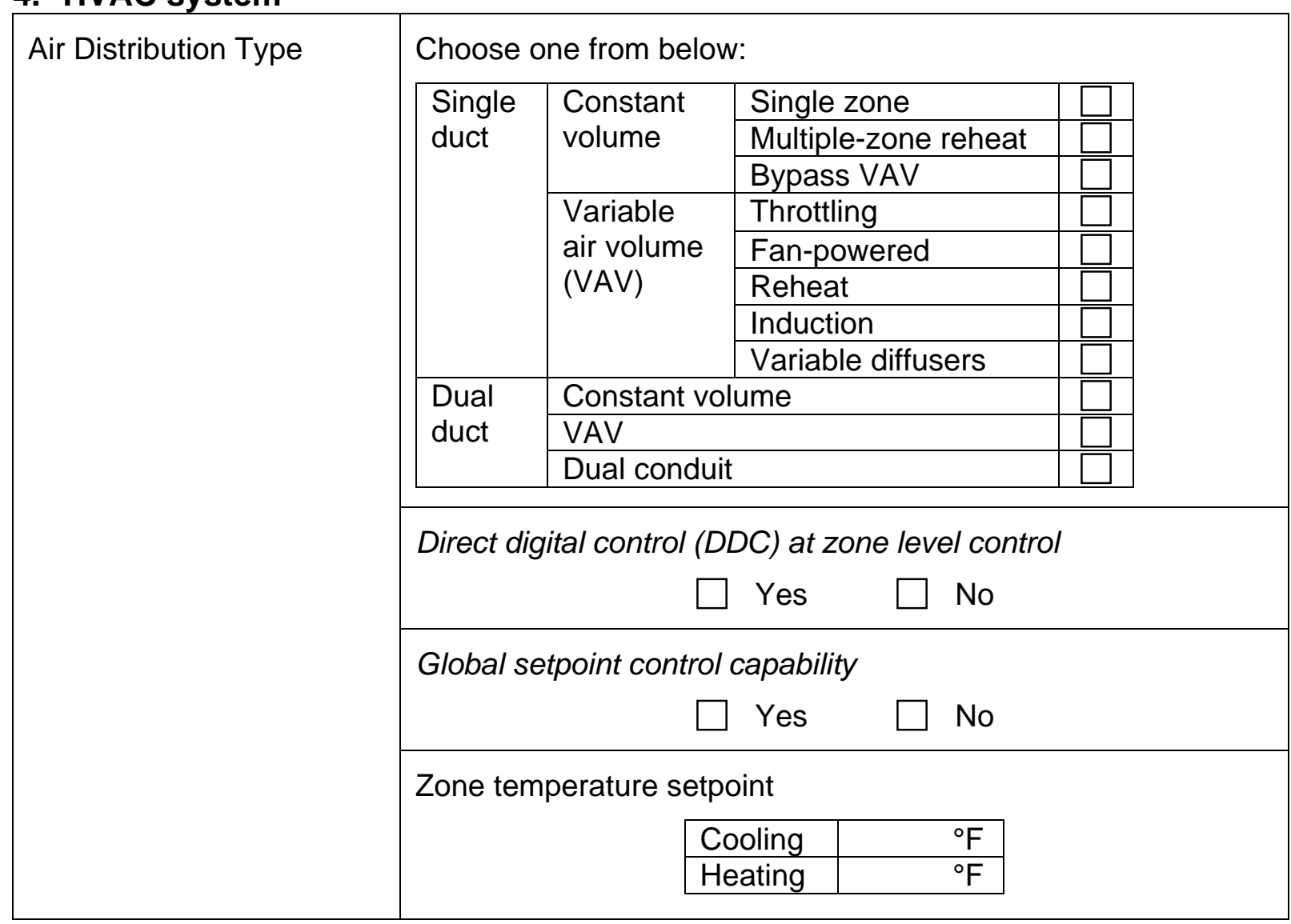




\begin{tabular}{|c|c|c|c|c|}
\hline \multirow[t]{12}{*}{ Cooling Plant } & \multicolumn{4}{|c|}{ Choose one from below: } \\
\hline & \multirow{6}{*}{$\begin{array}{l}\text { Central } \\
\text { cooling }\end{array}$} & \multirow{2}{*}{$\begin{array}{l}\text { Centrifugal } \\
\text { chiller }\end{array}$} & Constant volume & $\square$ \\
\hline & & & $\begin{array}{l}\text { Variable frequency } \\
\text { drive (VFD) }\end{array}$ & $\square$ \\
\hline & & \multirow{2}{*}{$\begin{array}{l}\text { Absorption } \\
\text { chiller }\end{array}$} & Constant volume & $\square$ \\
\hline & & & $\begin{array}{l}\text { Variable frequency } \\
\text { drive (VFD) }\end{array}$ & $\square$ \\
\hline & & \multirow{2}{*}{$\begin{array}{l}\text { Other } \\
\text { chiller } \\
\text { (describe): }\end{array}$} & Constant volume & $\square$ \\
\hline & & & $\begin{array}{l}\text { Variable frequency } \\
\text { drive (VFD) }\end{array}$ & $\square$ \\
\hline & \multirow{2}{*}{$\begin{array}{l}\text { Decentralized } \\
\text { cooling }\end{array}$} & \multirow{2}{*}{$\begin{array}{l}\text { Package } \\
\text { unit }\end{array}$} & Constant volume & $\square$ \\
\hline & & & $\begin{array}{l}\text { Variable frequency } \\
\text { drive (VFD) }\end{array}$ & $\square$ \\
\hline & \multicolumn{4}{|c|}{ Number and size (tons, kW) of equipments: } \\
\hline & \multicolumn{4}{|c|}{ Direct digital control (DDC)? } \\
\hline & & $\square$ Yes & $\square$ No & \\
\hline \multirow[t]{6}{*}{ Air Handling Unit } & \multicolumn{4}{|c|}{ Choose one from below: } \\
\hline & \multicolumn{2}{|c|}{ Constant volume } & & \\
\hline & \multicolumn{2}{|c|}{ Variable speed drive (VSD) } & & \\
\hline & \multicolumn{4}{|c|}{ Number and size (horse power, kW, CFM) of equipments: } \\
\hline & \multicolumn{4}{|c|}{ Direct digital control (DDC)? } \\
\hline & & $\square$ Yes & $\square$ No & \\
\hline
\end{tabular}

\section{Lighting System}

\begin{tabular}{|c|c|}
\hline \multirow[t]{3}{*}{ Zone control } & Choose one from below: \\
\hline & Single zone control \\
\hline & Multi-zone control \\
\hline \multirow[t]{5}{*}{ Control type } & Check all applicable: \\
\hline & Single circuit control for a zone \\
\hline & Multiple circuit control for a zone \\
\hline & Bi-level switching \\
\hline & Dimmable ballast \\
\hline
\end{tabular}




\begin{tabular}{|l|l|}
\hline $\begin{array}{l}\text { General description of } \\
\text { types of lamps and } \\
\text { fixtures (e.g., CFLs, T- } \\
\text { 12s, T-8s, High Intensity } \\
\text { Discharge) }\end{array}$ & \\
\hline Centralized control & Centralized lighting control? \\
& $\square$ Yes $\square$ No \\
\cline { 2 - 2 } & Is the lighting control integrated into EMCS? \\
& $\square$ Yes $\square$ No \\
\hline
\end{tabular}

\section{Energy Management and Control System}

\begin{tabular}{|c|c|c|c|}
\hline EMCS vendor & & & \\
\hline What protocol is used? & & & \\
\hline $\begin{array}{l}\text { Remote monitoring/ } \\
\text { control capability }\end{array}$ & $\begin{array}{l}\text { Control systems } \\
\text { (Check all appli }\end{array}$ & $\begin{array}{l}\text { re viewable } \\
\text { ble): }\end{array}$ & controllable via \\
\hline & & Viewable & Controllable \\
\hline & Web-browser & & \\
\hline & Off-site & $\Rightarrow$ & $\begin{array}{l} \\
\end{array}$ \\
\hline & On-site & & \\
\hline & Never & & $=$ \\
\hline Data collection at EMCS & Does the EMCS & ave capabi & $y$ to trend logs? \\
\hline & & $\square$ Yes & $\square$ No \\
\hline & If yes, data poin & ollected: & \\
\hline & Trend interval $(r$ & hute) & \\
\hline
\end{tabular}




\section{Energy Information System (data monitoring and collection)}

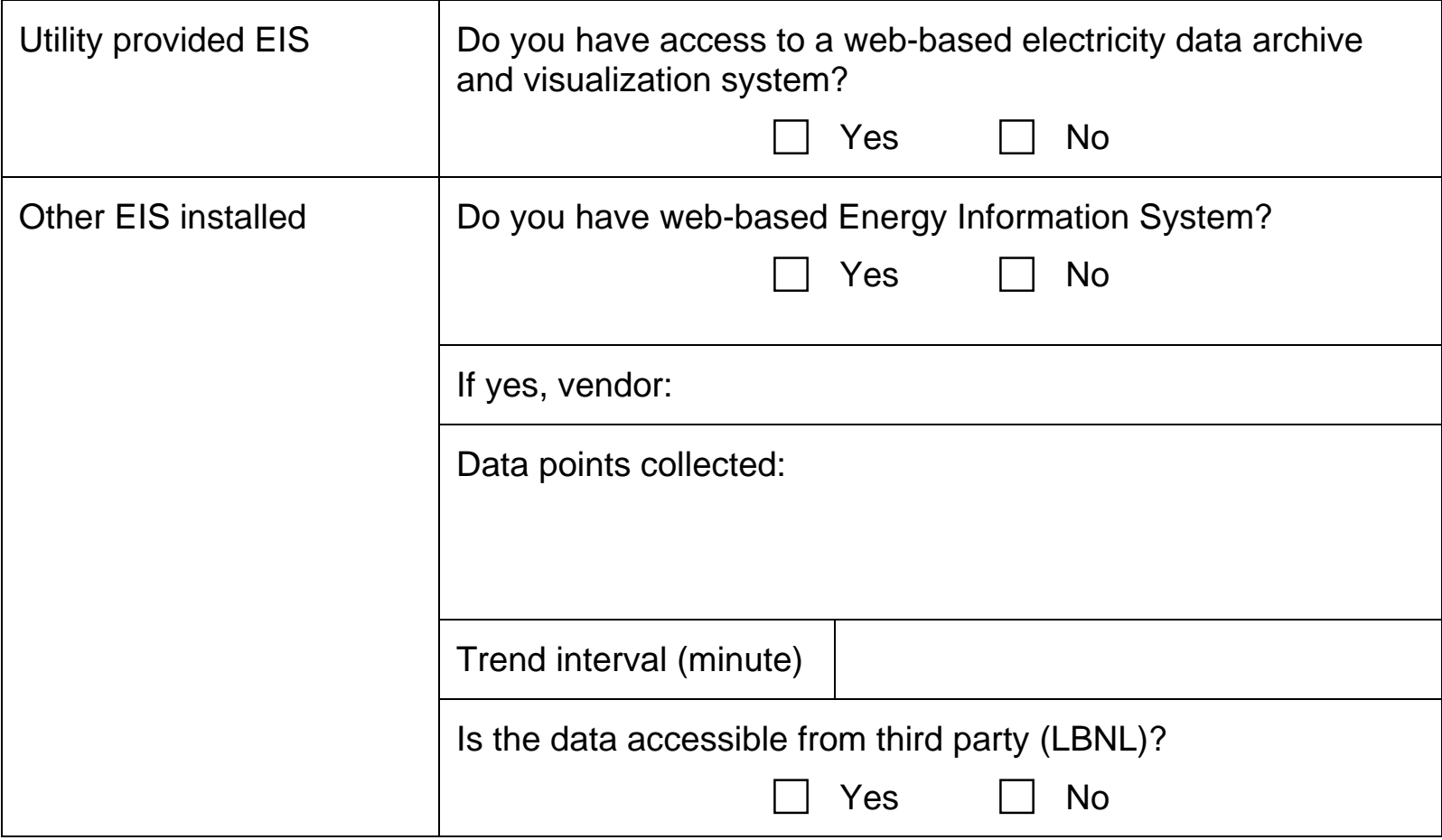

\section{Connectivity - Connecting the EMCS to the Internet}

\begin{tabular}{|l|l|}
\hline $\begin{array}{l}\text { (a) Does the site have Internet connectivity for tenants? } \\
\text { (i.e., can they surf the Web?) }\end{array}$ & $\square$ Yes $\square$ No \\
\hline (b) Is EMCS data viewable through a Web browser on \\
site?
\end{tabular}

\section{Shed Plan}

\begin{tabular}{|l|l|}
\hline $\begin{array}{l}\text { When called upon on } \\
\text { Energy Alert days how do } \\
\text { you reduce your load? }\end{array}$ & \\
\hline $\begin{array}{l}\text { Is your building able keep } \\
\text { the temperature set points } \\
\text { on hot summer days? }\end{array}$ & $\square$ Yes \\
\hline $\begin{array}{l}\text { Do you have any shed } \\
\text { control ideas? }\end{array}$ & \\
\hline $\begin{array}{l}\text { How much kW do you } \\
\text { think you can shed? [kW] }\end{array}$ & \\
\hline
\end{tabular}




\section{Appendix D: Baseline Calculations}

There are three baseline models considered for the small commercial buildings study:

1. Adjusted outside air temperature (OAT_MA) regression baseline model,

2. Adjusted $3 / 10$ baseline model (3/10_MA), and

3. $3 / 10$ baseline model.

The goal of this document is to describe three baseline models and outline the calculation methods so that these baselines can be developed and demand reduction feedback is provided using the various baselines.

\section{Adjusted outside air temperature (OAT_MA) regression baseline model}

LBNL has developed several baseline models to estimate the demand savings from the DR strategies. For this study, OAT baseline had to be calculated after the events because there was not a real-time outside air temperature reading that could be used to generate a dynamic baseline. Electricity consumption data for each site is collected from the current transducers that are installed as a part of the Advanced Telemetry installation. The actual metered electricity consumption is subtracted from the baseline-modeled consumption to derive an estimate of demand savings for each 15-minute period. Recent research recommends a weather-sensitive baseline model with adjustments for morning load variations (Coughlin, 2008). Weather data is obtained from the temperature sensors that are installed at each site. Being cautious about potential gaming by the customers, utilities in California offered to use a four-hour adjustment as opposed to a two-hour adjustment period. Therefore, all the morning adjusted baseline models use a morning adjustment multiplier that is calculated over four hours before the DR event starts.

To develop the baseline electric loads for the demand savings, ten "non-demand response" days are selected. These 10 baseline days are non-weekend, non-holiday Monday through Friday work days. In the OAT_MA model, first the whole building power baseline is estimated using a regression model that assumes that whole building power is linearly correlated with OAT (Motegi et al. 2004). Input data for this baseline development are 15-minute interval whole building electric demand and 15-minute interval or hourly OAT. The baseline is computed as:

$L i=a i+b i T i$

where $L i$ is the predicted 15-minute interval electric demand for time $i$ from the previous non$\mathrm{CPP}$ work days. Depending on the frequency of the available weather data, $\mathrm{Ti}$ is the hourly or 15-minute interval OAT at time $i$. ai and $b i$ are estimated parameters generated within the model from a linear regression of the demand data for time $i$. Individual regression equations are developed for each 15-minute interval, resulting in 96 regressions for the entire day (24 hours/day, with four 15-minute periods per hour; $i$ is from 0:00 to 23:45). 
Second, the actual morning load is used to adjust the regression model. The regression model is shifted up (or down) by a multiplier that is the ratio of the actual load to the predicted load four hours prior to the event start time. The adjusted load is computed as:

$L^{\prime} i=P L i$

$P=[M(t-4)+M(t-3)+M(t-2)+M(t-1)] /[L(t-4)+L(t-3)+L(t-2)+L(t-1)]$

where $L^{\prime} i$ is the adjusted load for time $i, P$ is the multiplier, and $t$ is the DR event start time, $M$ is the actual load of the facility and $L$ is the predicted load. For example, if the event starts at noon, the actual load for hour ending at 9, 10, 11 and 12 are considered.

\section{3/10 Baseline Model}

The 3/10 baseline model is the average hourly load shape of the three highest consumption days during the DR period in the last 10 business days excluding holidays, weekends and DR event days. The baseline algorithm considers the site electric consumption during the DR period when selecting the highest three days. The 3/10 baseline may be lower than the actual demand if the site's demand is weathersensitive. Rank Order Correlation between weather temperature and whole building loads is used to calculate weather sensitivity of buildings (Coughlin, 2008)

\section{Morning Adjusted 3/10 (3/10_MA) Baseline Model}

The same morning adjustment factor $(P)$ calculated to adjust the OAT regression baseline model in the previous sections is used to calculate 3/10_MA where the adjustment factor is multiplied with each entry. 


\section{Appendix E: Results of the Field Tests}

\begin{tabular}{|l|l|}
\hline Building Use & Restaurant \\
\hline Industry Classification & N/A \\
\hline City & San Juan Capistrano, CA \\
\hline Gross Floor Area & $2,200 \mathrm{ft}^{2}$ \\
\hline Conditioned Area & $2,200 \mathrm{ft}^{2}$ \\
\hline \# of Buildings, floor & 1 -building, 1-floor \\
\hline Peak Load kW & $10 \mathrm{~kW}$ \\
\hline Peak W/ft ${ }^{2}$ & $4.55 \mathrm{~W} / \mathrm{ft}^{2}$ \\
\hline Tenant Type & $\mathrm{N} / \mathrm{A}$ \\
\hline Facility Management & Advanced Telemetry \\
\hline Weekday Schedule & $\begin{array}{l}6: 30 \text { am }-10 \mathrm{pm} \\
\text { dining room } 6: 30 \mathrm{am}- \\
1 \text { am kitchen }\end{array}$ \\
\hline Non-weekday Schedule & $6: 30$ am - 10 pm \\
dining room $6: 30 \mathrm{am}-$ \\
\hline Building Details & 1 am kitchen \\
\hline
\end{tabular}

HVAC System Summary

\begin{tabular}{|l|l|}
\hline Air Distribution Type & N/A \\
\hline Air Handler Unit & 2 RTUs - 7.5 tons and 12 tons \\
\hline HVAC Control System & Advanced Telemetry \\
\hline DDC Zone Control & No \\
\hline
\end{tabular}

Data Trending

\begin{tabular}{|l|l|}
\hline DDC Zone Control & \multicolumn{1}{|c|}{ EMCS Trends=yes Submeter=yes } \\
\hline Data Trending Detail & $\begin{array}{l}\text { kitchen temp, dining room temp and kitchen and dining room } \\
\text { thermostat set points }\end{array}$ \\
\hline
\end{tabular}

A total of four tests events were dispatched. A summary of the events and strategies are displayed below. This section displays the load profiles for each event day for each facility followed by a summary table that shows the average load shed with the three baselines. 


\begin{tabular}{|c|c|c|c|c|c|}
\hline Site & Test Date & Precooling & Start time & End Time & DR strategy \\
\hline San Juan Capistrano & $10 / 16 / 2008$ & 1-2pm & $2 \mathrm{pm}$ & $3: 15 p m$ & $\begin{array}{l}\text { Pre-cool at 72Deg starting at } 1 \text { pm and set up temp . } 76 \mathrm{~F} \\
\text { from 2-2:50, 77F from 2:50-3, 78F from 3-3:15, event } \\
\text { canceled at 3:15 }\end{array}$ \\
\hline Hesperia & $10 / 16 / 2008$ & No & $2 \mathrm{pm}$ & 3:15pm & $\begin{array}{l}\text { 76F from 2-2:50, 77F from 2:50-3, 78F from 3-3:15, event } \\
\text { canceld at 3:15 }\end{array}$ \\
\hline San Juan Capistrano & $10 / 17 / 2008$ & $1-2 \mathrm{pm}$ & $2 \mathrm{pm}$ & $4 \mathrm{pm}$ & $\begin{array}{l}\text { Pre-cool starting at } 1 \text { pm and set up temp at 70Deg. 1-74, 2- } \\
75,3-76,4-77\end{array}$ \\
\hline Hesperia & $10 / 17 / 2008$ & $1-2 \mathrm{pm}$ & $2 \mathrm{pm}$ & $4 \mathrm{pm}$ & $\begin{array}{l}\text { precool starting at } 1 \text { pm and set up temp at 70Deg 1-76, 2- } \\
76,3-77,4-77\end{array}$ \\
\hline San Juan Capistrano & $10 / 22 / 2008$ & 2-3pm & $3 \mathrm{pm}$ & $5 \mathrm{pm}$ & $\begin{array}{l}\text { Pre-cool at 70F starting at 2pm. 3-5pm 10\% Shed from 3/10 } \\
\text { MA baseline }\end{array}$ \\
\hline Hesperia & $10 / 22 / 2008$ & 2-3pm & $3 \mathrm{pm}$ & $5 \mathrm{pm}$ & $\begin{array}{l}\text { Pre-cool at 70F starting at 2pm. 3-5pm 10\% Shed from 3/10 } \\
\text { MA baseline }\end{array}$ \\
\hline San Juan Capistrano & $10 / 24 / 2008$ & 11am-noon & $11 \mathrm{am}$ & $2 \mathrm{pm}$ & $\begin{array}{l}\text { Pre-cool at } 70 \mathrm{~F} \text { starting at } 11 \mathrm{am} \text {. Noon to } 2 \mathrm{pm}, 10 \% \text { Shed } \\
\text { from } 3 / 10 \text { baseline }\end{array}$ \\
\hline Hesperia & $10 / 24 / 2008$ & 11am-noon & noon & $2 \mathrm{pm}$ & $\begin{array}{l}\text { Pre-cool at } 70 \mathrm{~F} \text { starting at } 11 \mathrm{am} \text {. Noon to } 2 \mathrm{pm}, 10 \% \text { Shed } \\
\text { from } 3 / 10 \text { baseline }\end{array}$ \\
\hline San Juan Capistrano & $11 / 7 / 2008$ & 8am-noon & noon & $2 \mathrm{pm}$ & $\begin{array}{l}\text { Pre-cool at } 70 \mathrm{~F} \text { starting at } 8 \mathrm{am} \text {. Noon to } 2 \mathrm{pm}, 10 \% \text { Shed } \\
\text { from } 3 / 10 \text { baseline }\end{array}$ \\
\hline Hesperia & $11 / 7 / 2008$ & 8am-noon & noon & $2 \mathrm{pm}$ & $\begin{array}{l}\text { Pre-cool at } 70 \mathrm{~F} \text { starting at } 8 \mathrm{am} \text {. Noon to 2pm, } 10 \% \text { Shed } \\
\text { from 3/10 baseline }\end{array}$ \\
\hline Hesperia & $11 / 14 / 2008$ & 8am-noon & noon & $2 \mathrm{pm}$ & $\begin{array}{l}\text { Pre-cool at } 70 \mathrm{~F} \text { starting at } 8 \mathrm{am} \text {. Noon to 2pm, } 19 \% \text { Shed } \\
\text { from } 3 / 10 \text { baseline }\end{array}$ \\
\hline
\end{tabular}

\section{October 22, 2008}

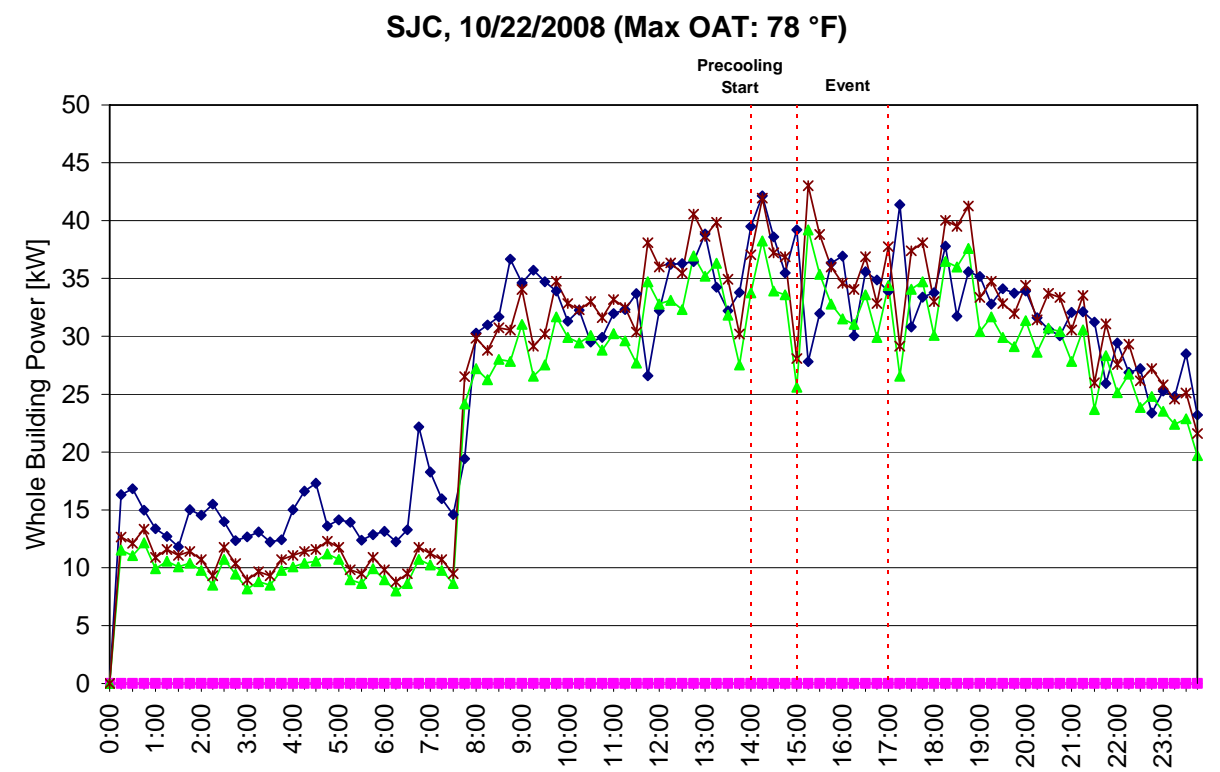

- Actual $\rightarrow$ OAT MA Baseline $-3 / 10$ beseline $*-3 / 10$ MA Baseline

\begin{tabular}{|c|c|c|c|c|c|c|c|c|}
\hline \multirow{2}{*}{ Date } & \multirow{2}{*}{ Baseline } & \multirow{2}{*}{ Event Time } & \multicolumn{2}{|c|}{$\mathbf{k W}$} & \multicolumn{2}{|c|}{$\mathbf{W} / \mathbf{f t}^{2}$} & \multicolumn{2}{|c|}{ WBP\% } \\
\hline & & & Max & Ave & Max & Ave & Max & Ave \\
\hline \multirow{3}{*}{ Oct-22 } & $3 / 10$ & \multirow{3}{*}{ 3:00-5:00 } & 11 & 0 & 5.18 & 0.02 & $29 \%$ & $-1 \%$ \\
\hline & 3/10 МА & & 15 & 3 & 6.91 & 1.50 & $35 \%$ & $8 \%$ \\
\hline & OAT MA & & - & - & - & - & - & - \\
\hline
\end{tabular}


Hesperia, 10/22/2008 (Max OAT: $78^{\circ} \mathrm{F}$ )

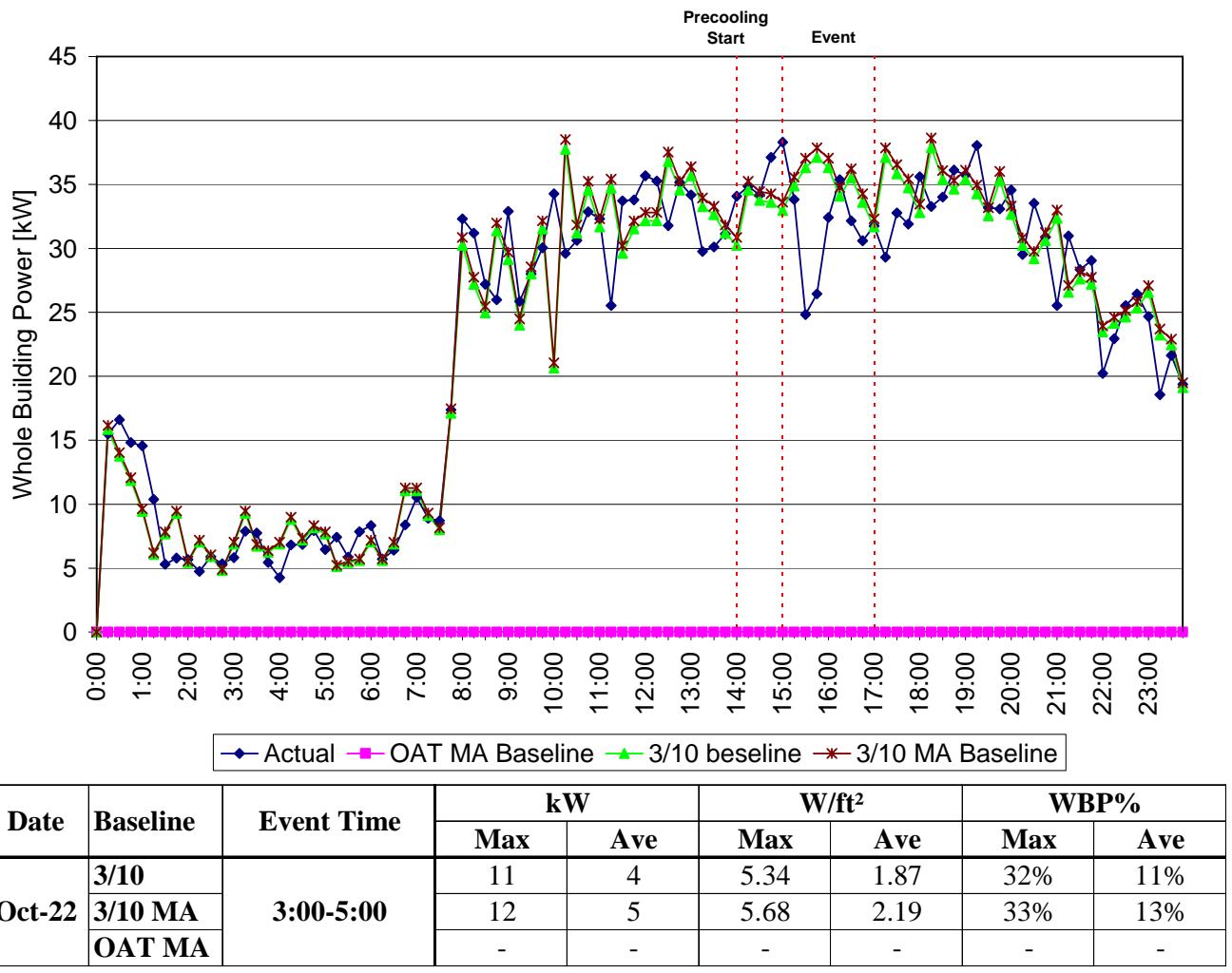

October 24, 2008

SJC, 10/24/2008 (Max OAT: $\left.100^{\circ} \mathrm{F}\right)$

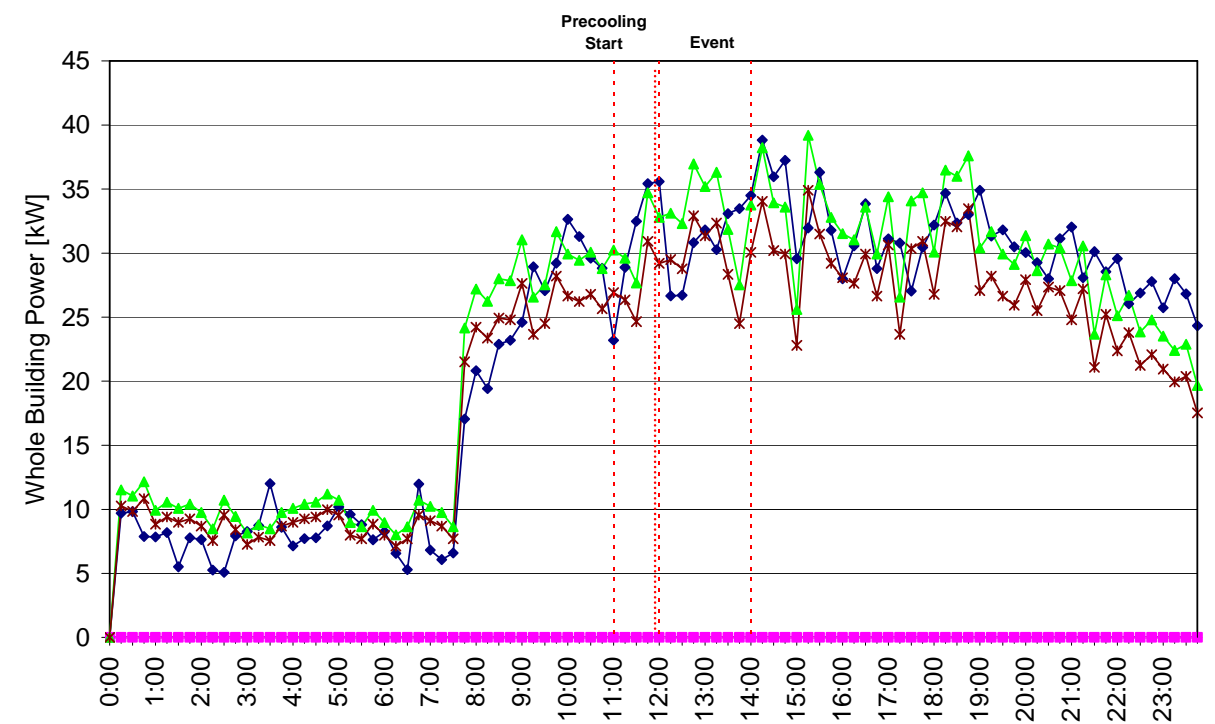

$\rightarrow$ - Actual $\rightarrow$ - OAT MA Baseline $\rightarrow 3 / 10$ beseline $*$ * 3/10 MA Baseline

\begin{tabular}{|c|c|c|c|c|c|c|c|c|}
\hline \multirow{2}{*}{ Date } & \multirow{2}{*}{ Baseline } & \multirow{2}{*}{ Event Time } & \multicolumn{2}{|c|}{ kW } & \multicolumn{2}{|c|}{$\mathbf{W} / \mathbf{f t}^{2}$} & \multicolumn{2}{|c|}{ WBP\% } \\
\hline & & & Max & Ave & Max & Ave & Max & Ave \\
\hline \multirow{3}{*}{ Oct-24 } & $3 / 10$ & \multirow{3}{*}{ 12:00-2:00 } & 6 & 2 & 2.94 & 1.12 & $20 \%$ & $7 \%$ \\
\hline & 3/10 MA & & 3 & -1 & 1.29 & -0.54 & $10 \%$ & $-5 \%$ \\
\hline & OAT MA & & - & - & - & - & - & - \\
\hline
\end{tabular}


Hesperia, 10/24/2008 (Max OAT: $82{ }^{\circ} \mathrm{F}$ )

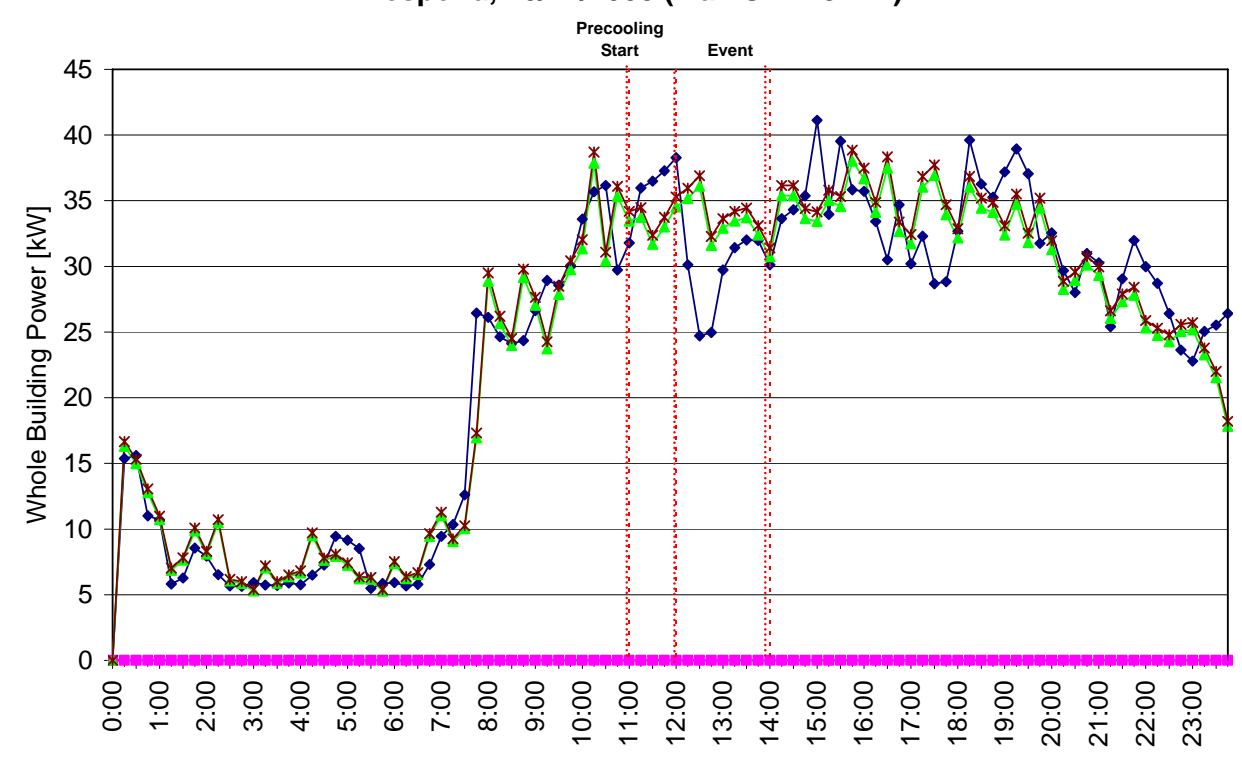

$\rightarrow$ Actual $\rightarrow-$ OAT MA Baseline $₫$-3/10 beseline $*$ 3/10 MA Baseline

\begin{tabular}{|c|c|c|c|c|c|c|c|c|}
\hline \multirow{2}{*}{ Date } & \multirow{2}{*}{ Baseline } & \multirow{2}{*}{ Event Time } & \multicolumn{2}{|c|}{$\mathbf{k W}$} & \multicolumn{2}{|c|}{$\mathbf{W} / \mathbf{f t}^{2}$} & \multicolumn{2}{|c|}{ WBP\% } \\
\hline & & & Max & Ave & Max & Ave & Max & Ave \\
\hline \multirow{3}{*}{ Oct-24 } & $3 / 10$ & \multirow{3}{*}{ 12:00-2:00 } & 11 & 4 & 5.30 & 1.80 & $32 \%$ & $11 \%$ \\
\hline & 3/10 MA & & 12 & 5 & 5.67 & 2.14 & $33 \%$ & $13 \%$ \\
\hline & ОАТ МА & & - & - & - & - & - & - \\
\hline
\end{tabular}

November 7, 2008

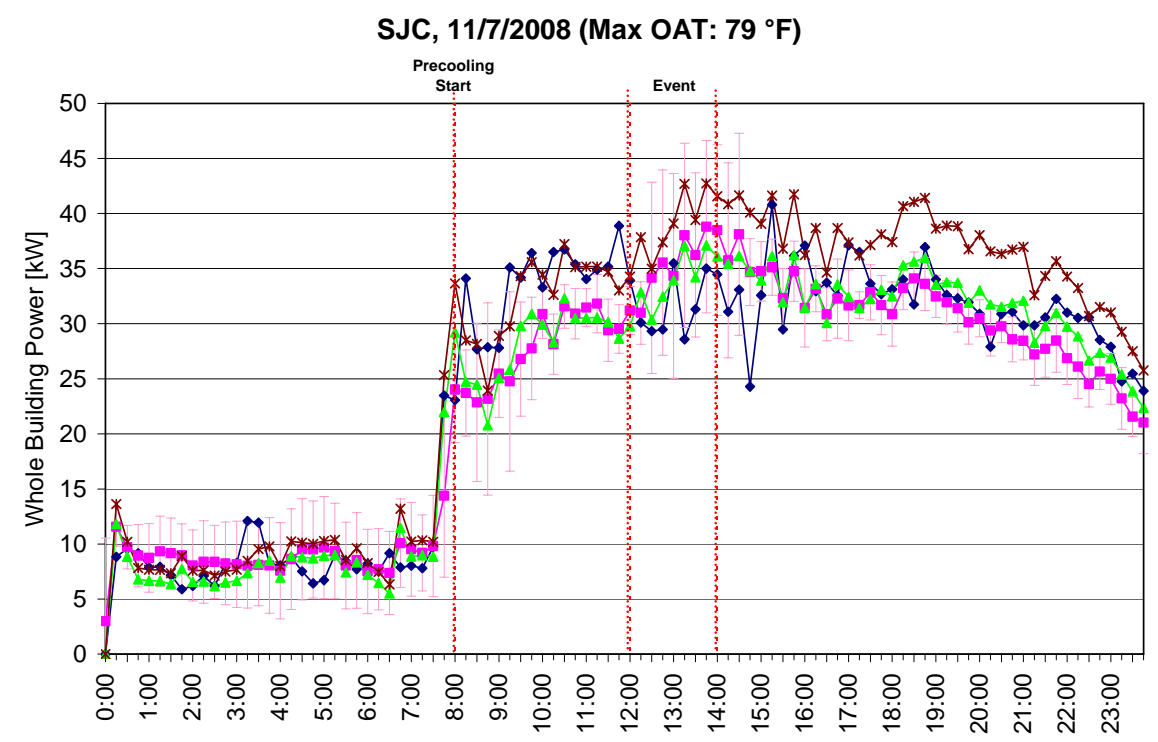

$\rightarrow$ Actual $\rightarrow-$ Baseline $\rightarrow$ CPP Baseline $\rightarrow$ CPP_MA

\begin{tabular}{|c|c|c|c|c|c|c|c|c|}
\hline \multirow{2}{*}{ Date } & \multirow{2}{*}{ Baseline } & \multirow{2}{*}{ Event Time } & \multicolumn{2}{|c|}{ kW } & \multicolumn{2}{|c|}{$\mathbf{W} / \mathbf{f t}^{2}$} & \multicolumn{2}{|c|}{ WBP\% } \\
\hline & & & Max & Ave & Max & Ave & Max & Ave \\
\hline \multirow{3}{*}{ Nov-07 } & $3 / 10$ & \multirow{3}{*}{ 12:00-2:00 } & 8 & 3 & 3.85 & 1.15 & $23 \%$ & $7 \%$ \\
\hline & 3/10_MA & & 14 & 8 & 6.42 & 3.52 & $33 \%$ & $19 \%$ \\
\hline & OAT & & 14 & 8 & 6.42 & 3.52 & $33 \%$ & $19 \%$ \\
\hline
\end{tabular}


Hesperia, 11/7/2008 (Max OAT: $66^{\circ} \mathrm{F}$ )

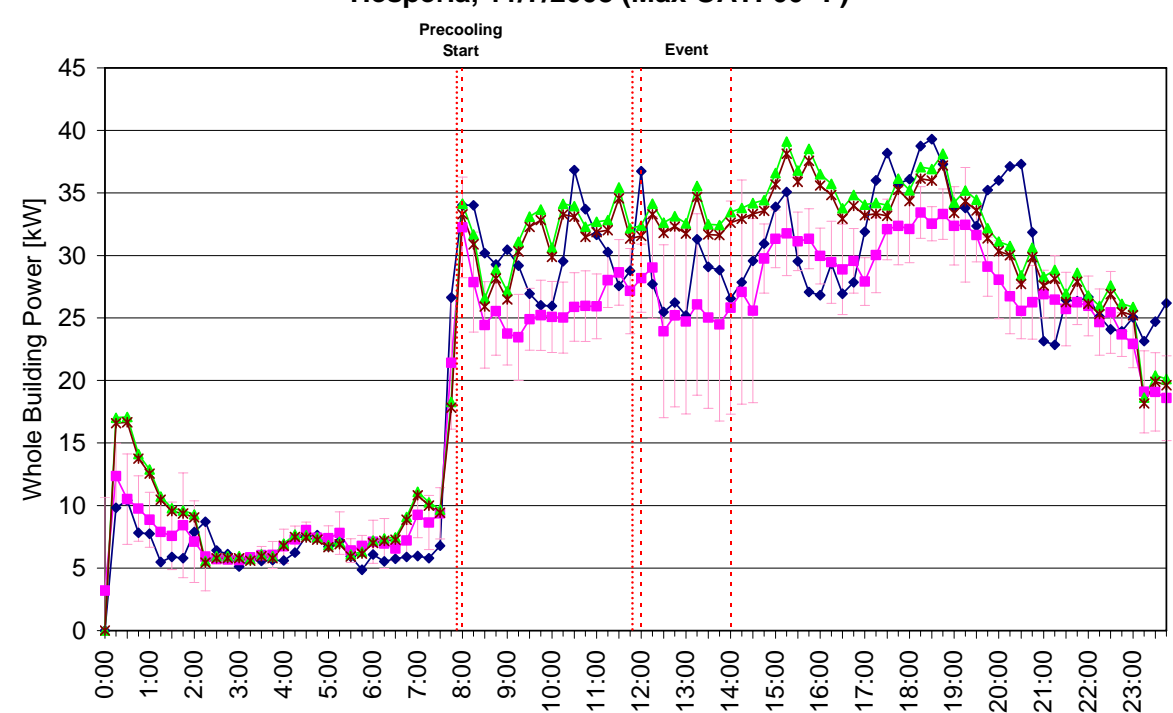

$\rightarrow$ - Actual $\rightarrow$ - OAT Baseline $₫-3 / 10$ beseline $*$-3/10 MA Baseline

\begin{tabular}{|c|c|c|c|c|c|c|c|c|}
\hline \multirow{2}{*}{ Date } & \multirow{2}{*}{ Baseline } & \multirow{2}{*}{ Event Time } & \multicolumn{2}{|c|}{ kW } & \multicolumn{2}{|c|}{$\mathbf{W} / \mathbf{f t}^{2}$} & \multicolumn{2}{|c|}{ WBP\% } \\
\hline & & & Max & Ave & Max & Ave & Max & Ave \\
\hline \multirow{3}{*}{ Nov-07 } & $3 / 10$ & \multirow{3}{*}{ 12:00-2:00 } & 7 & 6 & 3.43 & 2.68 & $23 \%$ & $17 \%$ \\
\hline & 3/10 MA & & 7 & 5 & 3.06 & 2.29 & $21 \%$ & $15 \%$ \\
\hline & OAT & & 1 & -2 & 0.62 & -0.94 & $5 \%$ & $-8 \%$ \\
\hline
\end{tabular}




\section{November 14, 2008}

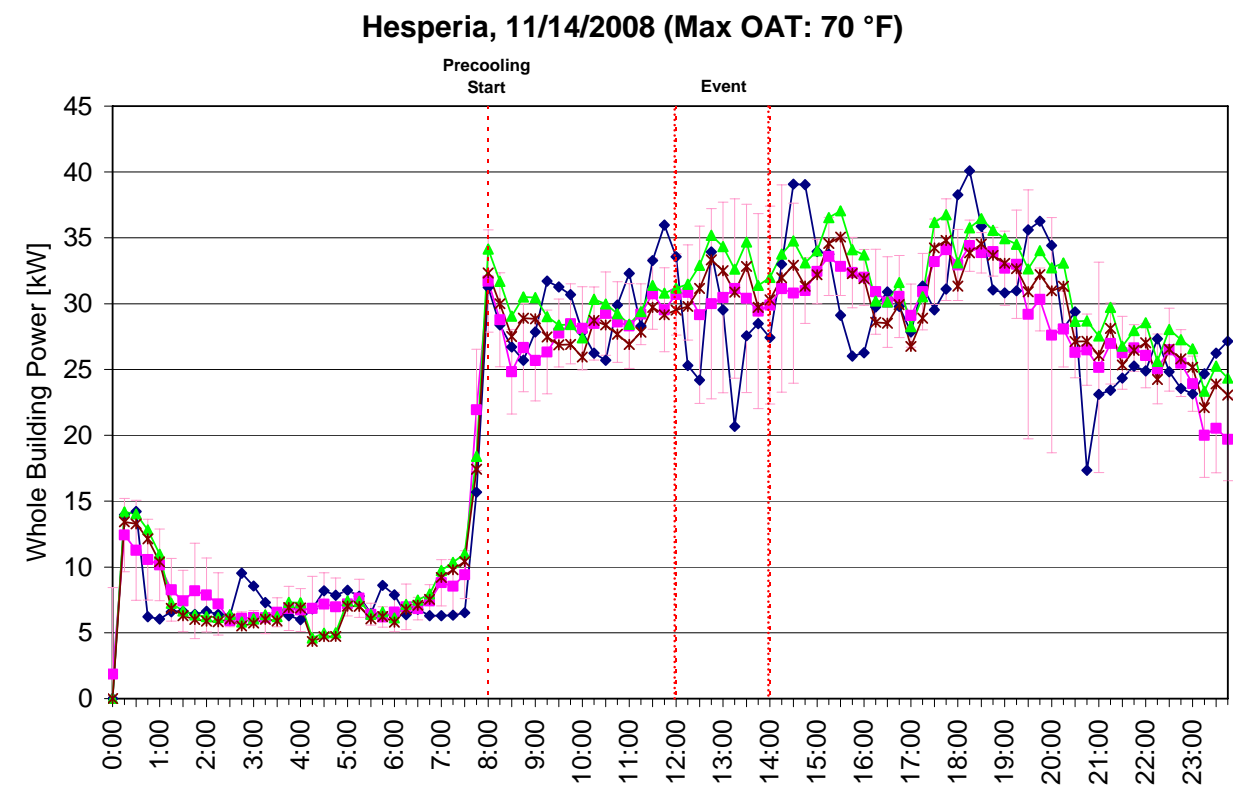

$\rightarrow$ Actual $\rightarrow$ - OAT Baseline $\rightarrow-3 / 10$ beseline $*$ 3/10 MA Baseline

\begin{tabular}{|c|c|c|c|c|c|c|c|c|}
\hline \multirow{2}{*}{ Date } & \multirow{2}{*}{ Baseline } & \multirow{2}{*}{ Event Time } & \multicolumn{2}{|c|}{ kW } & \multicolumn{2}{|c|}{$\mathbf{W} / \mathbf{f t}^{2}$} & \multicolumn{2}{|c|}{ WBP\% } \\
\hline & & & Max & Ave & Max & Ave & Max & Ave \\
\hline \multirow{3}{*}{ Nov-14 } & $3 / 10$ & \multirow{3}{*}{ 12:00-2:00 } & 12 & 6 & 5.56 & 2.76 & $37 \%$ & $18 \%$ \\
\hline & 3/10 MA & & 10 & 4 & 4.75 & 1.94 & $33 \%$ & $13 \%$ \\
\hline & OAT & & 10 & 3 & 4.87 & 1.41 & $34 \%$ & $10 \%$ \\
\hline
\end{tabular}




\section{Appendix F: Site Selection Criteria for the Small Commercial Study}

This document outlines the selection criteria for the small commercial building study with SCE. The criteria are divided into two categories: 1) minimum requirements, and 2 ) additional requests. Sites varying in technologies are preferred.

\section{Minimum requirements:}

\section{Type of Facility:}

Lockheed Martin Aspen study (April 12, 2006) commissioned by SCE states that the small commercial building segment of the market is dominated by retail facilities and offices. These type of facilities tend to have low load variability so it will be easier to predict and asses demand reductions and understand the repeatability aspects of demand savings. We suggest the following types of facilities:

Retail (with and without refrigeration requirements)

Office

\section{Ownership:}

One-off, Chain or small chain dictates whether they have a service contract with a vendor or not. Prefer to have sites that do not have service contracts with other vendors. County is easier than multi-tenant facilities.

\section{Size:}

While the 10 to $35 \mathrm{~kW}$ segment technologies are very similar to residential technologies, $150 \mathrm{~kW}$ to $200 \mathrm{~kW}$ segment tend to have technologies similar to large commercial segment so we suggest recruiting facilities whose loads are between 35 and $150 \mathrm{~kW}$.

\section{HVAC System:}

Most facilities in the small commercial group tend to have packaged air-cooled HVAC systems. We suggest recruiting sites with Variable Air Volume packaged units instead of Constant Air Volume units as these systems allow for better controllability. Units may have single or double compressors. In addition, multi-zone units propose another level of complexity with which we'd like to experiment. Some important questions to be answered are:

Does the thermostat need $24 \mathrm{~V}$ power?

Does the site have a service contract with a company? 


\section{Lighting System:}

The minimum requirement for the lighting system is that it has some level of bi-level switching at the panel or at the switch leg as mandated by Title 24 .

\section{Loads and occupancy schedule:}

This study is going to explore strategies for HVAC, lighting and refrigeration systems but will attempt to identify and control other loads found in the facilities.

7. IP Connection: Sites with some sort of always on connection (cable, DSL, T1, etc) to the Internet.

\section{Other:}

In general, we are looking for sites with low variability of hourly loads whose HVAC systems are not undersized.

\section{Additional Requests (nice to have):}

Facilities: Mixed type of facilities that combine several different uses (Office facilities with a restaurant, automobile dealer with servicing department, etc.), hotel, healthcare, restaurants or any type of facility we have not yet experimented with.

Lighting: Dimmable ballasts

Metering: Sites with interval metering so that we can have historical data and experiment with tying into the kyz output of the meter to provide feedback.

\begin{tabular}{|l|l|l|}
\hline & Minimum & Additional \\
\hline \hline Facility Type & $\begin{array}{l}\text { Retail (w/ refrigeration) } \\
\text { Retail (w/out refrigeration) } \\
\text { Office }\end{array}$ & $\begin{array}{l}\text { Multi-type } \\
\text { Hotel } \\
\text { Healthcare } \\
\text { Restaurant }\end{array}$ \\
\hline Size & $\begin{array}{l}>35 \mathrm{~kW} \\
150 \mathrm{~kW}\end{array}$ & \\
\hline HVAC & $\begin{array}{l}\text { Packaged units } \\
\text { Single and multi zone } \\
\text { NOT undersized }\end{array}$ & $\begin{array}{l}\text { Dimmable Ballasts } \\
\text { Panel }\end{array}$ \\
\hline Lighting & Low variability & $\begin{array}{l}\text { Interval Metering } \\
\text { with historical data }\end{array}$ \\
\hline Loads & N/A & \\
\hline Metering & & \\
\hline Other & &
\end{tabular}

